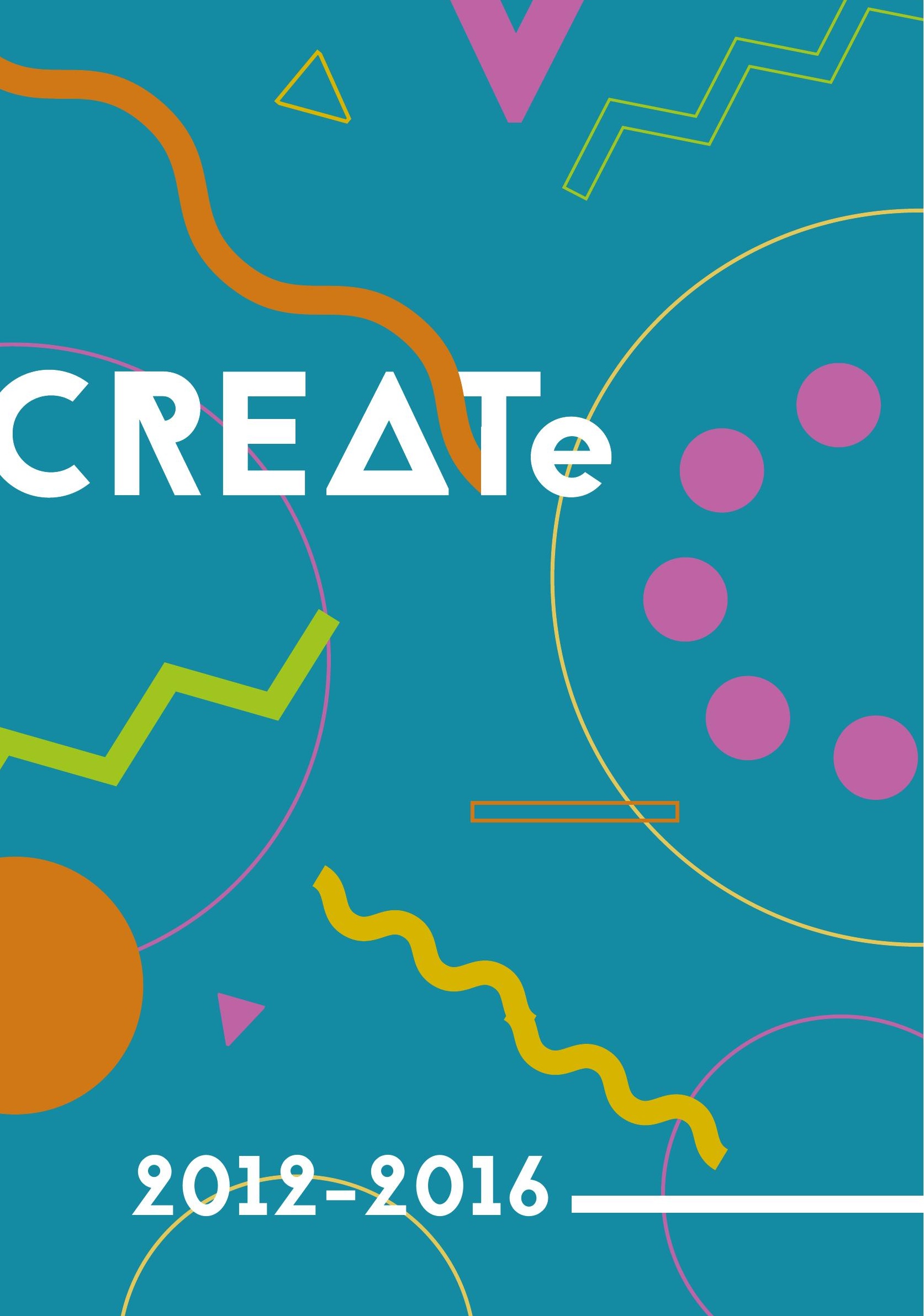




\section{CREATe 2012-2016:}

Impact on society, industry and policy through research excellence and knowledge exchange

Edited by: Kerry Patterson \& Sukhpreet Singh

\section{With contributions from:}

Alison Brimelow, Andrea Wallace, Andrew McHugh, Andrew Thompson, Barbara Townley, Bartolomeo Meletti, Burkhard Schafer, Daithí Mac Síthigh, Derek McAuley, Dinusha Mendis, Ealasaid Munro, Edina Harbinja, Elena Cooper, Emily Laidlaw, Emma

Barraclough, Frédéric Dubois, Gian Marco Campagnolo, Gillian Doyle, Hung The Nguyen, Jeremy Silver, Jesús Rodríguez Pérez, John Street, Kerry Patterson, Kris Erickson, Lilian Edwards, Martin Kretschmer, Maurizio Borghi, Megan Rae Blakely, Melinda John Street, Kerry Patterson, Kris Erickson, Lilian Edwards, Martin Kretschmer, Maurizio Borghi, Megan Rae Blakely, Melinda Ronan Deazley, Sukhpreet Singh, Theo Koutmeridis, Victoria Stobo, Xiaobai Shen

Consortium Members

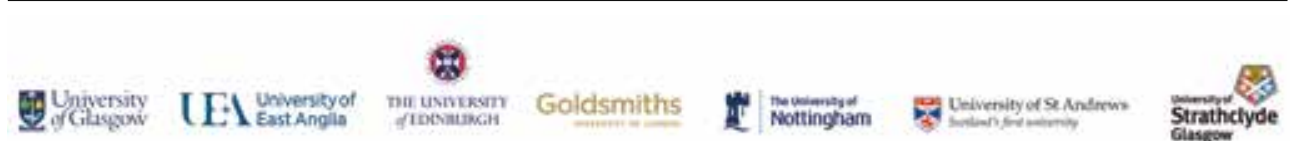

Funders

RESEARCH
COUNCILS UK

Associates

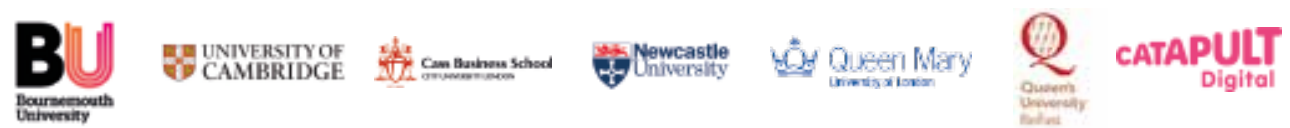




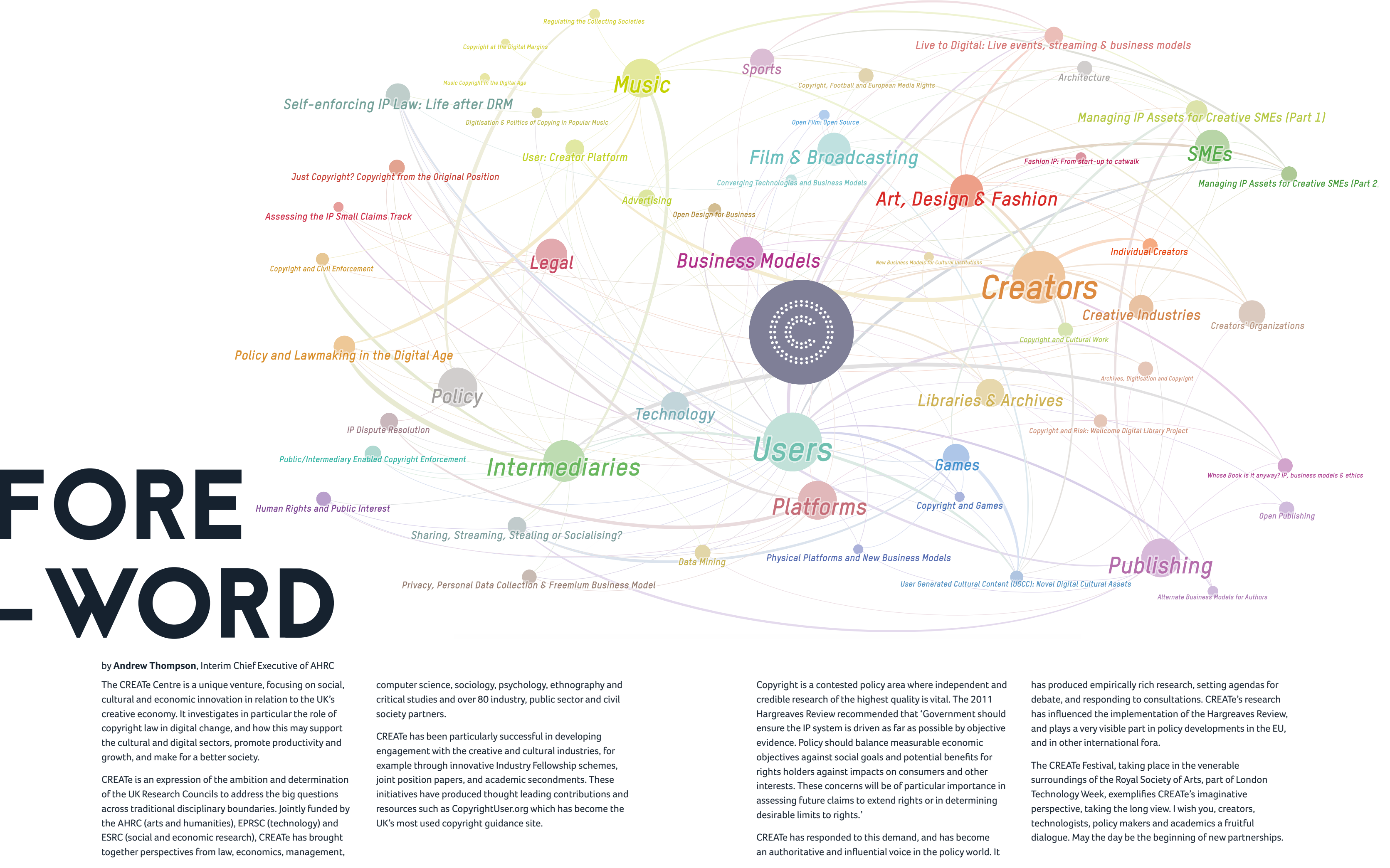



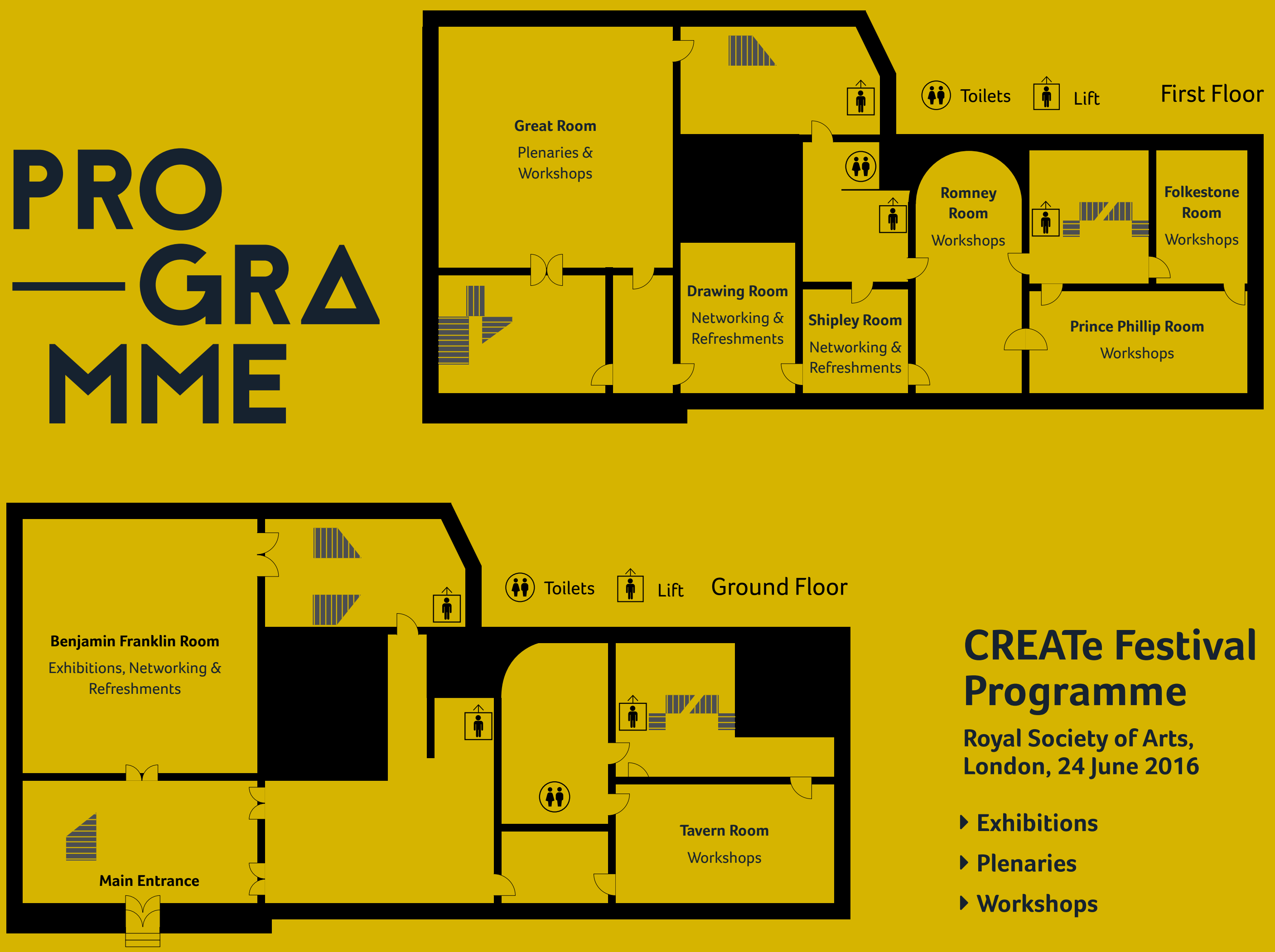

\section{CREATe Festival Programme}

Royal Society of Arts, London, 24 June 2016

- Exhibitions

- Plenaries

- Workshops 
Timetable

\section{June 2016}

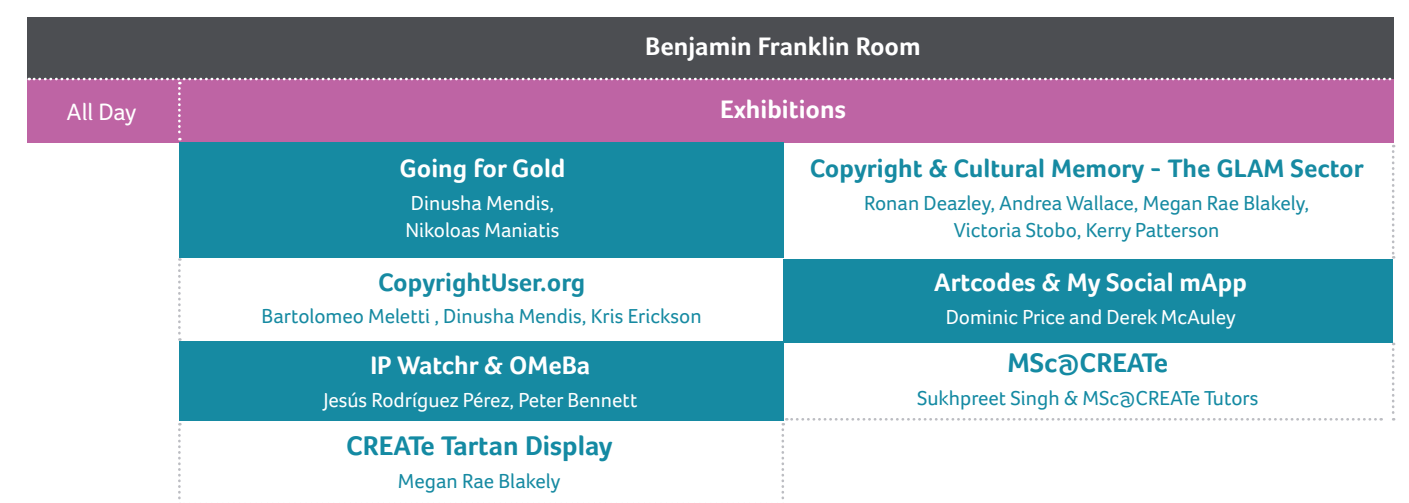

\begin{tabular}{|c|c|c|c|c|c|}
\hline \multirow{3}{*}{$\begin{array}{c}09: 30 \text { - 10:00 } \\
10: 00 \text { - 10:10 }\end{array}$} & \multicolumn{5}{|c|}{$\begin{array}{l}\text { Arrival and seating. } \\
\text { Tea and coffee available through the day. }\end{array}$} \\
\hline & \multicolumn{5}{|c|}{ Great Room } \\
\hline & \multicolumn{5}{|c|}{ Official Opening Mark Llewellyn / Director of Research, AHRC } \\
\hline \multirow[t]{2}{*}{ 10:10 - 11:00 } & \multicolumn{4}{|c|}{$\begin{array}{l}\text { The Future of Copyright } \\
\begin{array}{l}\text { Martin Kretschmer (Introduction \& Festival Chair), Keynote by Julia Reda MEP, } \\
\text { Pirate Party/Greens, Lionel Bently }\end{array}\end{array}$} & $\begin{array}{l}\text { Launch of } \\
\text { CREATe Tartan }\end{array}$ \\
\hline & Great Room & Prince Philip Room & Romney Room & Tavern Room & Folkestone Room \\
\hline \multirow[t]{2}{*}{ 11:10 - 11:50 } & $\begin{array}{l}\text { Saving news } \\
\text { with copyright? } \\
\text { Richard Danbury } \\
\text { (chair), James } \\
\text { Mackenzie, Andrew } \\
\text { JHughes, Eleonora } \\
\text { Rosati, John Halton }\end{array}$ & $\begin{array}{l}\text { CREATe Litigation } \\
\text { Stream } \\
\text { Georg von Graevenitz } \\
\text { (Chair), Sheona Burrow, } \\
\text { Marcella Favale, Jesús } \\
\text { Rodríguez Pérez, } \\
\text { Leslie Lansman }\end{array}$ & $\begin{array}{l}\text { Copyright and } \\
\text { Art Forgery: The } \\
\text { Painting that } \\
\text { Challenged the Law } \\
\text { Elena Cooper } \\
\text { 11:10-11:30 repeated } \\
\text { 11:30 to 11:50 }\end{array}$ & $\begin{array}{l}\text { Technology for } \\
\text { creative practices: } \\
\text { My Social mApp \& } \\
\text { Artcodes } \\
\text { Dominic Price and } \\
\text { Derek McAuley }\end{array}$ & $\begin{array}{c}\text { Behavioural } \\
\text { Experiment } \\
\text { Piers Fleming, Sven } \\
\text { Fircher, Melanie } \\
\text { Parravano, Daniel Zizzo } \\
\text { Please note this } \\
\text { workshop starts at } \\
11: 05\end{array}$ \\
\hline & \multicolumn{5}{|c|}{ Great Room } \\
\hline $12: 00-12: 50$ & & elde (Chair), Robin Willian & $\begin{array}{l}\text { Business Models } \\
\text { lanis Jefferies, Richard Pate }\end{array}$ & n, Jeremy Silver, Charle & \\
\hline $13: 00-14: 00$ & & & unch \& Networking & & \\
\hline
\end{tabular}

LONDON

ECHNOLOGY

WEEK 20-26.JNE16

\#LDNTech Week

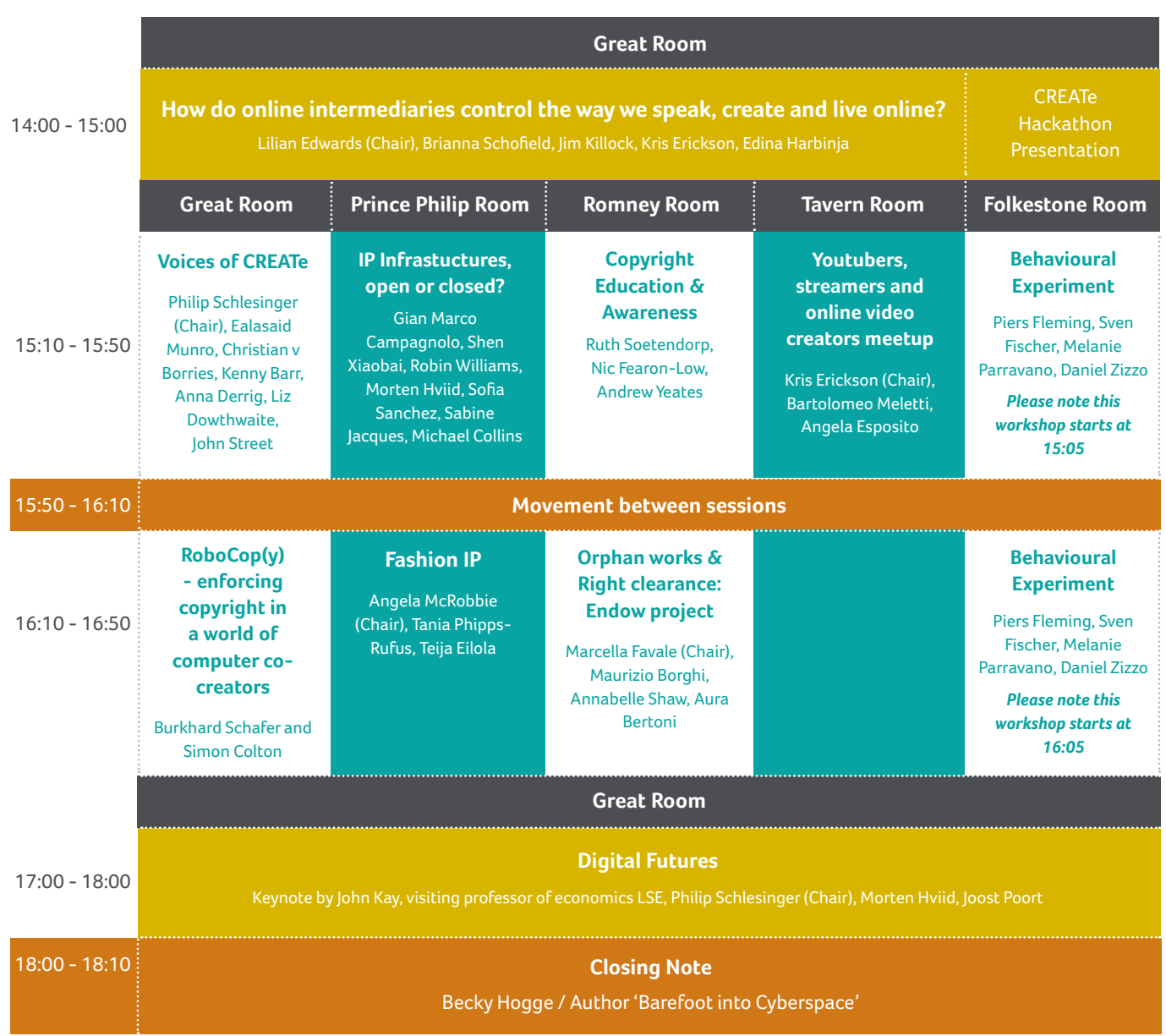

@copyrightcentre | \#createfest16 


\section{Exhibitions}

24 June 2016

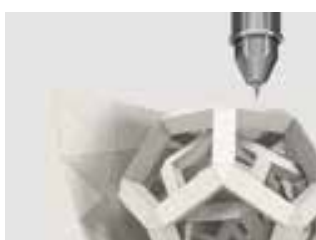

\section{Going for Gold}

Demonstration: 3D scanning \& 3D printing of jewellery

Dinusha Mendis / Bournemouth University, Nikotos Maniatis / Museotechniki Ltd

(D) Benjamin Franklin Room, All Day

3D scanning, 3D printing and mass customisation of ancien and modern jewellery raise a number of intellectual property issues. With a particular focus on copyright, design and licensing, CREATe associate Dinusha Mendis and Nikoloas Maniatis will demonstrate the scanning of museum artefacts and the manufacture of printed jewellery.

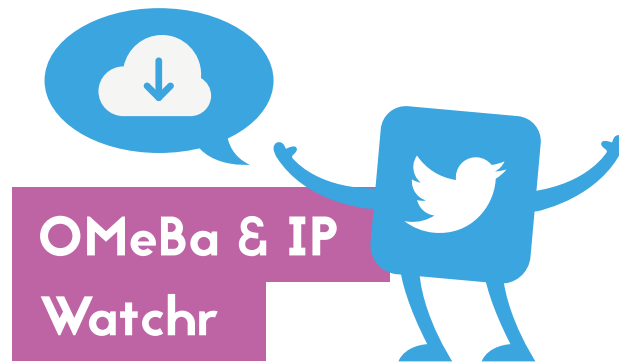

Demo of copyright infringement data tools Jesús Rodríguez Pérez, Peter Bennett/

University

(1) Benjamin Franklin Room, All Day

Come and see a demonstration of OMeBa and IP Watchr, two analytical and visualisation-based software programs made by CREATe's data developer Jesús Rodríguez Pérez. OMeBa Ontine Media Behaviour analytics) is a user-friendly tool, Which allows for investigation of the Ofcom/P $\mathrm{O}$ survey data Wantre acess and consumption behaviour inthe UK. IP

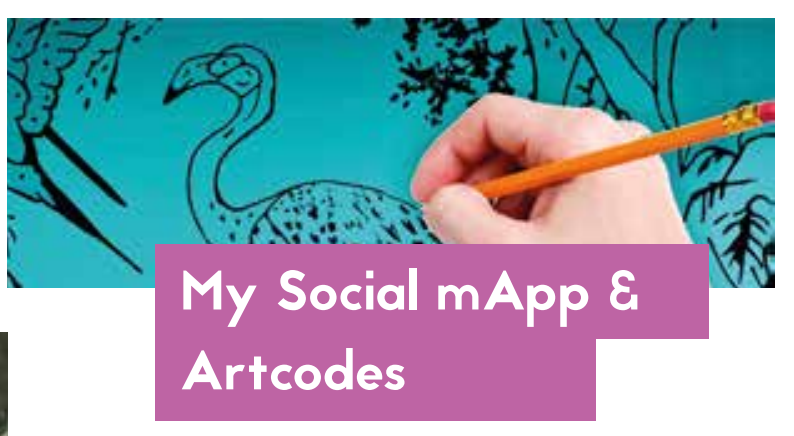

Copyright $\varepsilon$

Cultural Memory

Pop Up exhibition \& presentation Ronan Deazley / Queen's University Belfast; Megan Rae 作, University of Glasgow

(1) Benjamin Franklin Room, All Day

Exploring how intellectual property impacts the preservation, access and use of our shared cultural heritage has been a research priority for CREATe. Ronan Deazley, Megan Blakely, Kerry Patterson, Victoria Stobo, and Andrea Wallace address the challenges of digitisation, intangible cultural heritage, risk-based models of copyright compliance for archive collections, and surrogate intellectual property rights. Rolling presentations of their research will be on show, alongside a display of works from Display at Your Own Risk, a unique, open source exhibition project.

$\rightarrow$ displayatyourownrisk.or

\section{MSc@CREATe \\ MSc@OCREATe}

Come and meet the MScaCREATe team! Sukhpreet Singh \& MScDCREATe Tutors

(1) Benjamin Franklin Room, All Day

There will be an MScDCREATe stand through the day where you can drop in and meet the tutors. The MSc in IP. Innovation Creative Economy will also host an open house breakfast from 0830-0930, prior to The CREATe Festival.
Demonstration of tech tools to assist creative businesses

Dominic Price and Derek McAuley /

University of Nottinghan

(1) Benjamin Franklin Room, All Day

Social media platforms are an increasingly important tool for creative individuals and small businesses. My Social mApp is a free, open source tool to help with analytics of Twitter usage. tracking interactions and presenting them in a clear visualisation. Artcodes provide the functionality of $\mathrm{Q} R$ codes but with a twist,

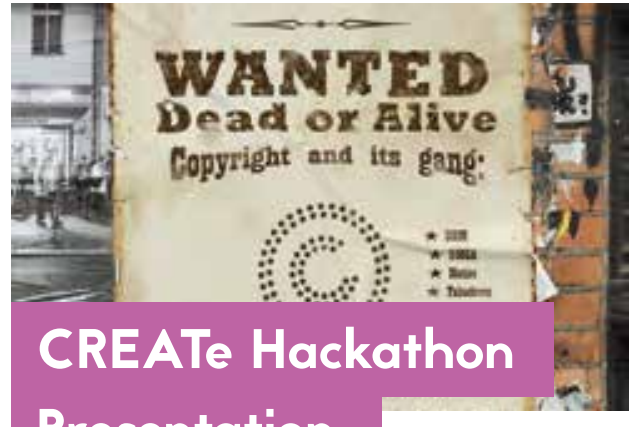

\section{Presentation}

Kris Erickson, Martin Kretschmer, Jesús Rodríguez Pérez University of Glasgow

(2) Part of Plenary, The Great Room, 14:00 - 15:00

A CREATe hackathon - an intensive software development session where teams competed to produce innovative mining and data visualization with an aim to provide evidence needed to push forward changes to copyright law - was organised on 3th and 14th May 2016. This session presents a short video showcasing the format and the winners' pitches. beautifu. Come along to find out more about both free tools and

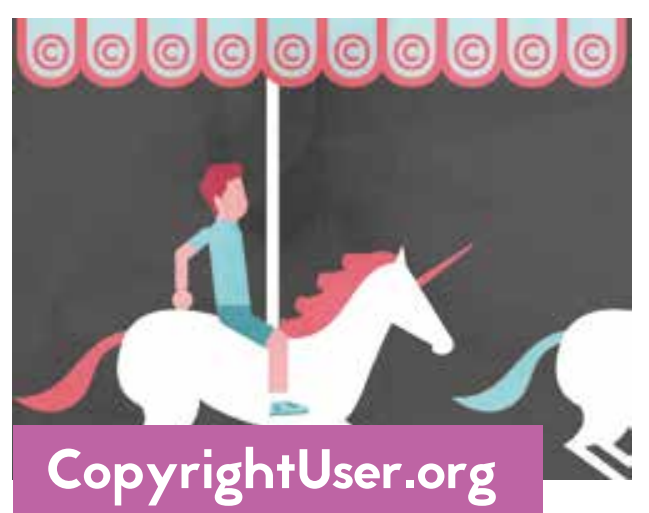

Find out more \& ask questions

Bartolomeo Meletti / CopyrightUser.org, Dinusha Mendis / Bournemouth University, Kris Erickson / University of Glasgow

(1) Benjamin Franklin Room, All Day

CopyrightUser.org is an independent online resource designed to make UK copyright law accessible to everyone. The website has become a point of reference for copyright guidance within the creative industries, cultural heritage organisations, and the education sector Meet the teag behind CopyrightUser.org, and find out the exciting future plans for the project, or ask some of your own copyright questions.

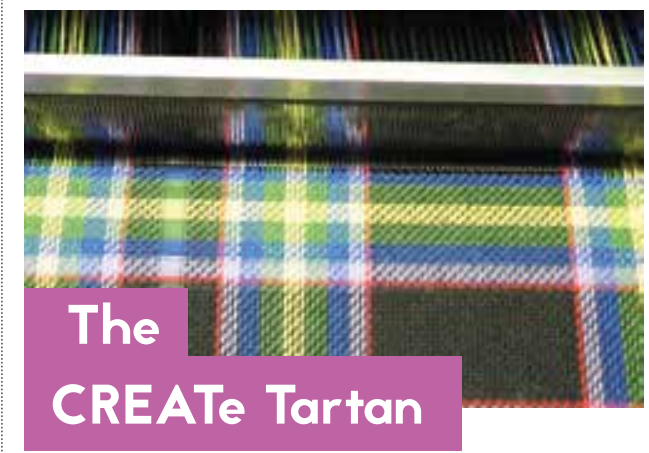

\section{Display \& launch}

Megan Rae Blakely / University of Glasgow

(1) Part of Plenary. The Great Room, 10:10 - 11:00

CREATe's own tartan will be officially launched at the Festival. Come and find out about the research behind the tartan and the process of its creation by CREATe researchers. You will also be able to see scarves made from the tartan and order one for yourself. 


\section{Workshops \\ 24 June 2016}

() For room and time info, see pages $8 \& 9$

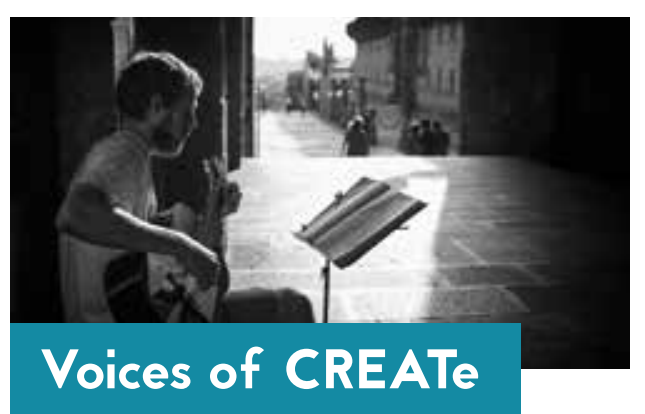

Philip Schlesinger / University of Glasgow (Chair), Ealasai Munro / University of Glasgow, Christian v Borries / Berli based Film maker \& Musician, Kenny Barr /

University of Glasgow, Anna Derrig / Goldsmiths,

Liz Dowthwaite / University of Nottingham, John Street /

University of East Anglia

In the cultural, creative and digital sectors, self-employed and freelance workers account for a large proportion of the labour force. 'Voices' explores the work of individual creators in the creative industries, looking at how they understand copyright and IP, and how technology has changed the way that they work.

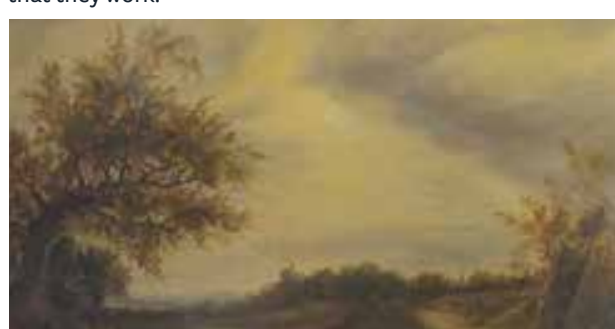

Copyright and Art Forgery

The painting that challenged the law Elena Cooper / University of Glasgow

The Royal Society of Arts holds a significant place in the history of artistic copyright in the nineteenth century. Elena
Cooper unravels this story, drawing on research undertaken at the RSA archives to be published in her forthcoming book 'Art and Modern Copyright: The Contested Image', (CUP 2017). She also links this to CREATe research on the place of criminal law in copyright history, focussing on a case heard by the Old Bailey in 1857 about whether the crime of forgery included the application of a false signature to a painting. This session will run twice within the 40 minute time slot, and attendees will be able to see a nineteenth century forgery of the painting at the centre of the case.

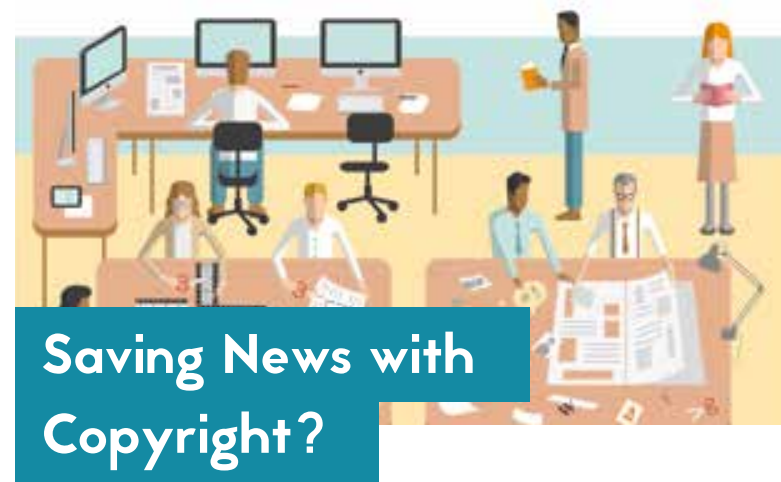

Richard Danbury / University of Cambridge (Chair), James Mackenzie / Cutbot.net, Andrew J Hughes / NLA Med Access, Eleonora Rosati / University of Southampton John Halton / FT

This workshop will be addressing the idea that there should be an amendment of European copyright and related law designed to benefit news, and possibly other content publishers. This is linked to the EU Commission's consultation pablished on the 23rd March 2016. Publishers have set out the reasons why they feel such a development is appropriate. Nonetheless, the proposals are controversia evidenced not least by the fact that $80 \mathrm{MEP}$ w wrote to the Commission in December 2015 expressing concern about the proposal that an ancillary right for the benefit of press publishers should be brought into EU law.

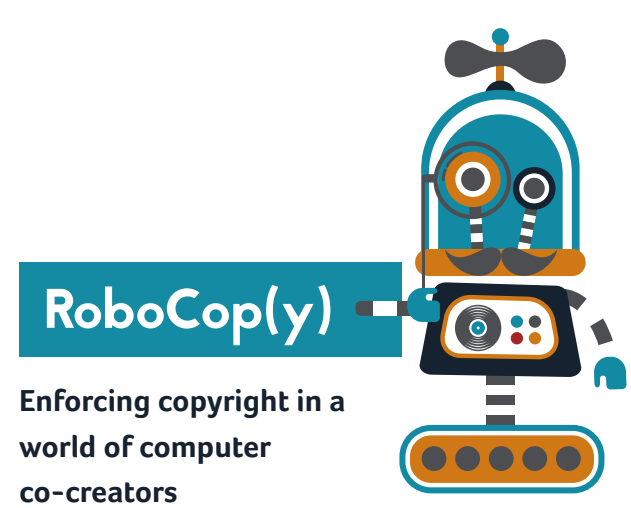

co-creators

Burkhard Schafer / University of Edinburgh and Simon Colton / Goldsmiths University of London

Autonomous computer systems are now sharing our creative spaces as consumers and producers of art. In 2016 we saw the performance of he first computer generated musical in London. Increasingly, computer generated paintings are also being included in art exhibitions. Led by Burkhard Schafe, this workshop examines how copyright will function in a world where humans lose their status as the sole creators. Howwill we teach the mach the rights of others?

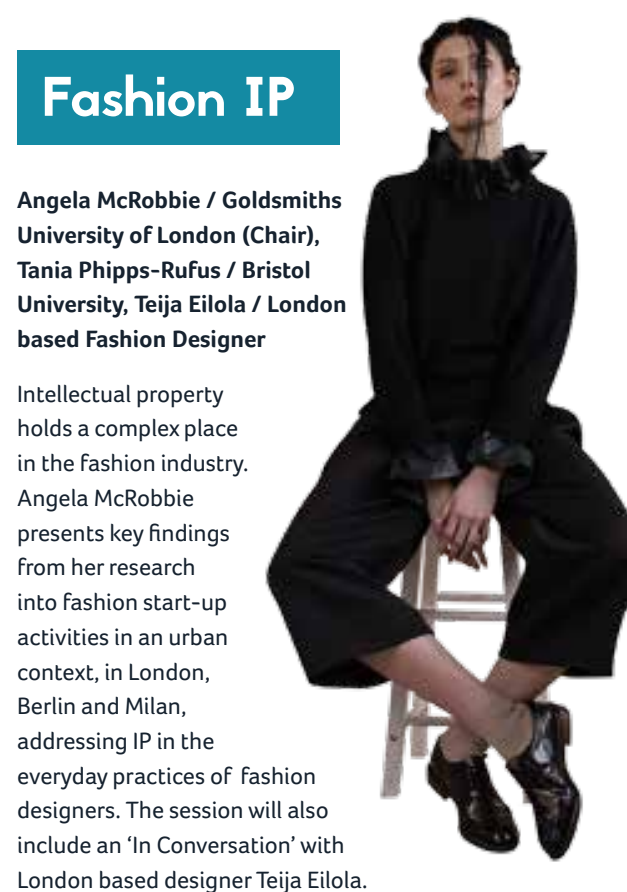

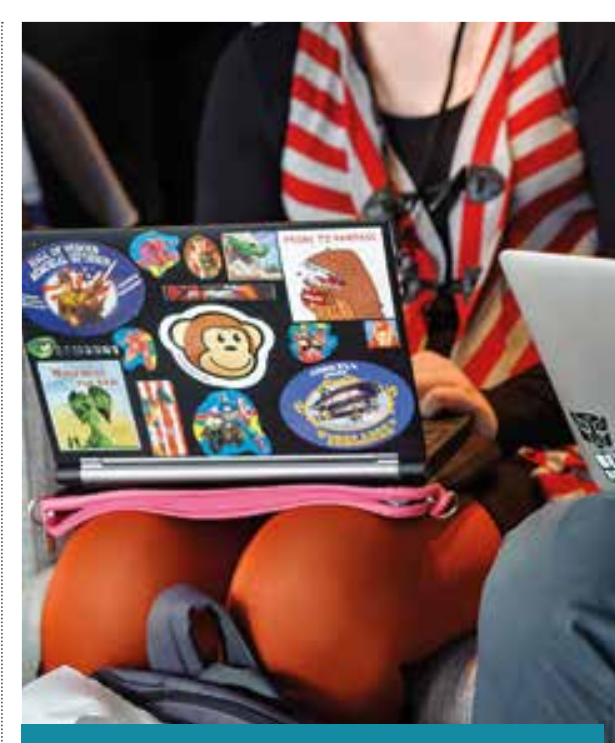

YouTubers and other

Online Video Creators Meet-Up

Kris Erickson / University of Glasgow (Chair), Bartolomeo Meletti / Copyright User, Angela Esposito / University of Glasgow, Dinusha Mendis / Bournemouth University, Marco Bagni / Lost Conversation, Mary Wild / Film Researcher

Come and meet other UK-based online video creators for an informal roundtable chat. The theme of this meetup is copyright and creativity in online video. Recent developments on You Tube and other platforms have raise questions and worries: How can small creators protect themselves against larger companies that take and embed content? What are some good ways to obtain licencefree music? Is it possible to parody clips from broadcast TV or film? What is the most effective way of dealing with an erroneous takedown request? The roundtable is an opportunity for UK video makers to meet face-to-face and talk about issues of importance in a growing industry. Come and get to know other online video entrepreneurs, share stories, and learn new strategies for dealing with copyright issues. 
$>$ we

.

Copyright Education

\section{\& Awareness}

Ruth Soetendorp / IPAN, Nic Fearon-Low / IPO, Andrew Yeates / ERA

Workshop to explore current initiatives in copyright education and awareness including from the IPO/CREAT supported Copyright Education \& Awareness (CEA) symposium on 24 May 2016; IPAN \& NUS research into perception and practice of HEI IP Policies (forthcoming 2016) and IPO IP learning resources.

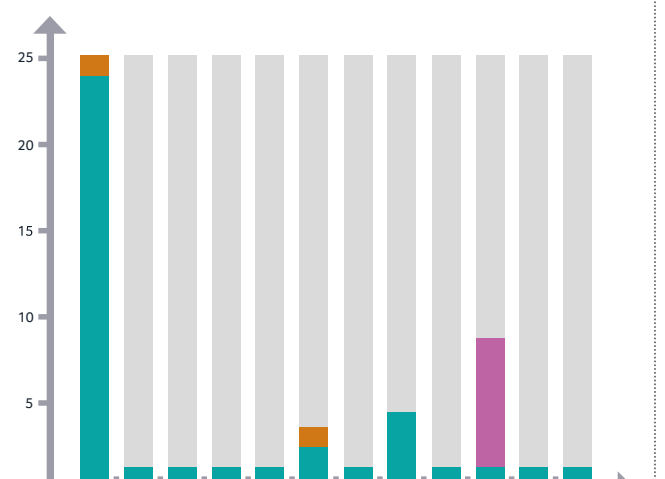

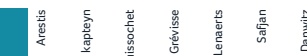 \\ Litigation Stream}

Georg von Graevenitz / Oueen Mary University of London (Chair), Sheona Burrow / University of Glasgow, Marcella Favale / Bournemouth University, Jesus Rodriguez Perez University of Glasgow, Leslie Lansman/ Queen Mary University of London

CREATe researchers have focused significant efforts to further an understanding of how the courts shape the effects of copyright protection. The session will provide an overview of this work ranging from analysis of decisions by the Court of Justice of the European Union to the IPEC Small Claims Track At the session we will launch the litigation Data Porta a website providing access to summary data of IPEC and Hit Court Judgements and Cases that are copyright related This Cour in

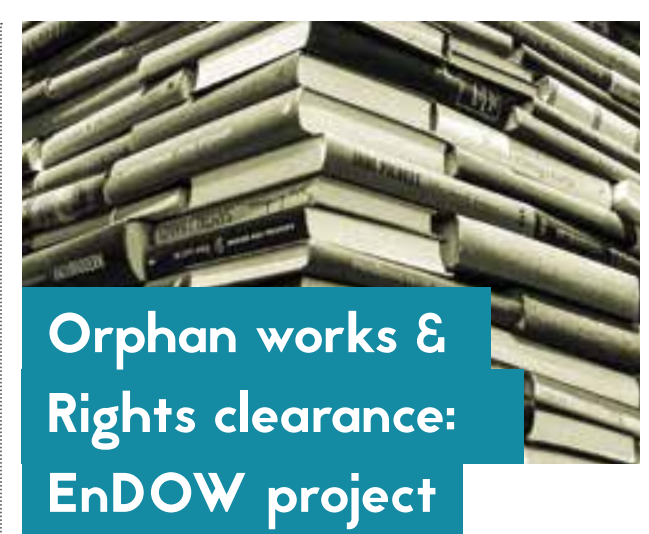

Notes

Marcella Favale/ Bournemouth University (Chair), Maurizio Borghi/Bournemouth University, Annabelle Shaw/British Film Institute, Aura Bertoni/ Bocconi University

EnDOW (Enhancing access to 20th Century cultural heritage through Distributed Orphan Works clearance)

is a European-funded project led by the CIPPM/ Bournemouth University in partnership with CREAT and leading cultural institutions across Europe. Its aim is to unlock the potential for mass digitisation and online publication of European cultural heritage, by helping museums, archives and libraries to digitize and share the collections with the public. The workshop will focus on the orphan works legistation, addressing the main hurdes that culturatintitution hav to face when carying out a diligent search of rightholdes. Theworshop will engate the publc in practical "dilyent searh excis", the outo the which will be subject to panel discussion.

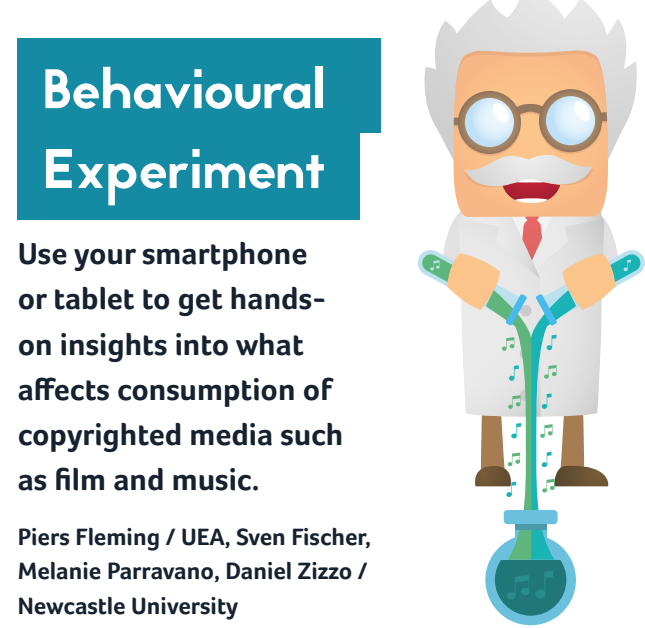
Newcastle University

Experience how decision-making experiments work, and learn how your own decisions and beliefs about how other people would behave, matches the research. The session is based on research by Piers Fleming, Daniel Zizzo, Melanie Parravano, and Sven Fischer.

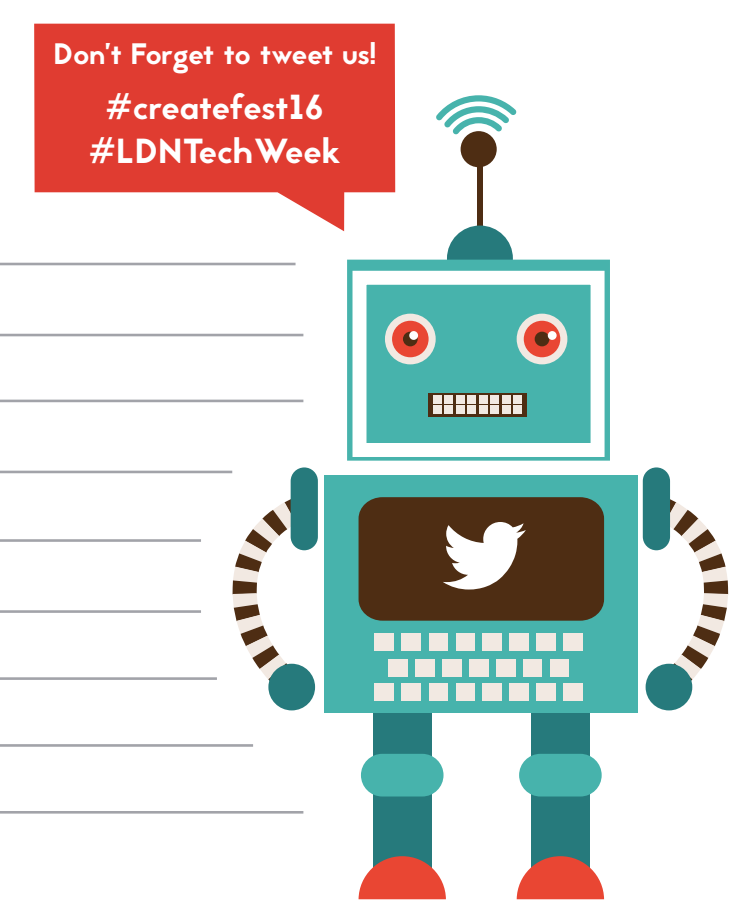




\section{CREATe LEGACY}

CREATe's Director Martin Kretschmer reflects: Do we need a research centre at the intersection of law, technology and social science

Research matters. And it matters most where there are faut lines in society Faut lines may appear unbridgeable, and (to stay in the metaphor) they are places where quakes and social separation can occur.

CREATe's core concern is the future of creative production, and in particular the relationship between law and digital innovation. What is the role of copyright, among alternative modes of identification, appropriation and finance?

As we come to the end of the first phase of the CREAT project, it is becoming clear that the creative economy need to be understood in the context of the radical challenge to industrial structures posed by the digital revolution: creative
industries are becoming a subset of data intensive industries. All online behaviour is potentially observable, and whoever All online behaviour is potentially observable, and whoe controls this data infrastructure will have a stake in the
creative economy that is very different from the role of earlier creative economy that is very different from the role of ear
cultural intermediaries. This change particularly affects cultural intermediaries. This change particularly affects firms with a long tradition of exploiting back catalogues of
rights but also opens opportunities for new digital entrants rights but also opens opportunities for new digital entrants
and for cultural memory organisations (such as archives and and for cultural memory organisations (such as archives and

Findings for creative economy and policy makers:

- CREATe's research demonstrates that sectors of the creative economy face very different challenges. 'Born digital' firms behave very differently than the owners ofback catalogues that are being challenged by new 'platform' intermediaries. The labour market for some primary creators has become more difficult, for example for journalists and photographers, but commercial success has always been the exception. There are continuities in the dynamics of cultural production and consumption, and the supply of creative content overall has increased.

- There is considerable tension between the emerging empirical evidence and entrenched beliefs. Even perfectly enforced copyright law is not a safeguard against technological change, and it can be a serious obstacle to innovation.

Findings for academe:

- Engagement with key stakeholders is not a burden but an opportunity (as long as the independence of academic enquiry is acknowledged and protected). CREATe takes

$\ddot{200}: \quad$ CREATe Research: $2012-2016$ great care to expose our methods and research designs to scrutiny by academic peers, by industry and policy users of research, and to make copynght law and empirical evidence accessible to the wider society.

- What skills are needed to investigate the digital creative economy? The capacity to conduct innovative multidisciplinary research remains fragile. Embedding of skills needs a sustained effort and career opportunities, for example for microeconomists focussing on innovation and the details of legal intervention; data developers for creative ind stres and at ease with empirical methods such as interviewing. thnography and computer assisted content an lysig.

my view, our main achievements to date include -

- CREATe has become a key player in a change of policy perspective. The role of copyright law in promoting creativity and innovation is now seen as open to empirical investigation, and CREATe has supplied credible and wide cited evidence, becoming recognised as a global leader in the field within a very short time. The CREATe brand is distinct and internationally acknowledged. For example the Annual Conference of the European Policy for intelectia Property (EPIP) Association meeting hosted at the University of Glasgow in 2015 focussed for the first time on copyright, and received a wide echo.

- Our digital resources define a new field of enquiry and have been used by hundreds of thousands of people from 161 countries. We developed and co-produced CopyrightEvidence org, CopyrightUserorg (with Bournemouth University \& Queen's University Belfast) and Bournemouth University \& Queen's University Belfast)
CopyrightHistory.org (with University of Cambridge).

- Peer production of public resources can create an open knowledge environment that is particularly suitable for interdisciplinary fields. CREATe has demonstrated that it is possible to involve users in research design and the development of open access platforms. The exhibitions and data explorer tools available during the CREATe Festival give a flavour of these efforts.

Copyright law does not cause famine or war, but the laws that regulate the infrastructure of the digital world affect every aspect of our lives, our cultural, social and economic development. The overlap of copyright law with data-driven policy interventions needs to be taken seriously. We are only at the beginning of an epochal change.

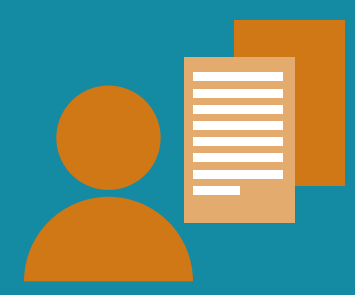

(1) Peer reviewed academic publications

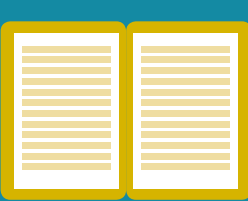

CREATe working papers published
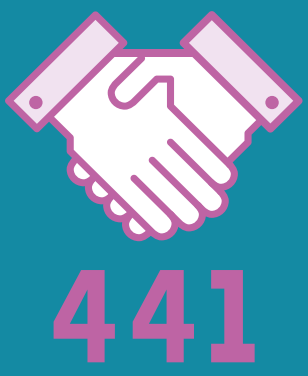

Industry

Engagements
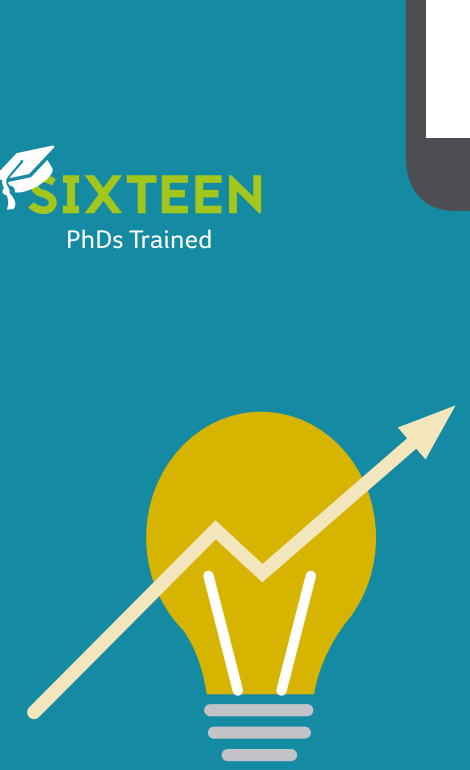

f1 MILLION +

New research funding generated (exactly, £1,006,000)
46
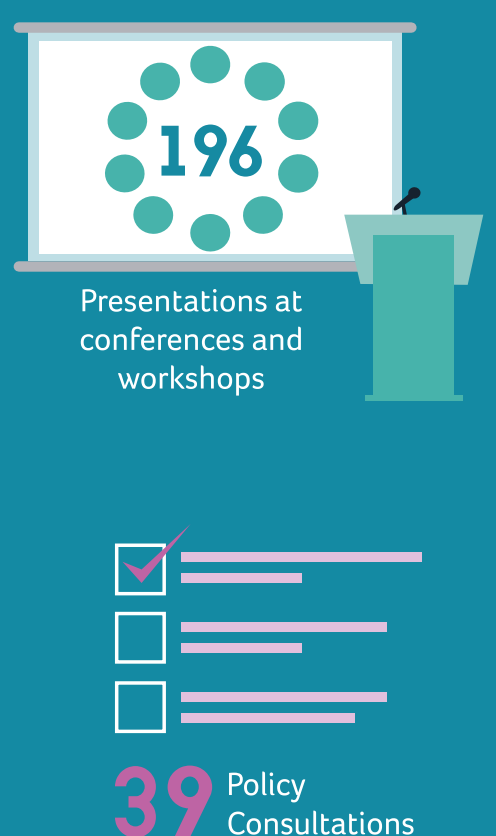

Subscribers to

CREATe mailing lis

(1,465 followers)

36

Postgraduate

0

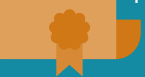

posts created

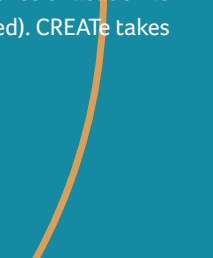


-O Unlawful File Sharing

Report Launch

\section{Stationers' Hall, London / April 2014}

A report on the human motivations underpinning unlawful filesharing was launched to a large gathering of creative industry representatives, policy makers, creators and

academics. Using systematic reviewing techniques from the medical sciences, CREATe's team of behavioural economists and psychologists from the University of East Anglia (Steve Watson. Daniel John Zizzo and Piers Fleming) undertook a scoping review of all evidence published between 2003-2013 into the welfare implications and determinants of unlawful file sharing. Studies dealing with music, film, television, video games, software and books were methodically searched; non-academic literature was sought from key stakeholders and research centres. A total of 54,441 sources were initially found with a wide search, and this was narrowed down to 206 articles which examined human behavior, intentions or attitudes. Whether unlawful file sharing confers a net societal cost or benefit to welfare remains unclear based on the available evidence

$\rightarrow$ bit.ly/1xV4gAz

\section{CREATe All Hands Conference}

House for An Art Lover, Glasgow I September 2014

Principally aimed at CREATe's seven Universities consortium members and associated fellows, the event was an opportunity to take stock of our collective efforts, map linkages between the multidisciplinary projects, reflect on progress, and look to the future. First, talks by Dominic Youn (Copyright Hub), Kieron O'Hara (University of Southampton) and Joe Karaganis (American Assembly, Columbia University) identified areas where cutting-edge empirical research from CREATe was beginning to address pressing economic and social questions. Secondly, presentations by Jeanette Hofmann (Social Science Research Center, Berlin) and Philip Schlesinger (University of Glasgow) highlighted the way in which CREATe was breaking new ground in terms of our relationship with society, industry and academia. The closing session underlined two areas where CREATe activities were beginning have an impact.

$\rightarrow$ bit.ly/1u9i116

\section{Sectoral Working Group}

Videos Games Workshop/ House for an Art Lover Glasgow / September 2014

Organized by Alison Brimelow, Daithi Mac Sithigh \& Sukhpreet Singh, this sectoral working group was an industry focussed brainstorming session where games industry representatives from across $\mathrm{UK}$ answered key questions of interest to the sector concerning copyright \& regulatory policy. The working group also shared copyright \& regulatio policy lessons from games that can inform other creative

\section{Valuing the Public \\ Domain}

\section{A Workshop for UK Creative Firms/} The Digital Catapult, London/ December 2014

'Valuing the Public Domain' was a 12-month research and knowledge exchange project carried out by Kris Erickson (University of Glasgow), Paul Heald (University of Illinois. Fabian Homberg (Bournemouth University), Martin Kretschmer (University of Glasgow) and Dinusha Mendis (Bournemouth University). The project 1) mapped the size of the public domain and frequency of its use; 2 ) analysed the role of public domain works in value creation for UK business and society; and 3) assisted UK media companies to identify business models that generate value from materials in the public domain. The study included analysis of over 2,500 media projects on the Kickstarter crowdfunding platform, usage statistics of photographs in over 1,700 biographical pages on the Wikipedia platform, and interviews with UK media businesses and independent creators.

$\Rightarrow$ bit.ly/1txkTuo

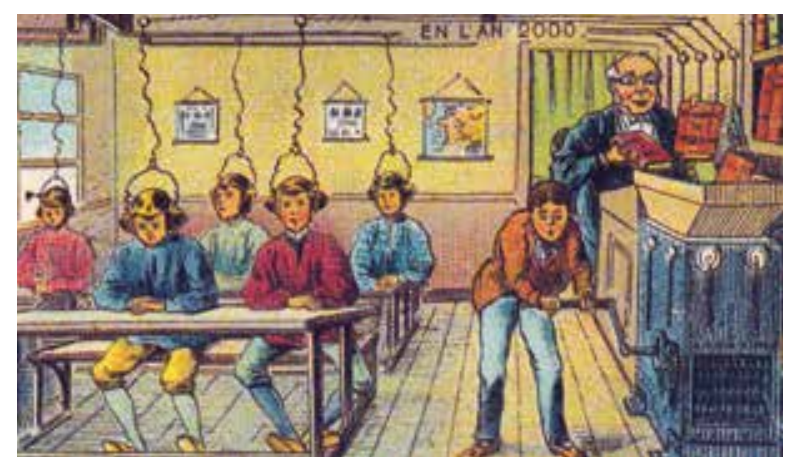

The Economics of Creativity and Competition

New Markets, New Challenges. University of East Anglia, Norwich / February 2015

This capacity building event, hosted by the Centre for Competition Policy at the University of East Anglia, explored the role of copyright and new business models in the creative industries, from an economics point of view. This two-day event was a forum to debate the relationship between competition and creativity; to consider how experimental economics can increase our understanding of consumers and producers and to examine the particular issues and problem that face new markets in the digital creative economy. The event allowed legal researchers to engage with economists, and to see how work in the field can supplement and develop their own research. As part of the event, brief presentations were given by new researchers working on new projects in this area of research. A keynote was given by Joel Waldfogel (University of Minnesota) on Creative Activity and Product 'Quality' in Music, Movies and Books since Napster/ Digitization.

$\Rightarrow$ bit.ly/1qF9L1]

\section{Copyright History and Policy \\ Symposium}

University of Glasgow / March 2015

Copyright history has long been a subject of intense and contested enquiry. Two landmark copyright decisions of the eighteenth century during the so-called Battle of the Booksellers between Scottish and London publishers - Milla v. Taylor (1769) and Donaldson v. Becket (1774) - continue to provoke debate today. Taking Gomez-Arostegui's work in this area as a point of departure, CREATe organised an international symposium on the interplay between copyright history and contemporary copyright policy. What justificatory goals are served by historical investigation? Does the study of copyright history still have any currency within an evidencebased policy context that is increasingly preoccupied with economic impact analysis? Speakers included Hector MacQueen (Edinburgh Law School), Howard Abrams, (University of Detroit Mercy). Lionel Bently, (University of Cambridge), Oren Bracha, (University of Texas), Mark Rose,
(University of California, Santa Barbara), Charlotte Waelde, (University of Exeter). As part of the Symposium, the Dutch section of the Digital Archive: Primary Sources on Copyright (1450-1900) was introduced by Stef van Gompel, (IViR, University of Amsterdam).

$\rightarrow$ create.ac.uk/event/copyright-history-and-policy

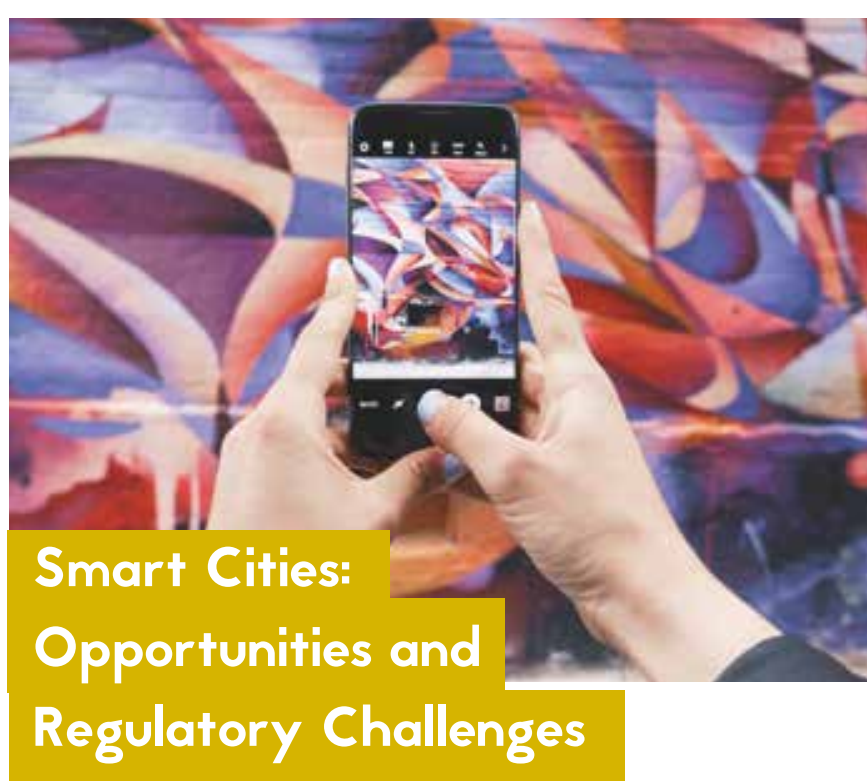

University of Strathclyde, Glasgow / 31 March - 1 April 2015

Like many other cities around the world, Glasgow - where the CREATe Centre is based - is part of the new phenomenon of 'smart cities,' with innovative services, applications and delivery platforms created by integrating public and private data sets at a citywide level. The city was awarded $€ 24 \mathrm{~m}$ in 2012 to run a prototype project based around smart transport, energy, policing and health to demonstrate how ubiquitous computing might enhance societal, economic an environmental well-being.

This conference, chaired by Lilian Edwards, focused on how contemporary urban life is increasingly marked and shaped by technology, and critically assessed what this means for (isting societal norms and regulatory structures. While the ngineering and architecture worlds are already excited by . 作 (n) igital walls \& graffiti, audience awareness and UGC ngagement with sport. $\Rightarrow$ bitly/1AK4HE2 


\section{1
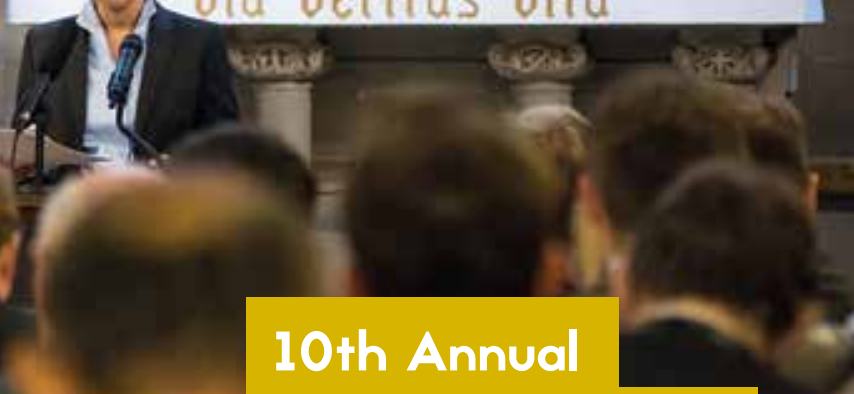 \\ Conference of the EPIP Association \\ The University of Glasgow / September 2015 \\ Delegates interested in the economic, legal and political aspects of intellectual property rights explored the role of IP in the Creative Economy, with a focus on copyright, data and the changing economics of the digital world. Organised in cooperation with the European Commission, the opening keynote was delivered by lan Hargreaves (Cardiff University,

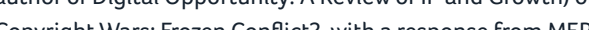

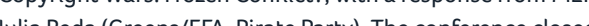

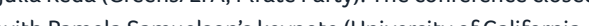

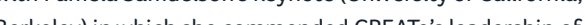 Berkeley) in which she som this key policy area and stressed hat EFP 2015 enabled new evidence led approach towards copyingh policy. She \\ $\rightarrow$ epip2015.org}

\section{SERCI Annual Congress}

\section{University of Glasgow /}

September 2015

Organised in conjunction with Richard Watt (University of Canterbury, New Zealand), SERCI was hosted alongside EPIP. SERCI's plenary keynote session on copyright collectives and contracts was chaired by Ruth Towse, who provided an economic theory perspective on contracts and copyright collecting societies. The plenary panel session on compensating creators was chaired by Marcel Boyer of the
University of Montreal and CIRANO. US Copyright Royalty Judge David Strickler spoke on Royalty Rate Setting for Sound Recordings by the U.S. Copyright Royalty Board: The Judicial Need for Independent Scholarly Economic Analysis. $\rightarrow$ serci.org

\section{GikII / W ZB}

Social Science Centre Berlin

\section{September 2015}

The annual Gikii - a conference for geek lawyers, techies interested in law or just geeks generally - was held in Berlin in September 2015. CREATe researchers Lilian Edwards, Burkhard Schafer, Derek McAuley, Smita Kheria, Judith Rauhofer and Edina Harbinja were active in presenting and chairing sessions. Following Gikii style, the event included presentations aiming to combine areas hardly imaginable for traditional legal researchers, i.e. science fiction and law, legal implications of popular culture, robots, cyborgs, artificial intelligence, holograms, neuroscience, superheroes and law. Gikii papers are meant to be experimental and fictional while tackling serious legal issues that futuristic technology cause.

\section{Understanding UK} Copyright Law

Workshops Series / Digital Catapult / London / 2014-15

Organised by CREATe and the Digital Catapult, the goal of these workshops was to better understand the real-world concerns and questions about copyright faced by the creative and cultural sectors, and develop sector-specific guidance that responds to their needs. In 2014/2015, the first three workshops were aimed at: photographers and illustrators (3rd December 2014); music writers and composers (19th March 2015), archives and libraries (29t September 2015). The involvement of leading copyright experts as well as industry and government representatives provided primary creators, media entrepreneurs and cultura heritage practitioners with an opportunity to discuss and. explore how copyright affects their everyday decisions an practice. Photographers and illustrators were particularly concerned over the unauthorised use of their digital imags and interested to know about enforcement options, such as the IPEC Small Claims Court. Songwriters and composers wanted to better understand ownership of rights in cases of joint authorship, and the relationship between copyright and contracts. Archivists, curators and librarians explored the new orphan works legislation in detail, through a series of case studies showing how a range of institutions have used the copyright exception and licensing scheme to digitise and make collections available online.

\section{The Copyright}

Education Symposium

BPI, London / May 2016

The Symposium was sponsored by CREATe, Authors' Licensing and Collecting Society (ALCS), Copyright Licensin Agency (CLA), Educational Recording Agency (ERA), PRS for Music, the Industry Trust for IP Awareness and supporte by the UK IPO. The aim of the symposium was to review the work of industry, academia and government in raising awareness of copyright law, and to explore how evaluation of data collection, research and education initiatives in this area might take shape. Attendees included policymakers, academics, creative industry representatives, independ consultants and information professionals. The event was opened by IP Minister Baroness Neville-Rolfe who suggested a roadmap to adequately assess the challenges and effectiveness of industry and academic interventions in copyright education. The day included presentations of different copyright awareness initiatives, and a series of workshops, which considered evaluation strategies for copyright education, potential collaboration between industry and academia, and future research questions. One of the key takeaways from the event was that education and awareness initiatives should be impartial, independent. authoritative and empowering for users. $\rightarrow$ bit.ly/11vvBvzv

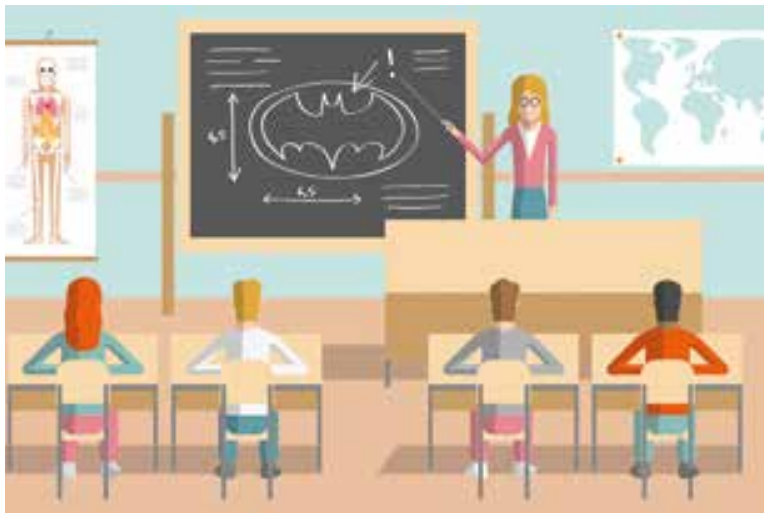

Copyright \& Cultural Memory Symposium

\section{The Lighthouse Glasgow /}

\section{June 2016}

How does copyright impact the access to and use of our shared cultural heritage across borders? This essential question unites the work of CREATe's four postgraduate researchers; Megan Rae Blakely, Kerry Patterson, Victoria Stobo and Andrea Wallace who presented findings from their respective projects at the symposium. Their work addresses the challenges and practicalities of digitising unique and distinctive artistic collections, the relevance of risk-based models of copyright compliance when enabling access to archive collections, and surrogate intellectual property rights archive collections, and surrogate intellectual property righ in the cultural sector. The day included a keynote by Simo Tanner, internationally-renowned expert in digital cultural featured respondents from the UK IPO, the British Library the Libraries and Archives Copyright Alliance Kicking off the symposium was a pop-up exhibition Alliance. Kicking off the of public domain artefacts (surrogacy) and digital access policies of cultural institutions. $\rightarrow$ bit.ly/1V1uEaX

$\Rightarrow$ displayatyourownrisk.org

-




\section{Opening}

Access and

Widening the

\section{Academic}

\section{Terrain}

Top 5 Most Downloaded

Papers (as of June 2016)

Frosio \& Derclaye (2014) Open Access Publishing: A Literature Review

Watson et al. (2014) Determinants and Welfare Implications of Unlawful File Sharing

3

Stobo et al. (2013)

Copyright and Risk: Scoping the Wellcome Digital Library Project

$4 . \quad$ Favale et al. (2013)

Copyright and the Regulation of Orphan Works

5

Edwards \& Harbinja (2013) What Happens to my Facebook Profile When I Die? Legal Issues Around Transmission of Digital Assets on Death
The CREATe Working Paper series is an open access resource designed to rapidly disseminate leading research by CREAT researchers and associated scholars to the wider community In addition to ensuring that new research becomes immediately available to the public in a rapidly-changing and innovative field of study, the series captures digital outputs which are not traditionally suited to the academic format but which nevertheless serve as anchor points for discussion, debate and advancement of understanding. CREATe researcher Kris Erickson (University of Glasgow) gives an insight into the workings of the CREATe working paper series. When the Working Paper series was conceived in 2012, CREATe anticipated an evolution of academic publishin practice towards open access, transparency and accountability to funders. A commitment to open access publishing is now a requirement for RCUK funded projects as well as those receiving Horizon 2020 funds. In a speech to the European Commission on Open Science and Open Innovation in 2015, Commissioner Carlos Moedas observed
that 'every part of the scientific method is becoming an open, collaborative and participative process'. Of course, an important aspect of this transformation is intellectua property, and the working paper series is both a tool for disseminating research about IP and a practical source of new knowledge in itself.

In deciding how papers would be archived and disseminated, the CREATe Centre weighed several options, including hosting them on the project website or using the privately funded Social Science Research Network SSRN (acquired by Elsevier in May 2016). After careful deliberation, the CREATecided to make papers avallable directly from the CREATewebsite, and to ardive and Commsion fund on presen CERN and OpenARE, with the mission to 'preserve and showcase multidsciplinary research results (data and publications) which

There are currently 46 papers in the series (as of June 2016) with new additions made constantly throughout the year.
Types of papers published include 1) specially commissioned pieces on topical issues, such as a 2014 piece by Monica Horton on the Aereo case and copyight in the cloud; 2) scoping reviews of relevant literature and methodologies, such as a 2014 paper by Ruth Towse on the purpose of academic literature reviews; 3 ) digital transcripts of live conferences and workshops, such as proceedings of an ESRC event on the role of evidence in copyright policy published in 2013; and 4) research outputs which may include preprints of articles or papers under development by CREATe associated researchers.

The Editorial Board of the CREATe Working Paper series is headed by Philip Schlesinger and consists of a group of 15 researchers who make selection decisions about research to feature in the series and evaluate unsolicited submissions for external review.

$\rightarrow$ create.ac.uk/publication 

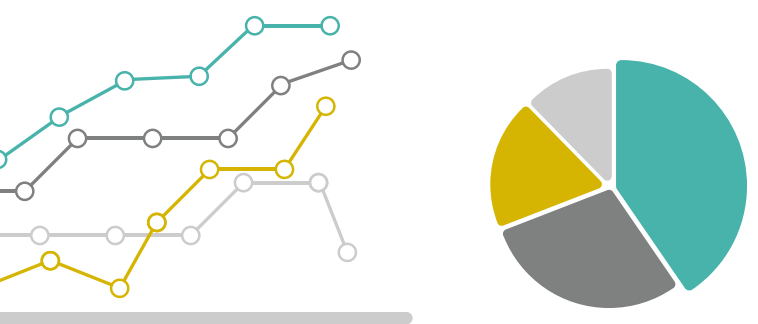

\section{CREATe}

\section{Resources}

CREATe's digital resources translate complex research findings, borne out of an equally complex legal context, into a more accessible format, enabling public discourse and wider debate. We make primary research materials available, both data and historical sources, in resources that reflect our interdisciplinary field. Our resources fall under three current themes: copyright evidence, copyright user and copyright history.

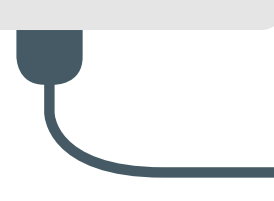

\section{Copyright Evidence}

OMeBa (Online Media Behaviour analytics): Exploring Online Behaviour with Data

Online media are changing continuously due to technological progress. The legal framework, copyright policy, digital innovation and business models are shifting too, transforming onling behaviour. In orderto understand the perplexing pattenn of robust evidence- based of appropriate data, assisted by visualisations, is not only (Univerity of Glasgow) introduces the OMeBa projlis MeBa project from this strand of research.

In 2012, the UK's communications regulator (Ofcom) and the Intellectual Property Office (IPO) with the market resear company Kantar designed a unique survey that has been repeated in six waves (last in spring 2016). While conceived as an "infringement tracker", the surveys in fact offer a rich tapestry of data connected with online access and consumption behaviour in the UK. Policy makers and academic researchers have just started to explore this outstanding database and the lesson it can provide. Identifying a need in the academic, policy and industry communities for direct access and easy readability of data in this area, CREATe developed a user-friendly tool, OMeB (Online Media Behaviour analytics), which not onlyallows users to further investigare interesting cross tabulations. The results are richlyvisualised.

The questionnaire survey involves 5000+ respondents each time. The original Ofcom design is very extensive and contains 520 + possible different questions with $5000+$ data points each. Each of the questions in the raw dataset is expressed as a code, and a separate file connects those codes to the questions in natural language. OMeBa helps simplify the process of browsing the survey data by linking these variable codes with questions in plain English taken from each of the surveys and allows easy extraction of the entire dataset or of selected variables in a popular format. For example, the data reveal that youngsters are the top spenders, top infringers and top legal consumers, at the same time! Specifically, in 2013 individuals of age 12-15 form the largest fraction (28.97\%) of top spenders (spending more than $\mathrm{E} 100$ in past 3 months). Individuals of age 12-15 form the largest fraction of infringers (no legal download in past 3 months) - this fraction decreased from $27.59 \%$ in 2013 to $25 \%$ in 2015 . Surprisingly, individuals of age $12-15$ also form the largest fraction of totally legal consumers to (100\% legal downloads in past 3 months) - this fraction decreased slightly from $26.6 \%$ in 2013 to $25.43 \%$ in 2015 . This is just an illustrative example of the possibilities this interface is offering.

$\rightarrow$ create.ac.uk/omeba

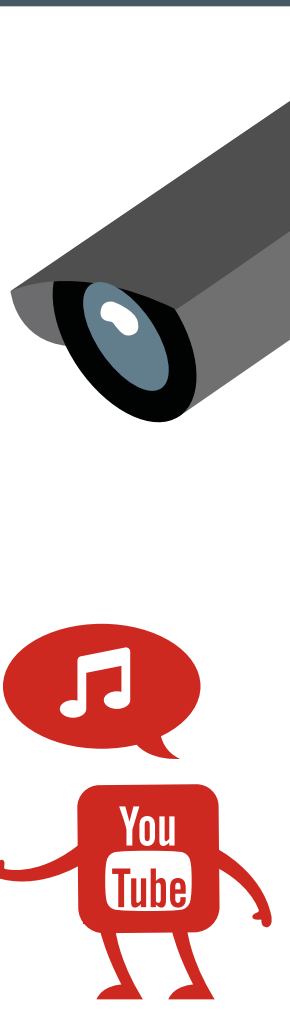

IP Watchr

The Copyright Evidence Wiki: Empirical Evidence for Copyright Policy

A body of evidence allows better navigation in any contested policy field. The 'CREATe wiki' at CopyrightEvidence.org does exactly that, says Theo Koutmeridis. This open, online examines copyright from an interdisciplinary perspective bringing evidence from studies in fields that were previously overlooked. Based on wiki technolo overlooked. Based onwitechology, it fully categorises more than 500 empical are able to propose and define studes. Competing research underying do un a global digital economy is associated with new challenges. for he dign of infor forthe design of literature review in

$\rightarrow$ copyrightevidence.org/evidence-wiki

Tracking IP infringement on Social Media

IP Watchr and OMeBa (see above) are two analytical and visualisation-based software programs created by CREAT data developer Jesús Rodríguez Pérez (University of Glasgow). As social media becomes more integral to our lives, users are increasingly using it to share links for downloading multimedia files containing predominantly movies, television series and computer software IP Watchris a web, te platform with an underlying software for real-time tracking fillegal dow pesign

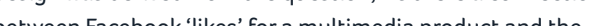
no

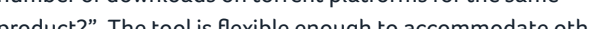

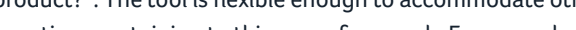
aill be

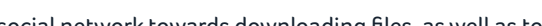

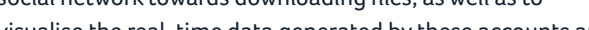
is derivatives.

$\rightarrow$ create.ac.uk/ipwatchr 


\section{From Anecdote to Evidence in Copyright Litigation}

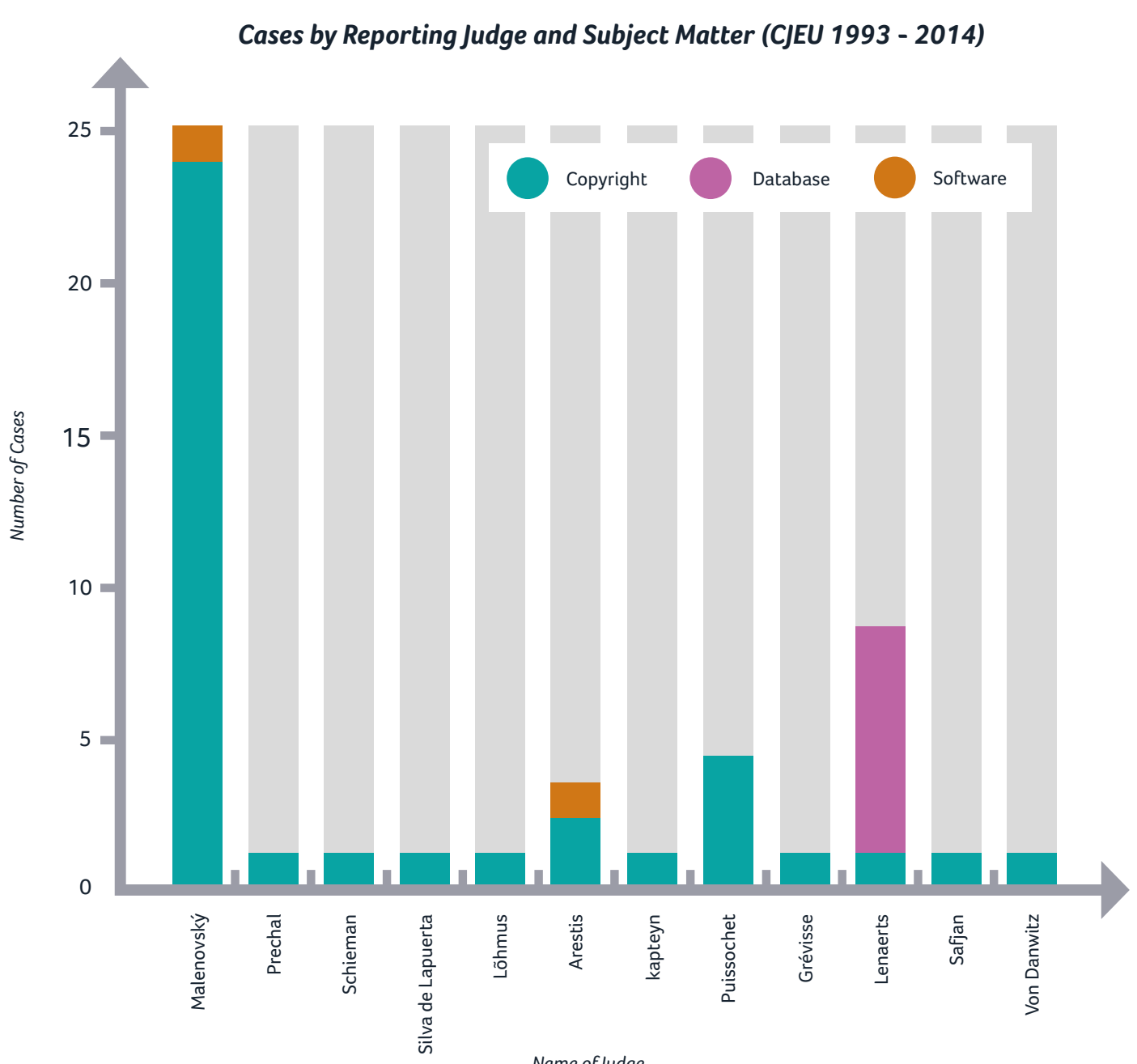

Name of Judge

What are the judicial trends in copyright law decisions from in the UK. CREATe Industry fellow Emma Barraclough, an the UK courts and how good is the quality of legal decisions? experienced trade press journalist with a particular interest in Do und Dopyright law who sues in the sall chims trackin tondof copyright law? Who sues in the small claims trackin London's the questions the questions beng conside prome copyright litigation stream. Project teams collect and analyse dat com cases brought peforethe national courts and the courtof usticeoflhe Euc IP, reports on CREATe's findings in this area.

CREATe researchers Marcella Favale (Bournemouth University), Martin Kretschmer (University of Glasgow) and Paul Torremans (University of Nottingham) have studied copyright and database cases brought before the CJEU, and analysed the allocation of cases to chambers within the courts, the composition of those chambers, and the judgments themselves. They concluded that no judge in the
CJEU had any specialism in copyright law before joining the Court. To compensate for a lack of prior expertise, the Court appears to allocate copyright cases to particular chambers and judges. One judge, Jirí Malenovský, served as rapporteu on 24 out of the 40 copyright cases the researchers studied. Malenovsky is less likely than his fellow judges to broaden the rights of copyright owners because he is more likely to interpret copyright narrowly and copyright law exceptions broady. The study, published in Modern Law Review, was launched in London on April 13th 2016 in an event co-organized with the British Literary \& Artistic Copyright Association (BLACA).

\section{Steering Judicial Policy}

Now the researchers are turning their attention to the way in which member states try to reverse or shape copyright law by fling written submissions in cases referred to the CJEU by national courts. By looking at documents in more than 70 copyright and database law cases, they have established that some countries, including Italy, France, the UK, Spain, Poland and Germany, file far more written observations than others. The researchers are trying to assess the importance of submissions from member states and the European Commission. So far, they have found the greatest correlation between arguments submitted by the Commission and the decision issued by the Court.

\section{UK Focus}

CREATe researcher Georg von Graevenitz (Queen Mary University of London) and his team are gathering information about copyright cases brought before the High Court. The researchers are drawing out trends in litigation as well as analyzing the quality of legal decisions by assessing the probability of a decision being reversed depending on a judge's experience and the complexity or novelty of the dispute. $\rightarrow$ bit.ly/1UUKCZA

Sheona Burrow (University of Glasgow) focuses on copyright litigation brought before the Intellectual Property Enterprise Court using its small claims track: a procedure designed to be relatively quick and informal. Claims are limited to $£ 10,000$ and the costs the successful party can claim are limited. Claimants, many of whom are unrepresented, are often uncertain about the detail of the law applicable to their case, requiring researchers who want to classify them to digest the details of the dispute rather than relying on the claim forms submitted in the case. Nearly $80 \%$ of claims specify copyright law, although the small claim track can also be used for trade mark, passing off and unregistered design cases. Burrow's data suggests that photographers are heavy users of the small claims track, representing almost half of claimants and nearly three-quarters of repeat claimants. Although photographers whose copyright is infringed often face a mo straightforward evidentiary hurdle than other IP owners, there is still scope for those in other parts of the creative industries to make better use of the small claims track to enforce their rights.

$\rightarrow$ bit.ly/1wqkXoh

Jane Cornwell (University of Edinburgh) works on copyright litigation in Scotland, based on a survey of IP practil files from 2008-2014. The data revels that a retately largen mef

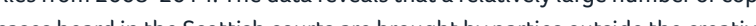
ind

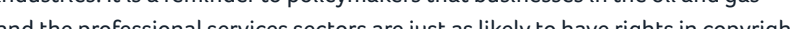
and the professional services sectors are just as likely to have rights in copyight $\rightarrow$ bit.ly/ZGbDQw

The findings of CREATe's data-heavy research is of value to policy makers who want to implement evidence-based policies, for court administrators, and for businesses and individuals involved in copyright disputes - and the lawyers who advise them.
Progress of Cases in IPEC Small Claims Track (\%) (2012-2014)

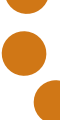
$70 \%$ 0 Judgement

Case Managment

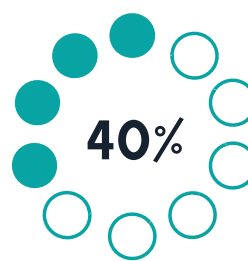

Defence Lodged

$90 \%$

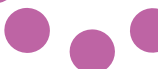

Service on Defendant

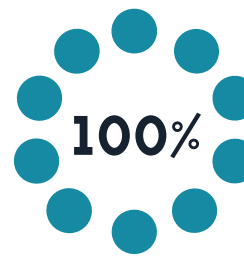

Claim Form

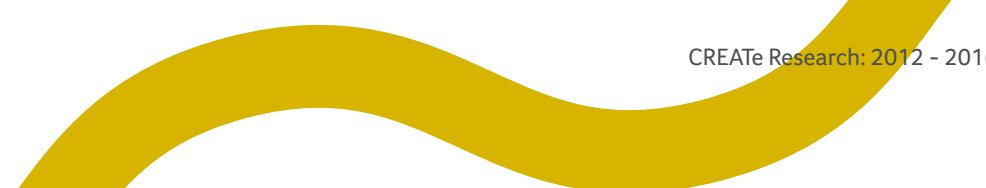




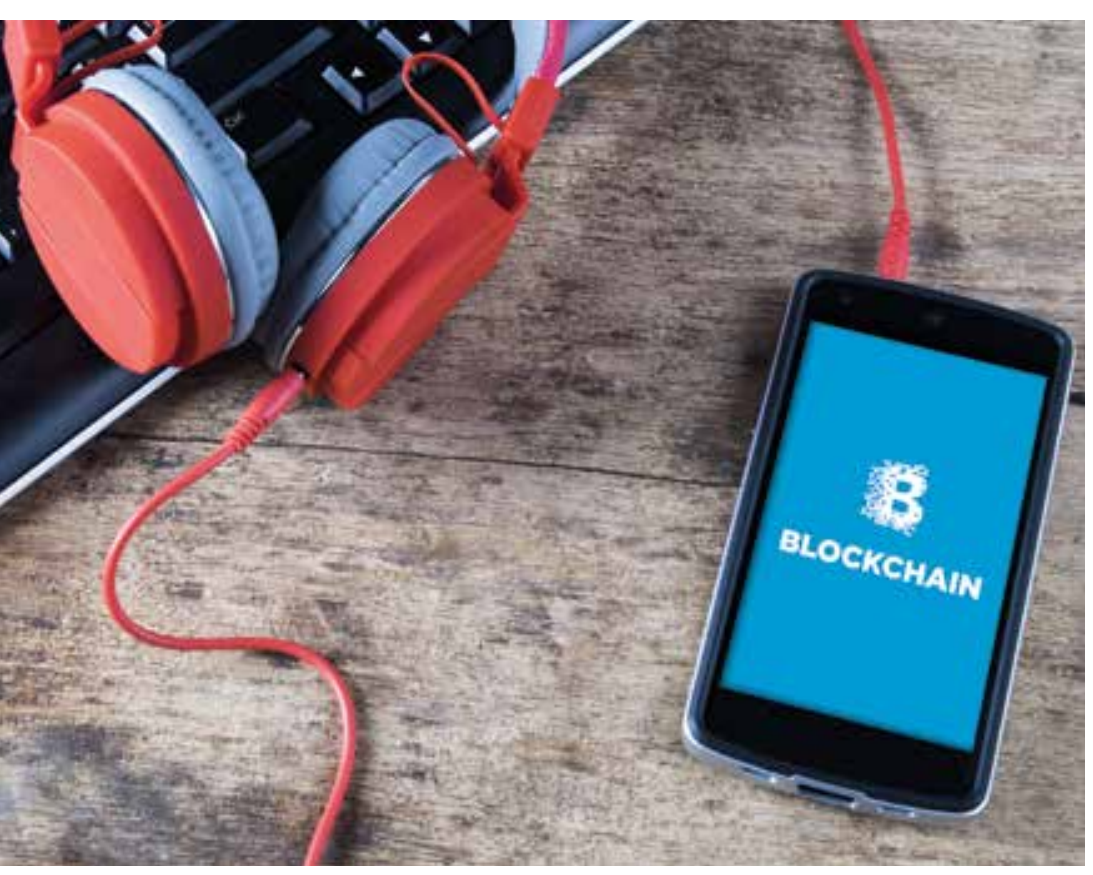

Blockchain or Chain Gang?

The relationship between the music industry and blockchain

Bitcoin took the world by storm, offering a radical new method of paying for transactions, which was underground and alternative. Blockchain emerged as a more respectable enabling technology, providng a chronological public record of all Bicoin transactions that have everbeen made. Artists and entrepreneurs in the music industry understood the media friendly attraction of something with such powerful technological potential and such a shady past, with origins in the darknet and notorious Stik Road website. In his role as a CREATe Industry Fellow, Jeremy Siver undertook a study of the application of blockchain to the music industry, interviewing a variety of executives in the field, from recording artists and technology startups to the heads of collecting societies. Could it be a means to produce a publicly accessible and regularly updated global database of publishing and recording rights data? Could it allow a new means of music discovery, whe consumers navigated music creatively and intuitively?

Investigations began just as a series of public events took place in London that heralded an almost unprecedented wave of interest in a new technology. The atmosphere at these events had something of the heady days of the first internet bubble. There was a strong sense of the possibilities and importance of blockchain but without a great deal of widespread understanding of what it could actually do, let alone how it worked. Forward-thinking label executives, eager CEOs of start-ups, recording artists and experienced entrepreneurs all had enough understanding to realize that blockchain was significant and world-changing. It might be the thing they craved to start building a new digital be the thing they craved to start building a new digital felt, to them, very broken. There were a number of areas of possible benefit Firstly, the incremental process of loading each new work as it was created onto blockchain could potentially enable the assembly of a meta-data database with more at thority and wider range of data contained in it, than had previously been achieved.

Secondly, the reduction of the need for intermediaries, which blockchain enables on individual transactions, theoretically reduced a price barrier to entry and could enable a larger number of artists to release content commercially. Thirdly, it looked as if bigger commercial players, like the major labels, could potentially use the blockchain to build much more efficient networks for their own transactions and business needs, such as secure media distribution or licensing. The theoretical value of the technology is undoubtedly huge, the real question is how far its implementation can be carried. Will existing incumbent players act as blockages to prod. Will the level of investment coming from pure technogr Wilt the level of investment coming from pure technology advantage of the technology just as the investors seek to take advantag of them? Tim alonewill thow rapily or slowly progresswith progress wh blockchain a made. There are a num ber

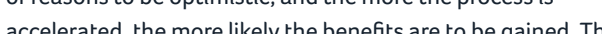
accellated the in his paper which can be found at $\rightarrow$ bit.ly/1XIq YjY

Jeremy Silver is an investor, author, digital media entrepreneur and CEO of the Digital Catapult. His research explored whether the technology presents an opportunity to solve several of the music industry's challenges, offering a new business model that is better than subscription.
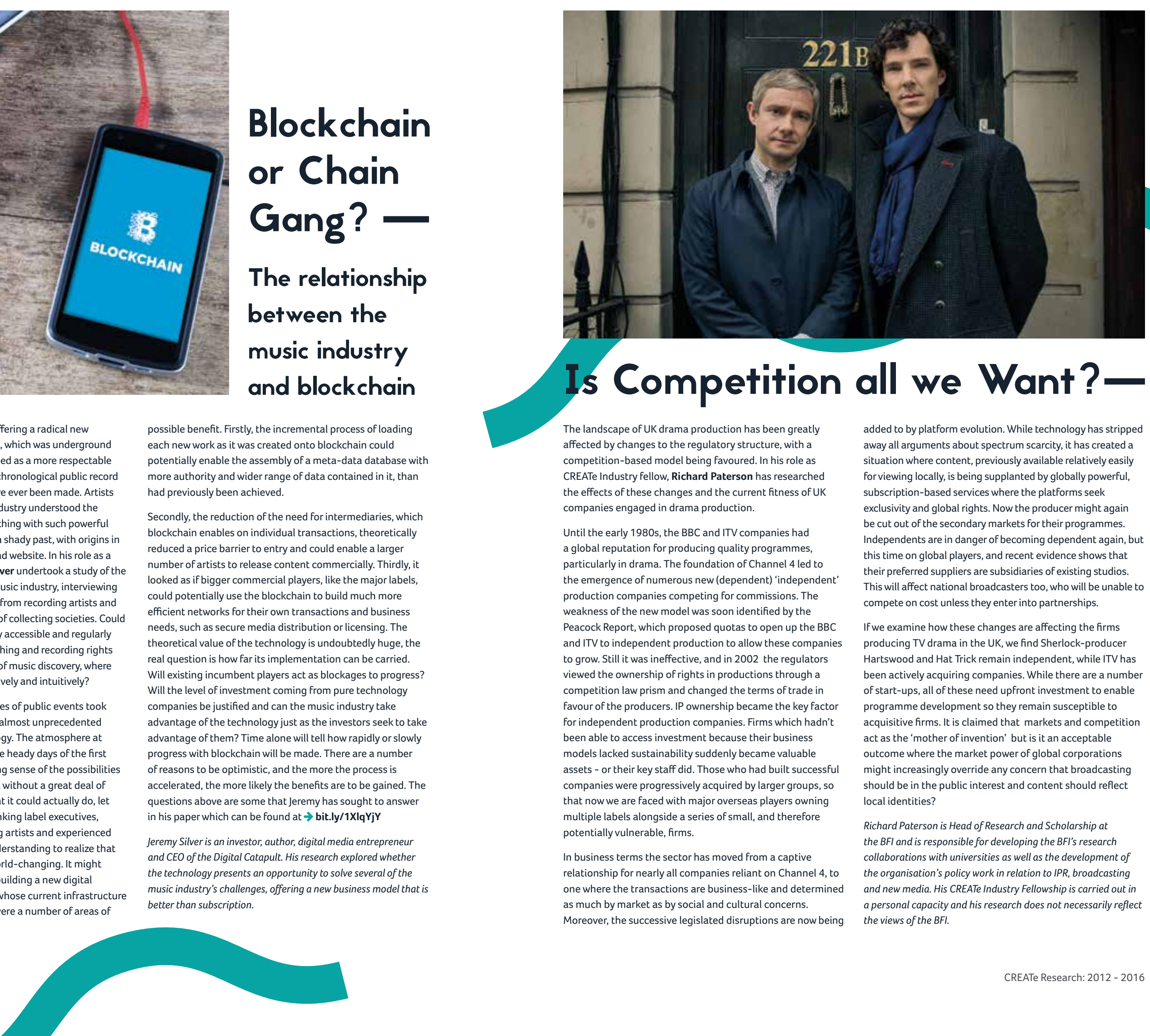


\section{Voices of CREATe:}

Understanding the

Cultural, Creative

and Digital

Industries

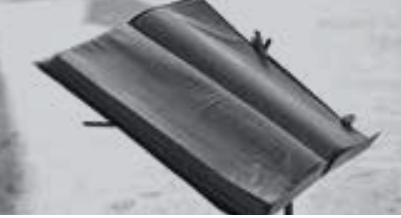

In the cultural, creative and digital sectors, self-employed and freelance workers account for a large proportion of the labour force. One of CREATe's objectives has been to investigate the activities of these 'individual creators', and to better understand the conditions under which they wo Ealasaid Munro (University of Glasgow) conducted this project to form a picture of CREATe's work across sectors such as music, fashion, publishing, games, comics, and film.

The findings of Voices of CREATe can be organised into thre main themes: how individual creators build a career in the creative industries; how technology is changing the way that they work, and how they understand copyright and IP. Even after 20 years of targeted government intervention in the cultural, creative and digital industries, individual creators are mostly extremely low-paid, precarious, and ultimately, marginal. Building a career in the creative industries is a long-term commitment, with no guarantee of financial stability. Creatives must build a 'portfolio' career in order to survive. The way that creators compile their portfolio is, of course, affected by what work is available at any one time. But it is important to recognise creators' agency, and the way that they seek to balance work that is commercially viable with work that is enjoyable and creatively satisfying Creators working within certain creative sectors have seen fundamental and rapid changes in recent years. Those disrupted by the advent, and increasing acceptance, of peerto-peer file-sharing and, later, streaming services.

Of these industries, music and book publishing emerged as two particularly important test beds for researchers seeking to understand the disruptive influence of technology on creators. It is notable that technology did not emerge as a particularly important theme within other sectors, such fashion and product design, dance, or theatre.

Another of CREATe's key concerns is the role played by IP in the day to day practice of individual creators. The project studied both the actual and perceived value of P. what meaningsindividat ceators ascibed to IP, and Te mech was a tension betwen the legl defintions of common-sense understanding of IP that prevailed amongst individual creators, who tended to see their IP as "the legal embodiment of their creative identity". Creators, particularly those with more experience, demonstrated a sound awareness of basic IP issues. Copyright infringement and IP disputes were common, but because of the time and expense involved in pursuing copyright infringement and IP disputes, only the most established businesses with the highest turnover were able to pursue compensation. Individual creators and microbusinesses often felt powerless to actif they found out their work had been copied, raising serious questions about whether the current copyright framework offers a what extent it functions as an in

\section{CREATe research portfolio consulted:}

\begin{tabular}{|c|c|c|}
\hline $\begin{array}{l}\text { Townley, B. \& } \\
\text { Berthold, H. (St. } \\
\text { Andrews) }\end{array}$ & $\begin{array}{l}\text { Managing Intellectual } \\
\text { Property Assets for } \\
\text { Creative SMEs }\end{array}$ & bit.ly/11txz3FA \\
\hline $\begin{array}{l}\text { Sithigh D. M. } \\
\text { (Newcastle) \& } \\
\text { Phillips, T. (UEA) }\end{array}$ & Copyright and Games & bit.ly/1omDINY \\
\hline $\begin{array}{l}\text { Dowthwaite, L. } \\
\text { (Nottingham) }\end{array}$ & $\begin{array}{l}\text { Open User and Creator } \\
\text { Platform: Web comics } \\
\text { project }\end{array}$ & bit.ly/1DfnuDW \\
\hline $\begin{array}{l}\text { Kheria, S. } \\
\text { (Edinburgh) }\end{array}$ & Individual creators & bit.ly/1vAmzgu \\
\hline Barr, K. (Glasgow) & $\begin{array}{l}\text { Music Copyright in the } \\
\text { Digital Age }\end{array}$ & bit.ly/1pgYYdn \\
\hline $\begin{array}{l}\text { Street J.\& Phillips, } \\
\text { T. (UEA) }\end{array}$ & $\begin{array}{l}\text { Copyright at the Digital } \\
\text { Margins }\end{array}$ & bit.ly/1qullzPl \\
\hline $\begin{array}{l}\text { Negus, K. } \\
\text { (Goldsmiths), } \\
\text { Street J. (UEA) } \\
\text { \& Behr, A. } \\
\text { (Newcastle) }\end{array}$ & $\begin{array}{l}\text { Digitisation and the } \\
\text { Politics of Copying in } \\
\text { Popular Music Culture }\end{array}$ & bit.ly/1q|4wOn \\
\hline $\begin{array}{l}\text { Kember, S. } \\
\text { \& Jeffries,.. } \\
\text { (Goldsmiths) }\end{array}$ & $\begin{array}{l}\text { Whose Book is it } \\
\text { anyway? Digital } \\
\text { publishing project }\end{array}$ & bit.ly/1wcWcvG \\
\hline $\begin{array}{l}\text { McRobbie, A., } \\
\text { (Goldsmiths) }\end{array}$ & $\begin{array}{l}\text { Fashion IP: From start-up } \\
\text { to catwalk: A Four City } \\
\text { Investigation }\end{array}$ & bit.ly/103LplE \\
\hline $\begin{array}{l}\text { Erickson, K. } \\
\text { (Glasgow) }\end{array}$ & $\begin{array}{l}\text { Value of the Public } \\
\text { Domain: Crowdfunding } \\
\text { project }\end{array}$ & bit.ly/1DepkGp \\
\hline
\end{tabular}

Business Models Buzzword or Constructive Tool?

CREATe carries the business model question in its byline, and every firm appears to have one. Business models are changing rapidly in the digital economy, and are often seen as a complement or even alternative to copyright enforcement. Critics argue the term remains ill-defined and unproven. Proponents point to its enduring popularity and strategic use. Whether buzzword or constructive tool business modes continu to influence industries. Nicola Searle (Goldsmiths) explores how the industries. Nicola Searle (Goldsmiths) explores how the and how creators and industry adapt to technological and market changes.

The definition of business models is ambiguous; both in practice and research its definition varies across CREATe projects. One interpretation is the business model as value chain, as describe in Jeremy Silver's work on music. This is supported by those interviewed in Tales from the Drawing Board (Grewer et al), however the phrase 'business model' was equally found to be vague, and used as a catch-all phrase to describe the narrative creators tell themselves and others about their activities and purpose. Reflecting the portfolio's diverse sectors and disciplines, the CREATe research confirms existing findings identifying inconsistencies in business models as a concept and methodology, and acknowledges its use in conveying meaning. Change?

A surprising finding is the resilience of some traditional business models. "Whose Book is it Anyway?" notes the print copy remains a robust publishing model. Likewise, Silver argues the advent of music streaming is not a majo industry and licensing change, but a minor variation in the retailer-consumer value chain. However, participants in Doyle's research claim 'heritage' models, based on advertis and audiences, are giving way to marketing-focused digital models. Collaboration with Baden-Fuller argues ideal business

CREATe participants and scholars note that declining remuneration is an increasing problem for individual creators. However, this reflects long-standing concerns of the persistently weak bargaining power of creators, the relative strength of intermediaries, and changes in market structure rather than a localised business model issue.

Business models \& copyright

The heterogeneity of business models makes it difficult to establish clear links with copyright. Position papers by industry experts Kaye and Mollet argue copyright is plato neutral. If copyright is agnostic, then its role in business models, which are purported as a means to adapt to new technologies and platforms, is diminished, Yet Doyle's work finds copyright infringement (piracy) of digital formats has changed television distribution and pricing strategies but piracy's business mol impar is secondary to the impact

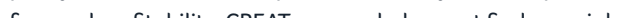
is a key driver of business model innovation.

Where next?

CREATe research findings demonstrate the diverse use of business models and do not point to a coherentset of business model 'solutions' for changing markets in creative industries. This heterogeneity suggests business models should only be one part of a widrinnovitiond creative economy policy.

Despite the general scepticism of scholars, the enduring popularity of business models leaves unanswered question For example, we know innovation support and quantitative investigation is scarce. The key to business models may not lie in their application, but in their ability to focus and articulate business aspirations. and enact practices of innovation. models have yet to be identified.

CREATe research portfolio consulted:

\begin{tabular}{|c|c|c|}
\hline Baden-Fuller, C. (2016) & EPSRC Building Better Business Models & bit.ly/1xVODKO \\
\hline D’Adderio L. et al. (2016) & The Practice of Business Models & bit.ly/213EpVD \\
\hline Doyle, G. (2016) & Digitisation and Changing Windowing Strategies in the Television Industry & bit.ly/1tBgwlt \\
\hline Grewar, M., Townley, B., \& Young, E. (2015) & Tales from the Drawing Board & bit.ly/1kKqaok \\
\hline Kember, S. and J. Jeffries (2015) & Friction and Fiction event, Whose Book is it Anyway? & bit.ly/1wcWcrc \\
\hline Kaye, L. (2015) and Mollet, R. (2015) & Position Papers: Whose Book is it Anyway? & bit.ly/1wcWeve \\
\hline Paterson, R. (2016) & Modelling the Evolution of the TV Drama production sector in the UK & bit.ly/1ZALLO8 \\
\hline Silver, J. (2016) & Blockchain or the Chaingang? & bit.ly/1XIqYjY \\
\hline Towse, R. (2015) & Copyright and Business Models in UK Music Publishing & bit.ly/1RoYMcS \\
\hline
\end{tabular}




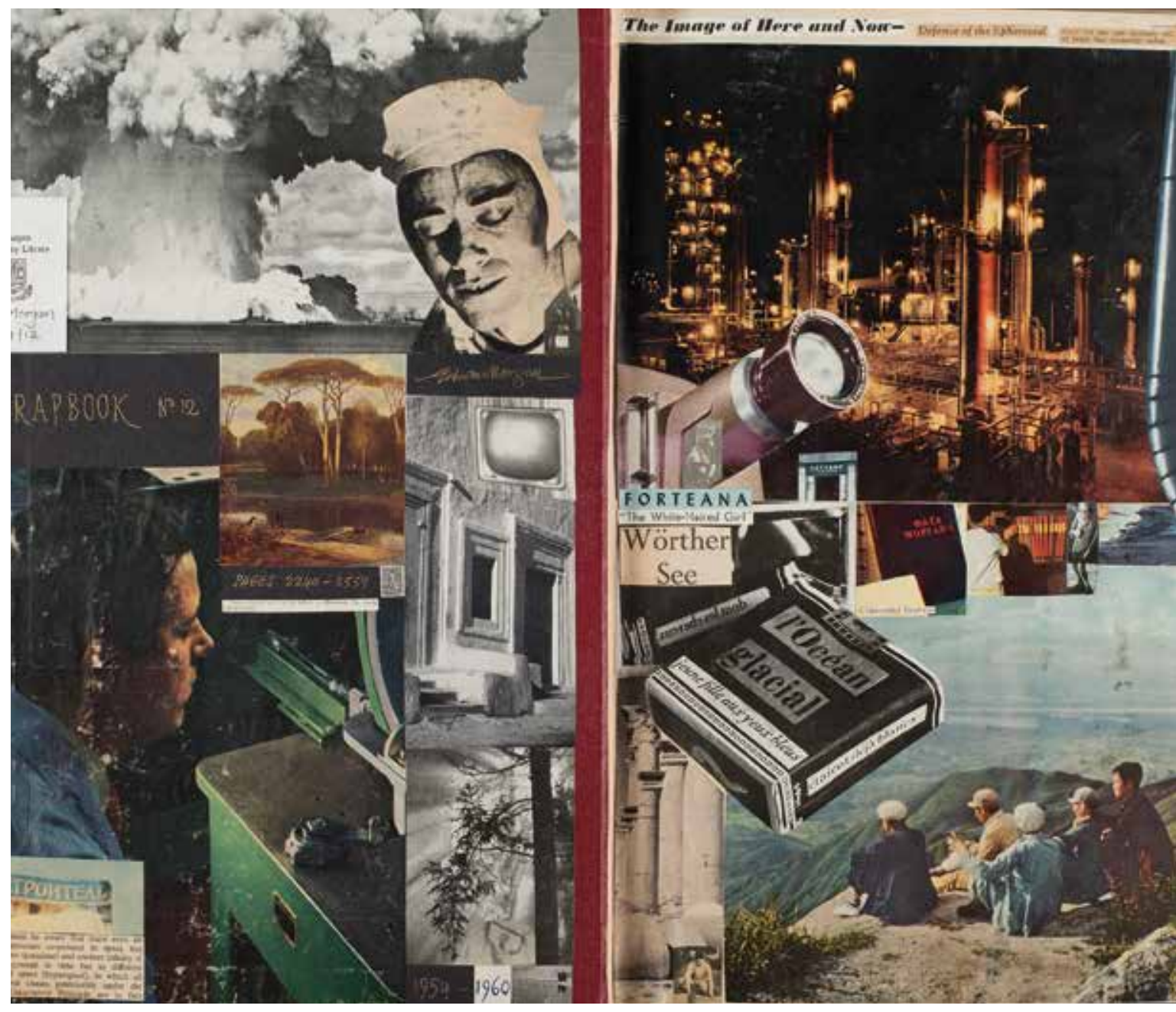

Exploring how copyright and other intellectual property norms impact the preservation, access and use of our shared cultural heritage, online and across borders, has been a core part of research programme since the centre was established. Led by Ronan Deazley (Queen's University, Belfast) the research team at the University of Glasgow has contributed to other CREATe initiatives, such as the Copyright Evidence Wiki. This body of work is much more than contracted 'deliverables': it is intellectually, and often, aesthetically compelling, and it is having real world impact.

Intangible Cultural Heritage and Intellectual Property: Megan Rae Blakely's research focuses on the effects of domestic government intervention relating to Celtic-derived intangible cultural heritage (ICH), tracing the relationship between intellectual property rights, commodification and cultural branding. Emphasising the unifying power of ICH as opposed to furthering the gap between cultures perceived to be 'knowledge producing' or 'culture producing,' her work highlights the challenges of reconciling the domestic regulation of diverse $\mathrm{ICH}$ in countries typically less geared toward ICH safeguarding. Harmonised global ICH recognition and protection, rather than geopolitically divided approaches and interests, would benefit both creative intellectua production as well as shared cultural practices.

Unique Collections, Orphan Works and Diligent Search: The prevalence, management and use of orphan works - works for which a myright owner cannot be found or is unknow - is a widely recognised challenge for the cultural heritage sector. In 2014, the European Orphan Works Directive and UK Orphan Works Licensing Scheme were implemented to address this issue. But do these schemes really offer solutions which are practical or desirable? Kerry Patterson's research makes use of the poet Edwin Morgan's unpublished scrapbooks as a platform for interrogating European and U copyright policy in this area. Compiled between 1931 and 1966, the scrapbooks contain tens of thousands of orphan works, typically newspaper and magazine clippings. Project outcomes include an annotated, online sample of scrapbook pages, along with critical commentary, analysis and guidance for other heritage institutions with unique collections of a similar nature.

Managing Copyright, Digitisation and Risk: Victoria Stobo's research explores the challenges and risks associated with making archive collections digitally accessible. Building upo the first UK sector-wide survey addressing these issues, as well as a series of in-depth case studies concerning attitudes
to and the implications of risk-informed digitisation initiatives, her research offers a timely review of how the law affects $2 \mathrm{D}$ digitisation activities within the cultural heritage sector. Victoria's work also seeks to improve the understanding and application of copyright law for archivists through postgraduate education initiatives and professional the necessary tools formanaging the risks associated with making copyright-protected archive material online.

Digital Surrogates and Surrogate IP Rights: Working closely with the National Library of Scotland, Andrea Wallace's research explores two related issues. First, it considers inw cultural hentage institutions have responded to the increasing need to engage in commercialisation activities duing a time of economic cutbacks. Second, it examines theimpat of technology on the public domain and the Dbstalles and opportunities generated by the digital real Drawing upon both of these research threads, her work provides important insights on the legal, cultural and ethica issues ina continue to chalenge cultural institutions, while communicating the complexity of these issues to the geric in an effort to increase public understanding.
pubs 
"It may be that people learn to avoid the legal barriers introduced by new legislation, at least with time"

\section{Why Unlawful Downloading}

The simple answer to the question of why some people engage in unlawful downloading is that, it is free. Undoubtedly there may be legal risks involved, but the evidence emerging is that the choice to engage in unlawfy downloading is not as straightforward as it seems. This subject has been investigated by a team of CREAT behavioural economists and psychologists Steven James Watson (Lancaster University). Daniel John Zizzo (Universiy of Newcastle) Piers Fleming and Melanie Parravano (University of East Anglia).

Existing evidence on why some people may download illegally is pretty patchy, and hence determining causality is problematic. The researchers ran an economic experiment trying to get at least a preliminary causal understanding of the role of three possible candidates of unlawfu downloading: financial and legal concerns, moral concerns and social norms. The consumers had three choices - not to buy, to buy or to obtain without paying. In this case, buying represented a gain to the consumer, because if you choose to buy something, it is assumed to be worth more to you than the monetary cost. If you choose to buy, then some of the money you pay goes to the seller. The choice to obtain without paying has a higher benefit to the consumer because you are getting something you would be prepared to pay money for for free. However in this study this choice carried a financial risk to caught.

The work was informed by the work of Nobel prize-winning economist Gary Becker. Becker said it could be rational to If this is true, the likelihood and severity of punishment should reduce crime as it tips the balance against the possible benefits. The results support Becker's work, because obtaining without paying was reduced as the penalty became more likely and severe. This suggests that in the real world people do not ignore risks and punishment, when these are high enough. However, it may be that people learn to avoid the legal barriers introduced by new legislation, at least with time.

In a large-scale survey it was found that people's judgments of the benefit (cost, flexibility and quality) but not judgements of risk predicted the amount of unlawful downloading they did in the following two months. Currently,

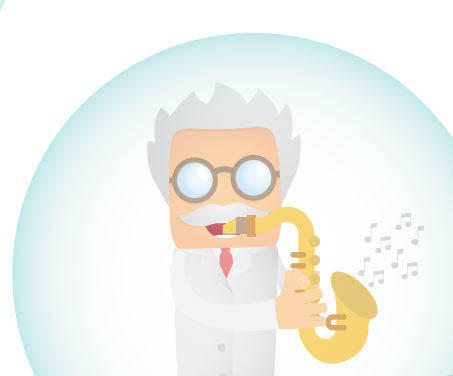

1

"Being aware that a seller is being damaged reduced unlawful downloading

the risks of file-sharing are theoretically relevant but have only a limited observable impact in practice. People usually don't weigh up the consequences, they mostly rely on gut instinct to judge the pros and cons of unlauft dow - the exceptions being if they believe they are anonymous on the internet and if they don't trust the legal framewrork regulators and industry.

The economic experiment revealed that moral concerns

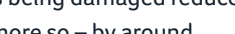
$5 \%$-if consumers were aware that sellers made an effort. Social norms, also mattered, we found that when unlawful downloading was rated as socially inappropriate, it was hugely reduced.

The study demonstrates that to reduce unlawful downloading, industry should increase the benefits of lawful options (e.g. flexibility, convenience and value) and raise awareness of the seller and their effort required to produce goods. They should also consider socially-focussed marketing messages which could raise awareness of social norms not to file share unlawfully.

$\rightarrow$ bit.ly/1 xV4gAz

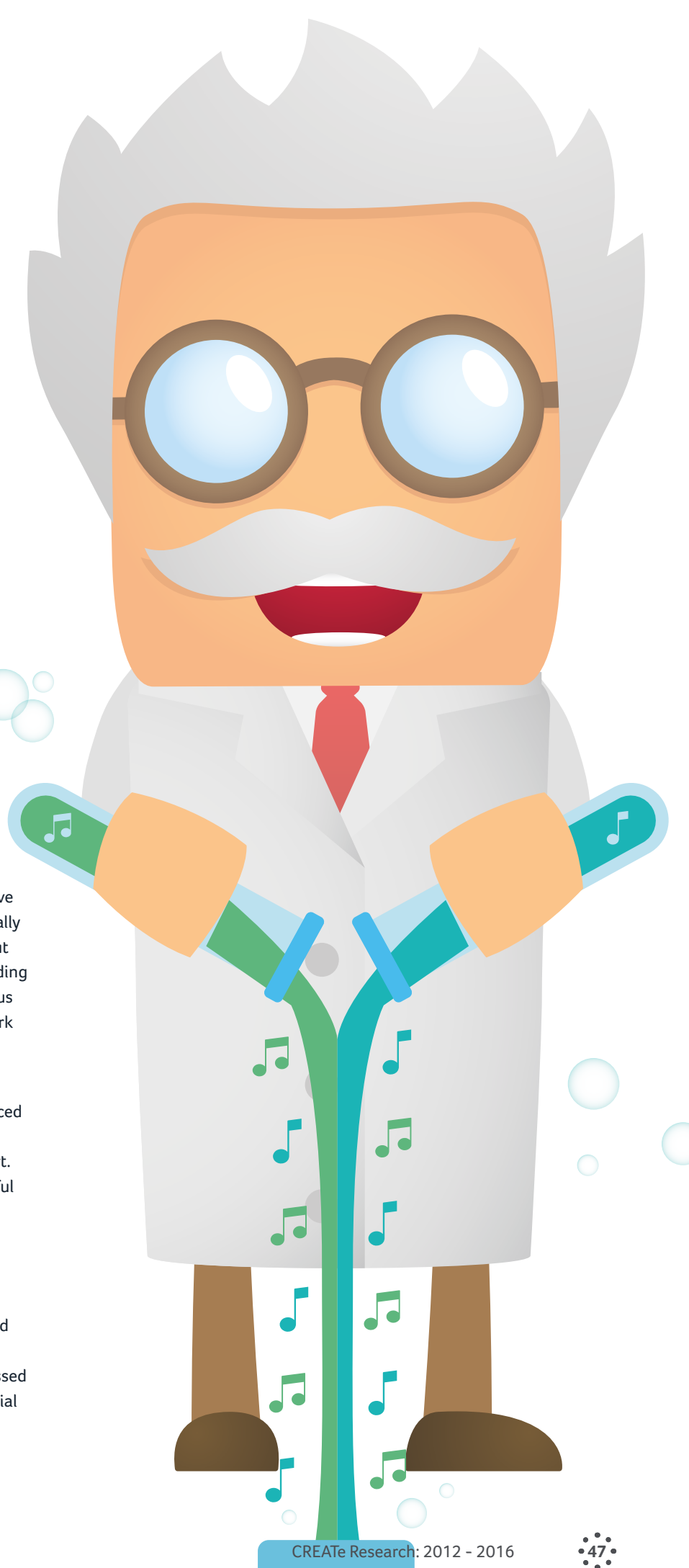




\section{Emergent Infras
for IP Trading}

Intermed Marco Campagno, CREATers (all a Ch Havers (all at he Unives afy interime, bit

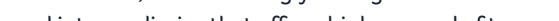
and a lowering of costs.

The research began with a study of the construction of the Copyright Hub, a UK-based initiative for streamlining permission licensing (i.e. getting permissions to legally reus copyright work). Following the stakeholders of the Copyright Hub from early stages provided a detailed account of how an IP infrastructure is nurtured socially and technically, as well as invaluable lessons into the trajectory of similar projects. This longitudinal study is being supplemented with a series of shorter studies across private sector initiatives, which focus upon the 'trial and error' processes of developing and sustaining these services; the often invisible organisational and technical work that makes disintermediation possible involved.
This is a crucial period in which many countries and territories are beginning to define, or are looking to establish, long-term strategic frameworks for an emerging digital economy which generates increasing pressure for IP reform and regulation around the world. In the US, no major legislation on copyright has been introduced since 1976 and hence, a number of exceptions have bee imposed upon copyright with courts intervening in many cases, and where the court approaches and outcomes have neither been consistent nor desirable. In Europe, a number of calls have been made for the establishment of a single digital market. Eighty billion euros has been made available through Horizon 2020 - the biggest-ever EU Research and Innovation programme spanning the period of seven years create a genuine single market for knowledge, research and innovation."

Similar national efforts can be observed in Singapore, Korea, China and other countries on the both sides of the Pacific Ocean In this context this research acts as a medium to convey critical thinking and scientific findings to policy makers, copyright practitioners, legal scholars as well as the wider public

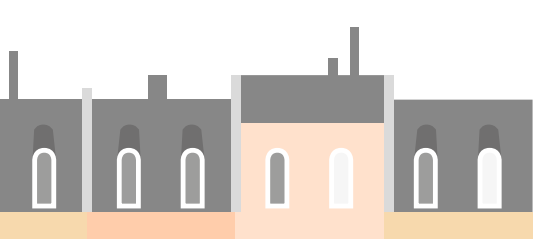

1
$\square$

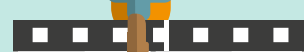

三丨!

वप्वप्त्व

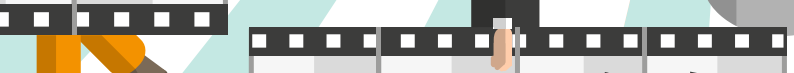

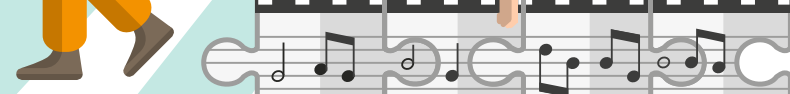
שים 10

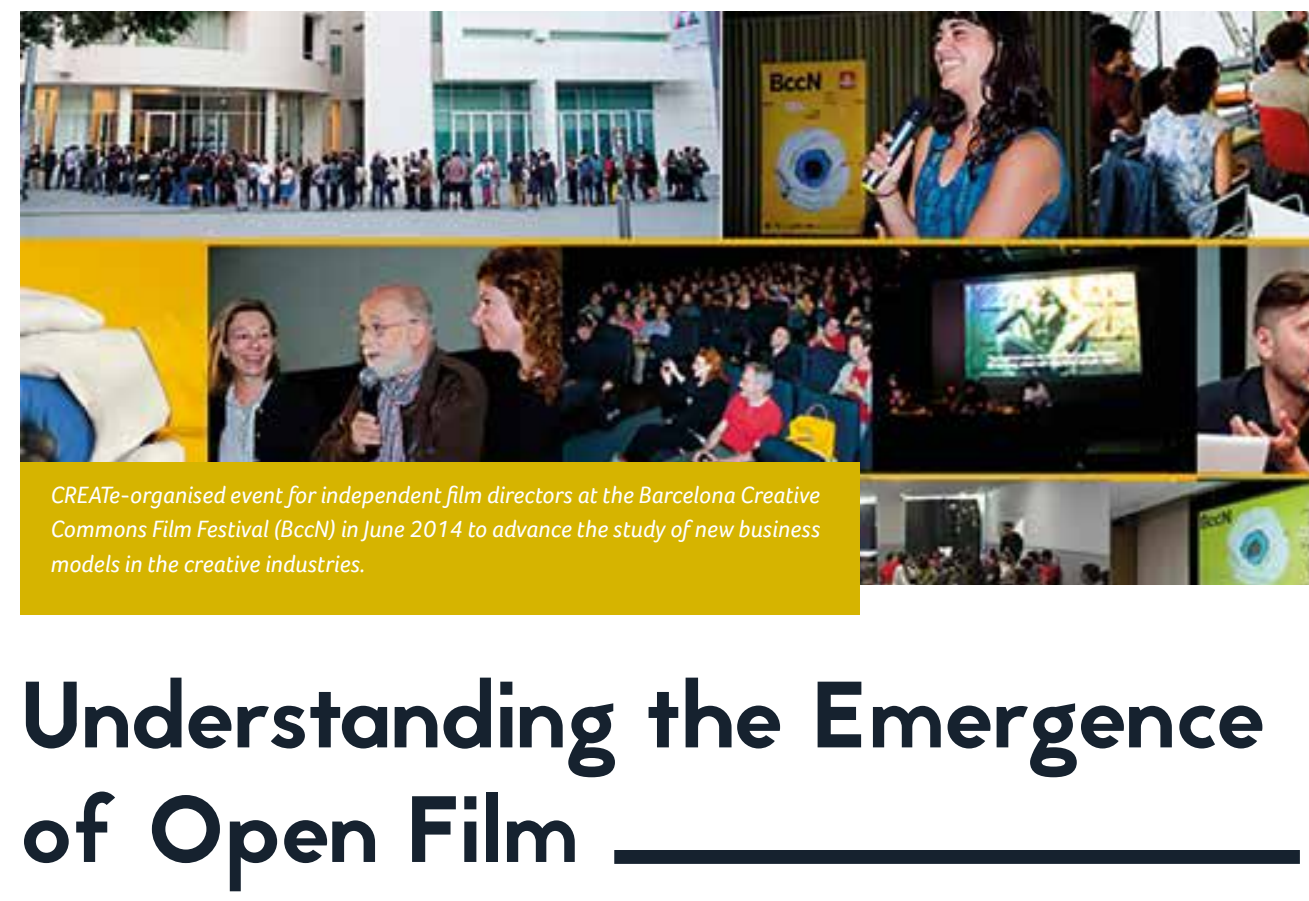

Openness is easy to promote in theory but more complicated to adhere to in practice. How do advocates and subscribers act upon their commitment to openness? Is their commitment sustainable? CREATe researchers Robin Williams and Gian Marco Campagnolo (both at the University of Edinburgh) explored the shaping of openness in the digital age through a study of open content film-makers (OCFs).

OCFs are creators of audio-visual content using nonproprietary means of production, distribution, exhibition or licensing. The project assessed OCF through multiple timeframes: the unfolding of an individual career (at what stage of a film-maker career is commitment to openness sustainable?); the lifecycle of a project (when openness comes into play in a film project): and as part of the development of the film-making industry as a whole (including tensions between mainstream industry and open content film making).

On the surface, the most common form of career move seen use of OCF as a 'calling card' to legitimate participation of new entrants in mainstream film industry. However more sophisticated types of move have emerged, including path that see people from mainstream industry move to OCF at later stages in their career. Established stakeholders (e.g. producers wanting to try film-making) rely upon this economy to trade their prestige with in a more independent. experimental domain. Through single-handedly managing direction as well as production and distribution - as it is customary in OCF-OC film-makers develop expertise relevant in other domains, such as higher education and research institutions, where there is increasing pressure to

Athough dual career/occupation tracks are commonplace in the film industry regardless of use of OCF, shared commitment to open formats in film and academic professions represent an interesting subset of this roup, which demonstrates how open content does not ways represent an entry point to regular distribution furthermore, when looking at how OC film-makers take licensing decisions, reports are divided. Those who provide ideological justifications have often not tried regular commercial formats. A more acute sense of strategy is apparent in responses by film-makers whose business seems o switch seamlessly across different licensing formats. transpires that licensing decisions derive from a rather symmetrical perception of the horizon of opportunities . of self-expression, OCF informants do not always manage to fully articulate the range of opportunities that a mixed model can offer. Given the opportunistic nature of the OCF conomic model, this asymmetry is particularly damaging. imitation in the ability to articulate the full spectrum of opportunities, including the developing field of trans-media advertising, is particularly apparent in early entrants, who conpla about training received at University. Of a different tone are accounts from film-makers whose productions can che Creative Commons license as a brand that helps increase further funding. They also describe 'crowdfunding' as a too to garner credibility and independence.

$\rightarrow$ bit.ly/1FMitFb use open content. 


\section{Supporting Creative \\ Practice through}

\section{Technology}

Research by the Horizon Digital Economy team at the University of Nottingham, consisting of Derek McAuley, Michael Brown, Dominic Price, Liz Dowthwaite and Dialechti-Christina Emmanouil, has focused on the development of new technologies to help support creative practice and explore novel digital creativity case studies, some of which are presented here.

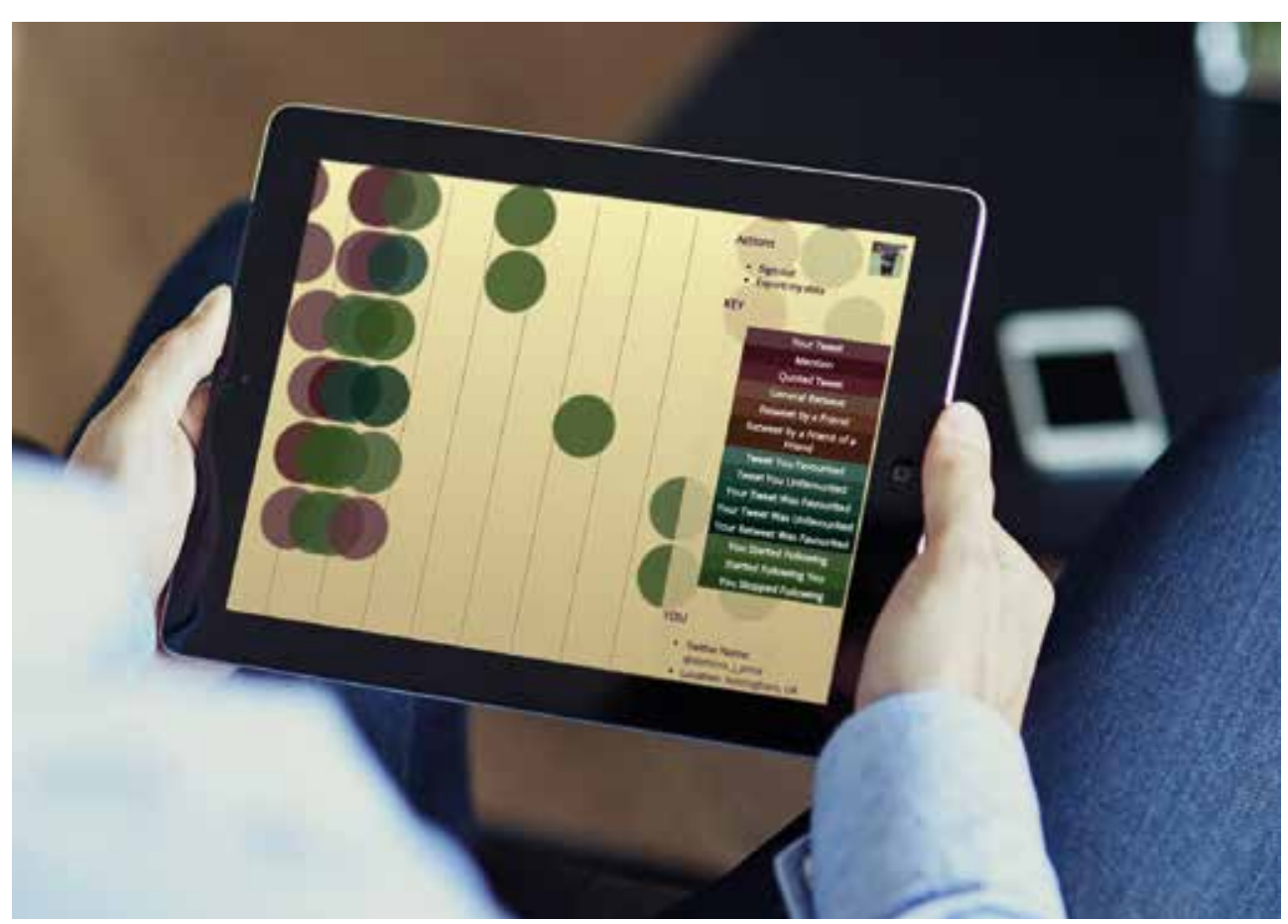

\section{My Social mApp}

My Social mApp is a platform for visualising Twitter interactions and helping creative practitioners to understan how their Twitter engagement is received by the public. Despite the seeming simplicity of Twitter - sending short messages of 140 characters- there are a large number of ways to engage with the platform: retweets, retweets of retweets, replies and mentions are the most common.

The default Twitter interface of a vertical timeline doesn't bring out the relationships between these interactions but My Social mApp displays interactions as a linked network
For example, you might see a time when you gained a large number of new followers and by back-tracking the network you can discover that this was because someone with a large number of followers re-tweeted one of your tweets. Realising this may lead to you modifying your tweeting behavior to direct relationship with the 'middle-man'.

The platform is intended to be of use to small creative businesses who use Twitter as a tool for promotion but don't have the resources to spend a great deal of time analyzing their Twitter interactions.

$\rightarrow$ create-www.cloudapp.net take advantage of that link, for instance by cultivating a

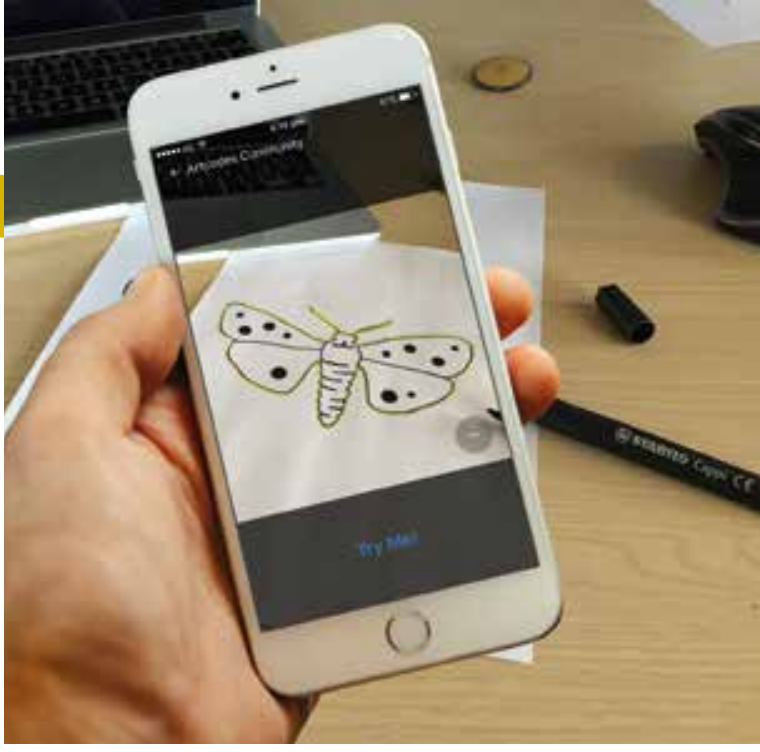

\section{Artcodes}

Artcodes is a new technology that allows users to interact with a range of decorative imagery and patterns. It is triggered using a smartphone with our app. Users point the app at an image and the app triggers whatever interaction has been allocated to the code embedded in the image.

This new interaction technology relies upon drawing and creativity to drive it; a paradigm shift in visual recognition technology. The Artcode has all of the interactive properties of a QR code but with an aesthetic quality. Images are programmed by observing some simple drawing rules, which enable the designer to create interactive imagery. The Artcode points to a future, where interactive devices are triggered by the artwork, patterns, motifs and tags that adorn our built environment, our public spaces, our homes, our clothes and our objects. Further details at

\section{$\Rightarrow$ artcodes.co.uk}

\section{Authors and Identity in Social Media}

Social networking sites are among the digital channels that assist creators in interacting with their audience. This project investigates how book authors engage in self-presentation using social networking sites. It explores authors' attempts to keep the incompatible contexts of their lives apart and reveals the identity-threatening situations they experience in social networking sites. By interpreting what these behaviours and experiences mean in practice and their consequences, new design recommendations emerge. Thes recommendations include the introduction of new features in social networking sites as well as an updated structural approach of the way that these platforms manage authors'
Studies have revealed that despite the lack of features to guard authors' self-presentation, the creativity that characterises this social group allowed them to use these platforms in ways that partially fulfill their needs, yet remain challenging. Authors use multiple strategies to protect other aspects of their lives online, such as using selective selfpresentation, where they create hybrids of real and fiction epresentations of themselves to establish the personas they crafted to publish their books. One of the findings of this study is that providing authors with the recommended features to facilitate their self-presentation practices could be of benefit to the data collection practices of social networking sites; despite the belief that these platforms' commercial purposes usually do not align with users' requirements.

\section{Copyright and online artists}

Online copyright law is a major issue for many in the creative industries. Independent artists often rely on sharing their work across social media and content-sharing sites, leaving them open to having their work stolen or misused. This research examined attitudes towards copyright and attribution amongst webcomic artists, in relation to curre artists are generally aware of the cover provided by copyright they feel that it is not necessaily relevant or effective within their creative working space. There is very little support and few resources availat to he work Whilst artists do get angry about actul tef and removal attribution they accept that they have to putup with certin violdions theywish tocolinu topuls comics for free on the Internet.

\section{Crowdfunding and online artists}

Crowdfunding - the collection of small amounts of money from a large number of people for the purposes of a specific project, has become a major factor in the business models of webcomic artists. This research looks at how such artists create and maintain communities through social media, and then capitalse on this through crowdfunding. The first study found that a large amount of time and effort across huge number of websites is involved, leading to extremely dedicated networks of readers. Although the webcomics content is provided for free, they are then able to sell merchandise, particularly books, clothes, and artwork. Many readers are also willing to support creators by donating money through crowdfunding.

Further research has shown that enabling creators to continue to provide free content, showing gratitude, and receiving rewards are amongst the most common reasons given. Further studies have been carried out to determine patterns of backing behaviour on crowdfunding sites, and the roles of reciprocity and altruism in the different motivations of readers to give, across two different models of crowdfunding, typified by Kickstarter (rewards, project based) and Patreon (subscription, creator based). 
Authors and Identity in Social Media

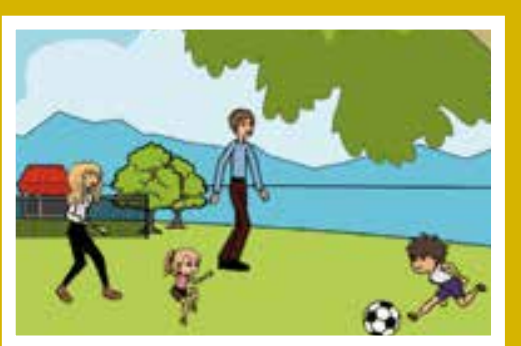
publishing house. She is married and has two small children. Her primary source of income is her job as an accountant. She tock

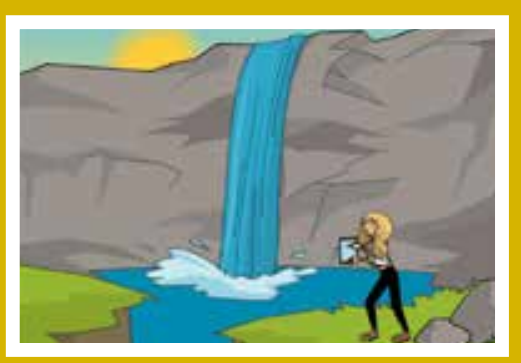

She took a picture of the landscape to share it on her auth

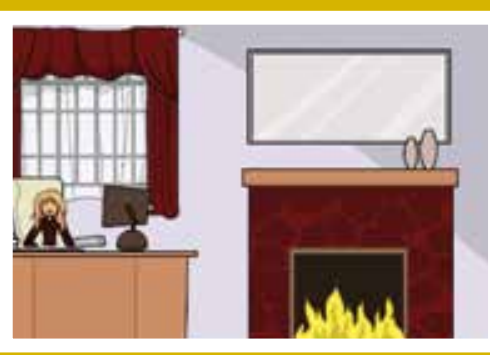

When they returned home Sophie logged into her Facebook correct page. She uses a pen name to secretly self publish "erotica and she accidentelly shared the picture and story or her

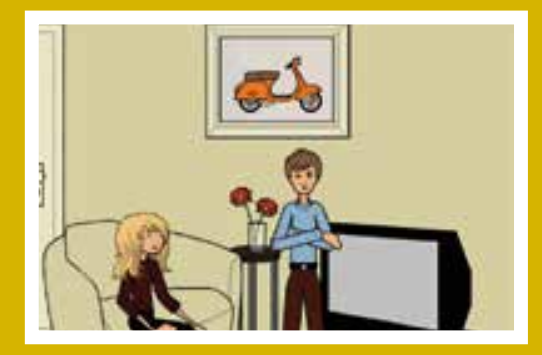

(a) are concerned about the management of her online identities.

$\because 52$

\section{Notes}

\section{Artificial Intelligence and Copyright}

In 2014, the claims of tech company Qentis caused considerable excitement in the technology world Oentis coima to technology world. Qentis claimed to have built an algorithm that created all the
potential pieces of text in the English language of up to 400 words, meaning that potential pieces of text in the English language of up to 400 words, meaning that they held the copyright in everything that can be sald in English, and were willing to sell the rights. Never again would anyone be allowed to write without Qentis receiving a royalty payment. Copyright and technology experts pointed out the serious flaws in their business model, as neither law nor technology allowed the creation of the ullimate copynght troll for now. Indeed, Qentis was revealed to the Austrian performance and technology artist Michael Marcovici, who regularly criticizes the commodification and commercial exploitation of creative works.

There is a serious message in Qentis'work: our intellectual property law was conceived at a time when humanity and creativity were synonymous. In particular, the copyright philosophy of continental Europe can be seen as the particicat the of the hum

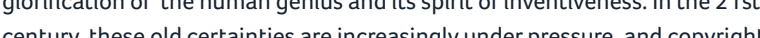

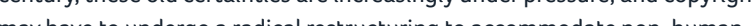
forms of creativity.

Burkhard Schafer (University of Edinburgh) and team address the issues raised by a world where humans and machines co-produce and co-consume artistic works and legal documents. How can we adjust our copyright regime for computer generated art to prevent a future Oentis, yet encourage investment in creative Als? Can software developers and robot engineers ensure that their creations observe the relevant legal parameters, and respect other people's copyright? Is there scope for something like Asimov's law of robotics, extended to copyright and the creative machine?

Al co-creation is not just an issue for artists; copyright lawyers increasingly d research explored how Al could potentially transform the landscape for copyright lawyers and the practice of litigation. How can we harness Als to reduce the costs of litigation, by more effective handling of e-discovery? How can licensing and license management be automated? Are there dark applications of Al in copyright law - such as speculative invoicing, algorithm-driven new business models for some firms in the grey area of professiona

ethics?

Building on the lessons made with Digital Rights Management technology, the team investigated whether we can teach robots copyrights from copywrongs. Research indicates that real benefits can be found when combining existing DRM with an Al that is more explicit and legal, removing it from its tradition antagonistic setting to applications where all parties want and need automatic legal compliance. Petri networks emerged as tools that can help roboticists to build machines that comply with both the copyright and privacy interests of third parties. They could be a way to help digita publishing houses or algorithmic news services make their products accessible to citizens with disabilities, or assist lawyers in more efficie handling of copyright issues.

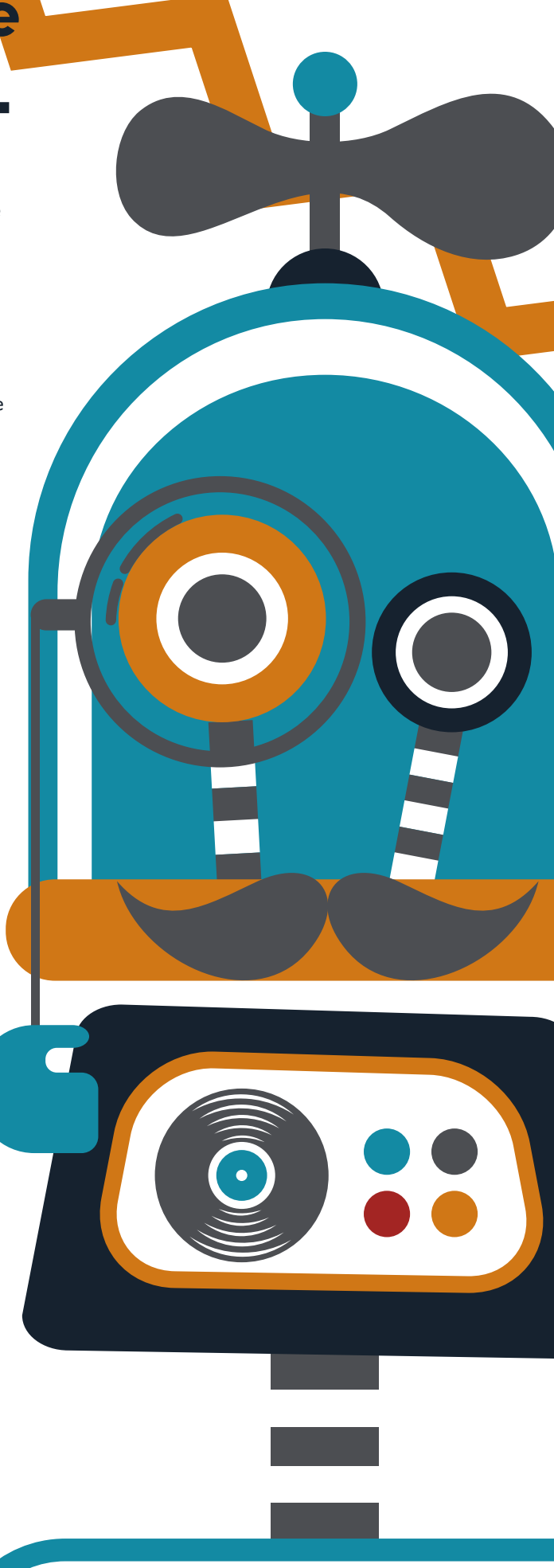


Increasing Access to Cultural Heritage using the Crowd

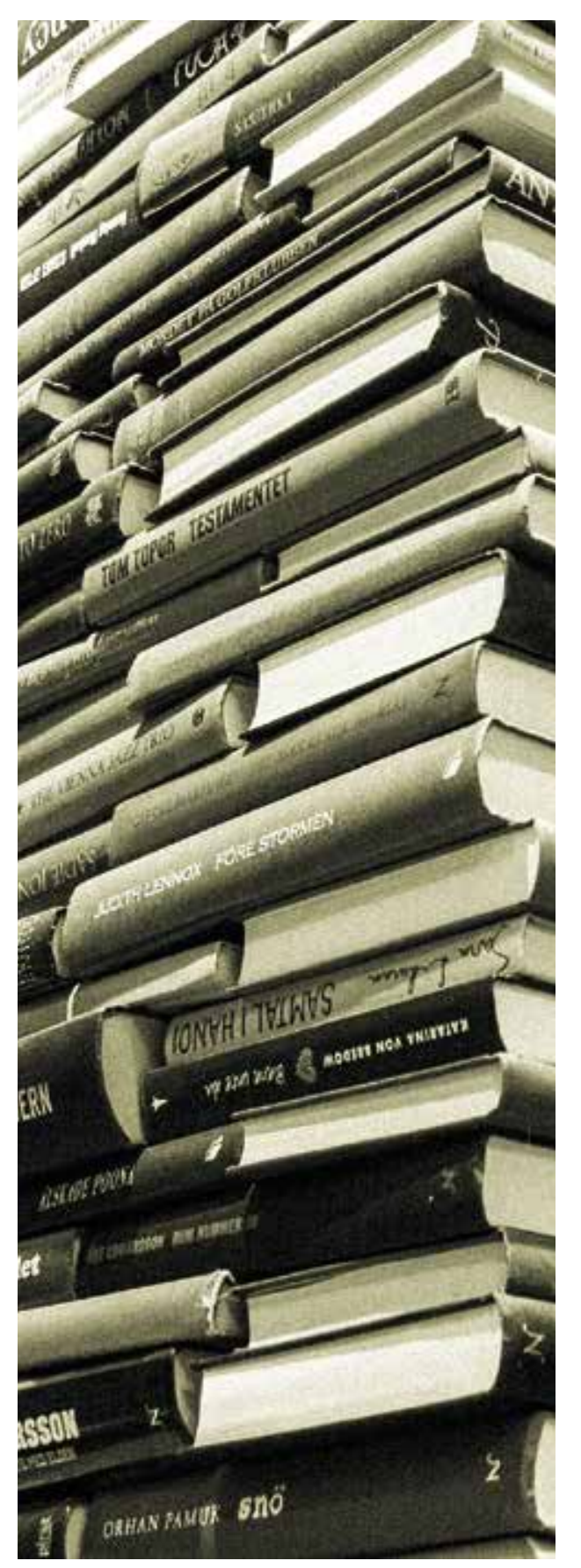

The Internet promises access to culture from everywhere in the world. Much of this cultural material is held in the collections of museums and ibraries, institutions who are heritage, for individual study, curiosity or research. However this process must overcome a powerful hurdle: copyright and related rights. Many of these works have unknown or untraceable creators, hence are 'orphan works,' but still need to undergo a rights clearance process in order to be search of potential rightholders is carried out in good faith by consulting appropriate sources. However, the conditions stated in law to comply with this requirement pose a significant burden to would-be users of orphan works.

EnDOW ("Enhancing access to 20th Century cultural heritage through Distributed Orphan Works clearance") is a collaborative project funded under Heritage Plus and led by CREATe associate Maurizio Borghi (Bournemouth University). The project is a partnership of four leading European research centres: CIPPM, (Bournemouth University); CREATe (University of Glasgow); IViR (University (Bocconi University, Milan).

The analysis conducted so far by researchers from all centres, reveals that carrying out a diligent search may require consultation of a vast quantity of diverse sources of information. A total of over 350 different information sources have been Netherlands. A diligent search on published books may require consulting up to 32 different databases in the Netherlands up to 80 in the UK, and up to 131 in Italy. Moreover a sizeable share of these sources are not easily accessible or ev notare at all. Of all the sources to be consulted to conduct a diligent search, $70 \%$ are freely accessible online in the UK, $56 \%$ in Italy and $54 \%$ in the Netherlands.

While legislative or soft-law action is required to address the problem of accessibility of sources, enormous costs are faced by cultural institutions to consult the sources that are accessible. Under such conditions, the undertaking of clearing rights on large collections of works is not viable for cultural heritage institutions. This where EnDOW steps in, by building an online platform to allow users from all over to the world to carry out diligent searches and help cultura institutions (at virtually no cost) to clear the rights for their collections. EnDOW is a visionary project based on the belief cultural capital should benefit everyone, and therefore

$\rightarrow$ diligentsearch.eu
Finding Value in the Public Domain for UK Creative

\section{Businesses}

The public domain consists of a vast reservoir of creative works and ideas that are available for uptake and

consumption by all. It includes works for which the copyright term has expired as well as stories and artworks pre-dating modern copyright law. It also includes materials freely gifted to the public domain by their creators via free and open licenses. But what role does the public domain play in fostering newinnovation and creativity? CREATe researcher Kris Erickson (University of Glasgow) investigated this as part of his research into the value of the public domain for consumers and innovators.

To address the question of how public domain inputs might be a source of value for commercial users, Kris interviewed UK-based creative firms such as Inkle, developers of a mobile app based on the work of Jules Verne, and Onilo, a technology company that offers animated children's story books to

schools some of which are adapted from public domain foll tales. The research was based on the theory that creative firms face a "make or buy" decision when deciding whether to engage in work-for-hire or develop their own original content. Designing original content may be more satisfying to creative firms, but it can be risky; and it may take years of trial and error before generating a hit product. The public domain offers firms another option; that of adapting public donain ofers firms anotheroption, hhat of adapting audience, while also gaining the ability to commercially exploit the resultant IP in a variety of ways unencumbered by third-party rights holders.

Creative firms exploit public domain inputs for many of the same reasons that innovators engage in private-collective innovation. They bundle their public domain products with other commlementary goods in order to appropi associated with their own innovation practice. There are lower costs associated with using public domain materials as an incentive. Incorporating free and open-source inputs early in a new product helps some developers to "fulfil the credible promise" of a prototype, stimulating further contributions and investment. Some creative firms actively engage with communities of users, for example, fans of Sherlock Holmes or H. P. Lovecraft to develop new adaptations of those public domain works. The openness of such works to collective remixing lead to more innovative and radically collaborative products.

Mobile app created by Inkle, inspired by the work of Jules Verne

pot veyone had posive exp public domain materials. Some firms reported significant costs in locting an public domain materials. Some of these search costs relate to technical issues such as metadata and availability of digital reproductions. Other costs involved the time and effort needed to ascertain the legal status of a work. Beyon specific initiatives such as Wikimedia Commons and the British Library's Mechanical Curator project, there are no central national databases of works avaliable in the public domain. This means that only those firms with pre-existing knowledge of IP and rights clearance are better placed to locate and exploit such materials.

$\rightarrow$ bit.ly/1txkTUo

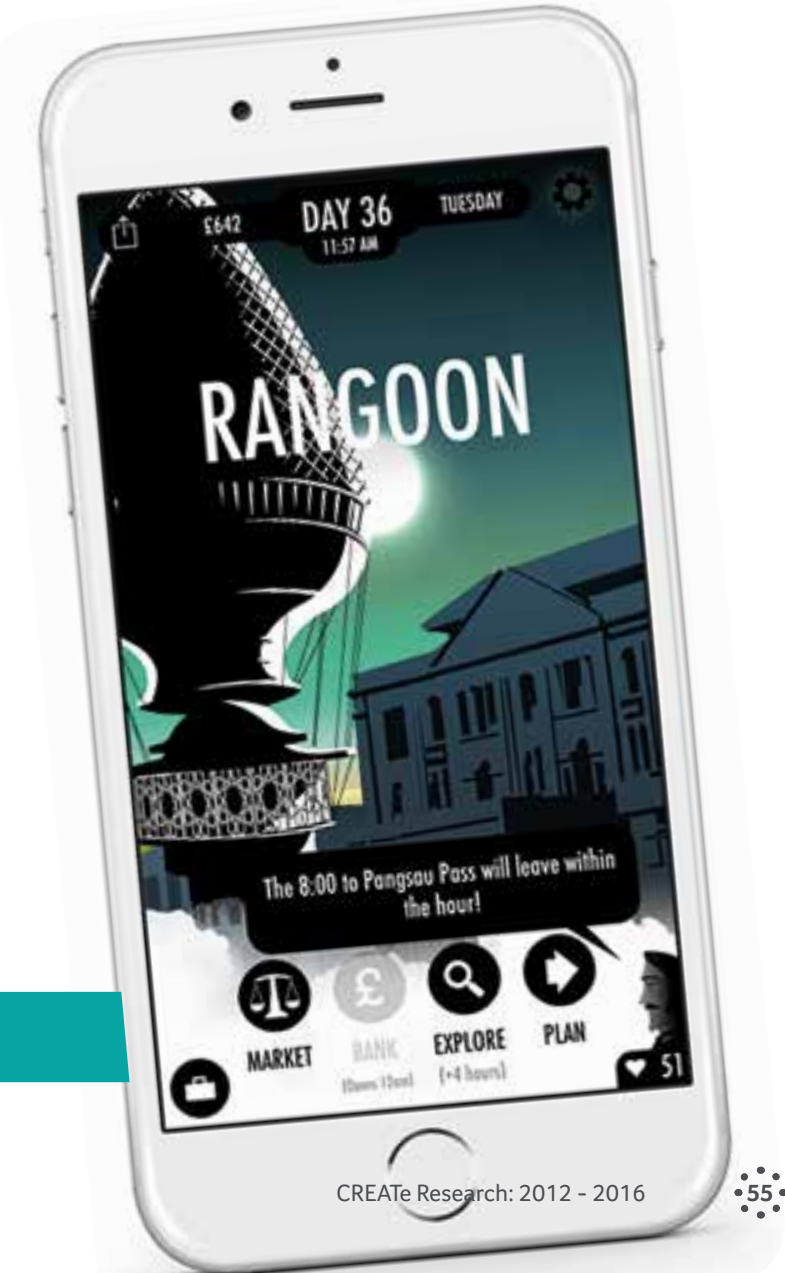


Is copyright the right doctrine?

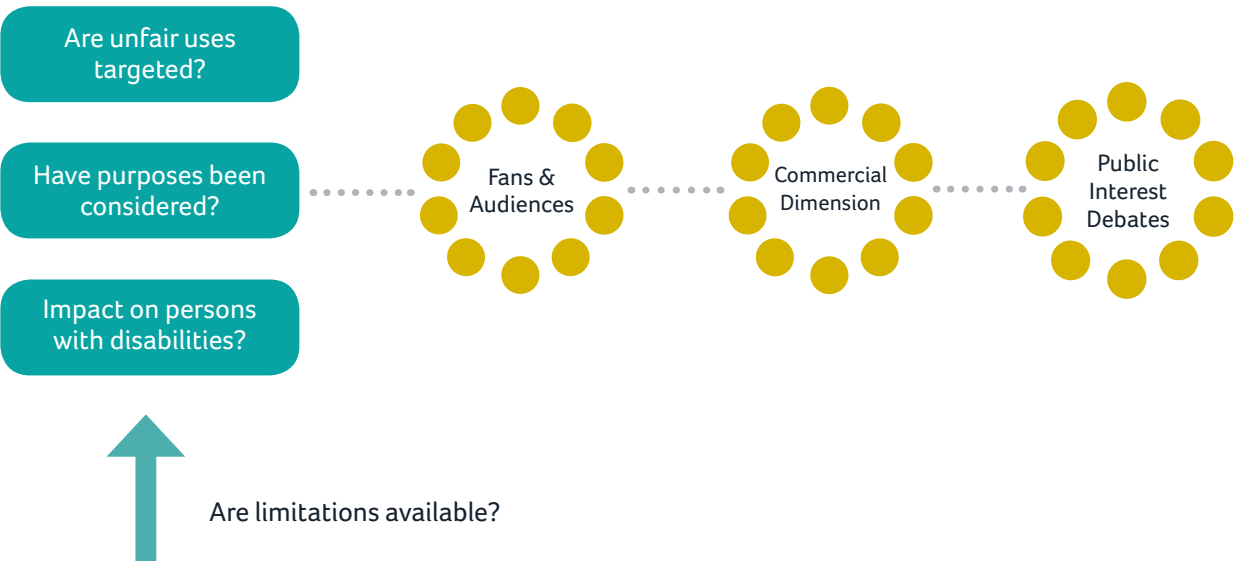

\section{Helping Copyright and Human Rights}

What does freedom of expression mean in the context of copyright, and how does this inform the understanding of other human rights in the context of copyright?

These questions have been explored in a project led by Emily Laidlaw (University of Calgary) with Daithí Mac Síthigh (Newcastle University). The goal is to identify what role freedom of expression should have in facilitating new business models, and whether there is a need for a public interest exception rooted in human rights principles. The team have produced a set of guidelines for copyright owners for respecting the right to freedom of

These guidelines seek to distil, from the literature review and from cases and statutes, principles of good practice for copyright owners to identify when a free expression right is implicated in the design, use, or enforcement of copyright. It is hoped that these guidelines can be used to clarify the contours of a copyright owner's rights, and to internalise and harmonise the impact of decisions regarding the use of works on the exercise of speech rights. This is a particuse appropriate time to adopt such guidelines. The United Nations Guiding Principles on Business and Human Rights entrenched a fiam

In Europe, the Court of Justice of the European Union has confirmed the applicability of freedom of expression, which is protected in the Charter of Fundamental Rights, in copyright cases. However, it is unclear how narrowly drawn such a right is in this context, and how informed it should be of the wider human rights case law under, for example, the European Convention on Human Rights. These guidelines seek to identify ways that industry can meet their obligations under the Charter and the duty to respect in the Guiding Principles. As with the Guiding Principles, there is no magic solution to the balance between copyright and free speech. However, it is hoped that good practice guidelines can flesh-out points of contact, as a basis for further reflection. This flowchart is a companion to the more detailed industry guidelines. These guidelines are aimed broadly at creative industries and should be useful for copyright owners, intermediaries, policy makers and consumers. They revolve around three themes: (1) assessing restrictions of copyright in light of the right to freedom of expression; (2) enforcement; (3) the practice of

$\rightarrow$ create.ac.uk/publication

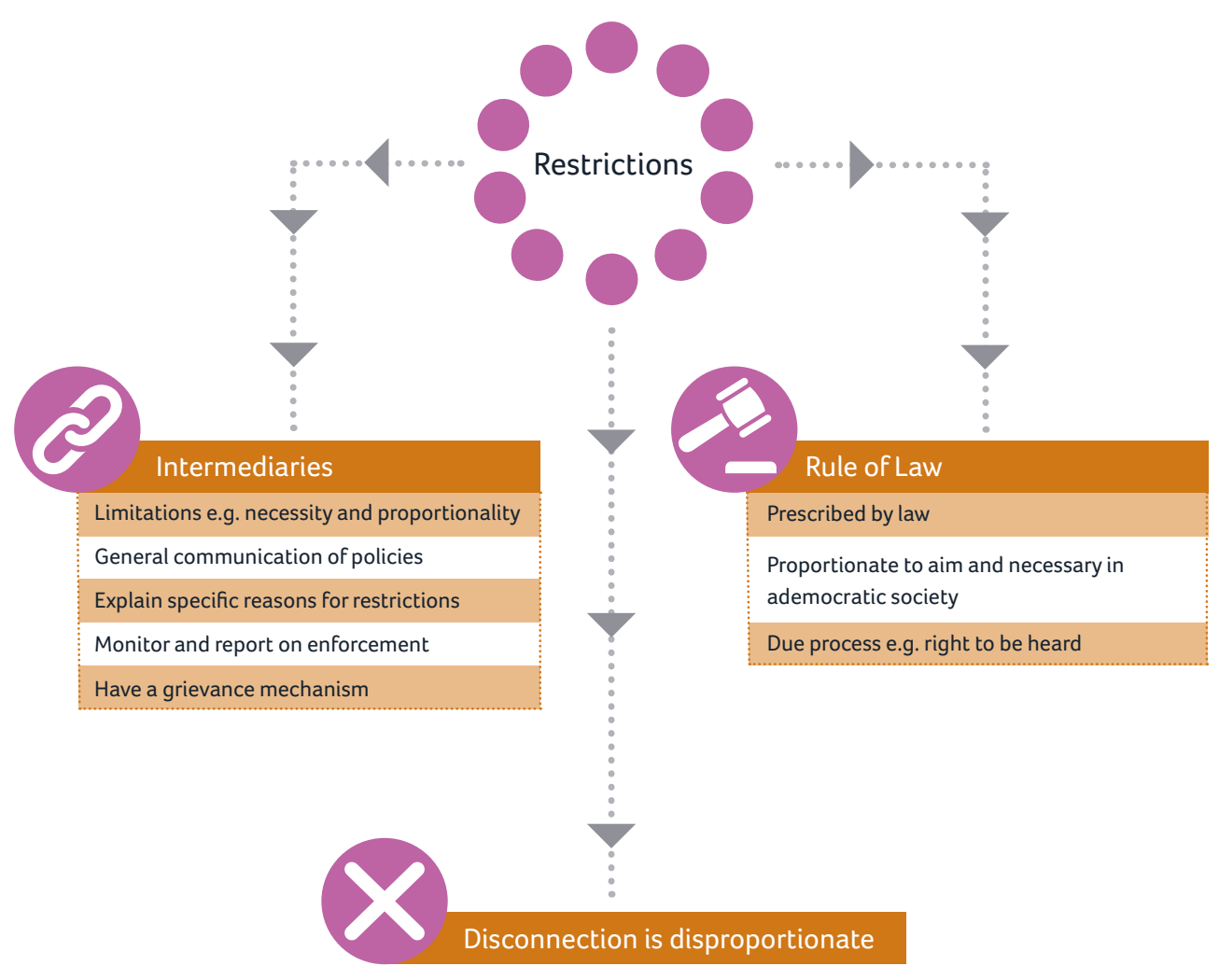

Know and show respect for human rights

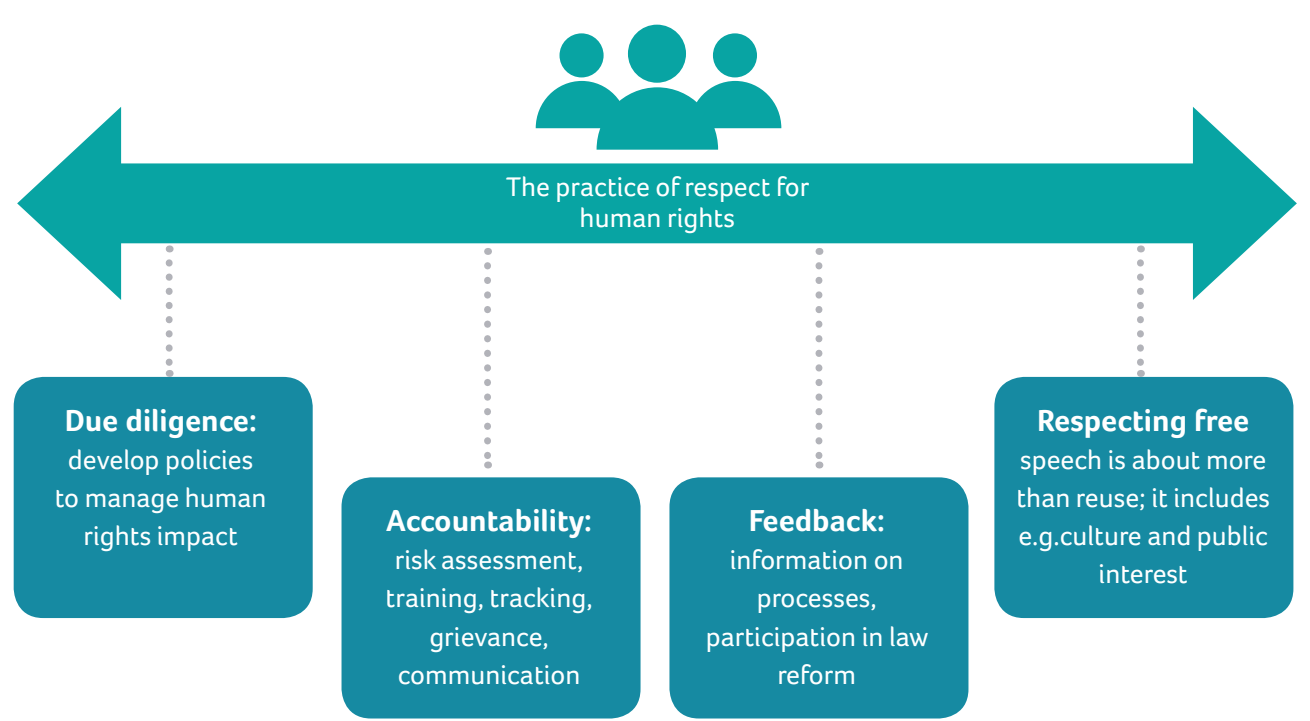




\section{Death and Digital Assets:}

\section{What Happens to My Facebook}

\section{Account when I Die?}

The above question is one commonly asked in an era when some two billion of us have active Facebook accounts and our everyday lives are inextricably intermingled with our digital ones. Our virtual lives acquire belongings just as our "real" lives do, and we want to know what happens to them when they die. Does ownership stay with the creator of a social media profile, or pass to the platform where the work is created or hosted? Is the matter regulated by copyright, by contract or by other laws such as data protection or breach of confidence? What is the authority of the terms anc conditions imposed by the platform as the price of access? Who should have preferred rights of ownership, the user or the platform, given the romantic notion of authorship as against the work and expense the platform puts into providing a place where users can play or converse? Do the business models of social networks and virtual worlds have be based on owning everything in a user account? Can data even be owned at all?

This multifaceted enquiry comes to a useful crux when we consider what happens to our data after death: who owns it before death, who inherits it (if anyone), and who contro access to our pictures, posts, videos, avatars, and other digital footprints after we die. If an asset is considered the property of a person, then in almost all countries it forms part of that person's estate on death and transmits to their heirs, either by will or by rules of intestate succession. The same is true for intellectual property (primarily copyright for the purpose of this research). If an asset cannot and should not be considered property, or protected by copyright, then arguably it simply cannot transmit on death.

This issue thus became the focus of the Death and Digital Assets project, led by CREATe's Deputy Director Lilian Edwards (Universty or Strathdyde) Whth PhD researcher ina Harbinja.

The first question the project team examined was the legal nature of digital assets, which we defined as including any online asset of personal or economic value which was potentially capable of post-mortem transmission. After life, we selected three of the most typical categories of digita

assets to examine in depth: property in virtual worlds; emails; and profiles and other assets in social networks. The project first examined what constitutes property, and how those fied, in a number of significant legal systems UK, US, France and Germany.

The team found first, that, somewhat contrary to popular belief, email contents, virtual world assets and social network profiles often do not fit well into the category of "property". This was prinarly because the law does not propertise or commodify (with some outstanding exceptions, such as EU database right and US "fresh news") mere facts and information, which need to be available in the public domain to further expression, invention and creativity. Some systems also struggled with recognising intangibles as property except in limited classes of intellectual property. However creative content may be protected by copyright, and thus be transmissible on death. This category will cover much digital content eg many emails, blogs, photos online etc, with the normal rules applying as to thresholds of originality (low), types of creative works protected, terms of protection, etc.

This however raises a further question: should digital assets that do not fall within copyright or IP still be capable of being regarded as property in the special circumstances of digital assets and death? Is this necessary to meet significant user interests and expectations? For example, in case law we examined, heirs often expected access to the deceased's th, or to be able to either take control network profiles after death. Media stories spoke of the pain relatives suffered at seeing invitations to Friend, or celebrate the birthday of, users they knew to have died. If these are compelling needs, our project concludes that legislative action may be required of some kind, as the ordinary law of succession and executry will not operate successfully in this environment and the online platform contracts (see below) also tend not to respect user rights. Such laws are already emerging in various U.S. States and other countries, primarily in relation to administration of estates and powers to access emall accounts after death, but on a patchwork and haphazard basis, when we would prefer to see a coordinated hitemational soldtion, especially given the global and transnational reach of online platforms.
Secondly, the project team found, when we turned to rights other than property, the dead also do not generally benefit from rights of data protection, privacy as a human right, breach of confidence or against libel - these all typically terminate on death. This leaves the reputations of the dead and their privacy, which may be uniquely exposed in social media and emails, in jeopardy. In response, the project tean posited a novel right of post-mortem privacy: the protection of the privacy interests of the deceased. We argue that this concept would foster and protect user autonomy and contro over their persona and deserves legal and policymaker consideration.

Thirdly, the project team examined the allocation of ownership of assets through service providers' contracts (e.g. the terms of service, acceptable use policies and priva policies of Google, Facebook, Twitter etc) and found that the approaches of service providers regarding ownership and transmission of dightal asset were not at all unfrorm. Platforms most typically assumed control and ownership over all user assets created online even when they were of considerable value (e.g. in-game assets). Some exception existed, eg in the game Second Life which awarded ownership of assets created online to its users, and there was a trend towards less one-sided contracts. However even sites which disclaimed any ownership of IP - notably Google and its family of apps - still typically left tit at platform discretion how access to accounts and their contents could be exercised on death. Facebook were a market leader in providing clear forms by which heirs, friends and family could seek to close down or alternately "memorialise" sites of deceased users after death, but these solutions remained at the discretion of the site in frustratingly vague ways, which were also not aligned with local succession or administration laws. We argued that user autonomy and control over online assets both in life and post-mortem was thus often not respected nor was transmission to, or access by, legal heirs predictable. Against this negative pattern of denial of user autonomy and unpredictable platform discretion, however, the team identified a newer trend, led by Google, and more recently, Facebook, towards allowing users to exercise control over their online assets by indicating preferences in advance as to how they wanted their accounts, and the content they contrined, to be dealt with on death. A kind of "post-mortef literary exe be

t)

the handling of such after death. These technological solutions, such as Google Inactive Account Manager and Facebook Legacy Account, in some way mimic the privacy preference tools that users can already use to shape their sites during life. These tools are not however a magic solution - for example, conflicts with traditional wills may arise and most users are probably still unaware of these options - and the project evaluated them and proposed some improvements. These include amendments to the Copyright, Designs and Patents Act 1988 to enable transmission of unpublished content protected by copyright, and changes to service providers' terms of service, so to achieve a more coherent post-mortem policy. On the whole though the team were positive about these in-platform solutions as a useful way to further and support user autonom

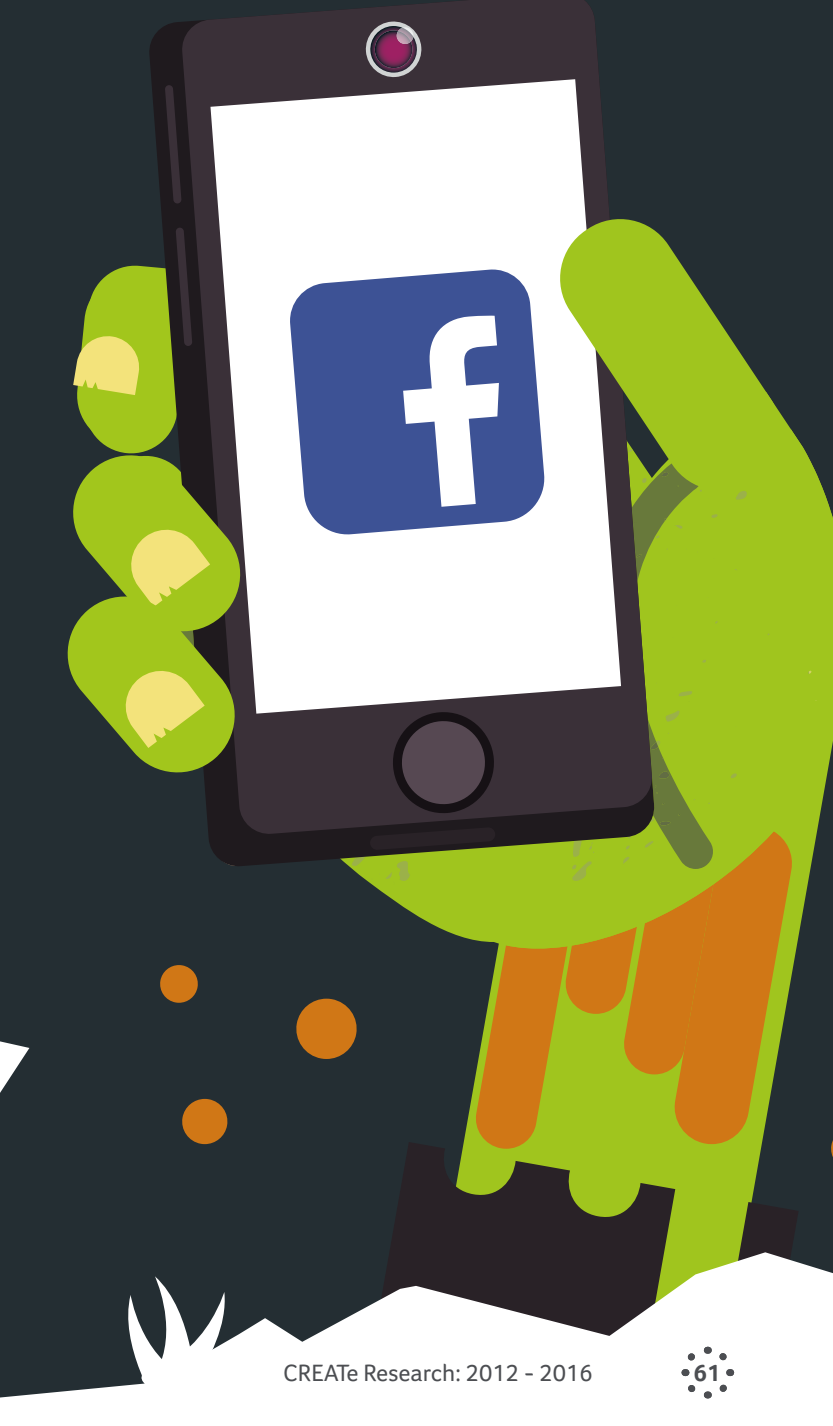




\section{Recognition and Awards}

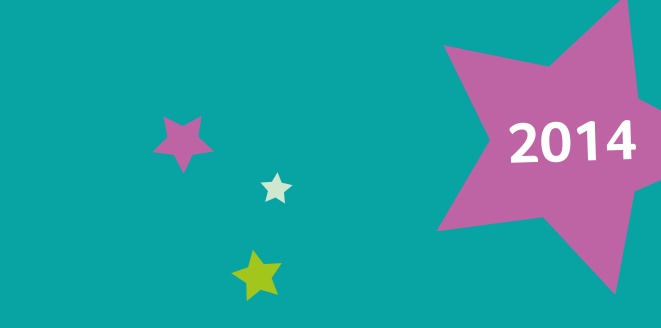

to the Content Board of Ofcom (2014-17), to represent the interests of the people of Scotland.

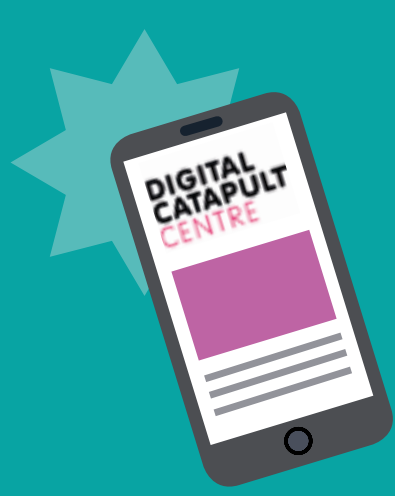

Lilian Edwards appointed as Researcher in Residence at the Digital Catapult, and acting manager of the Digital Catapult's Personal Data and Trust Network.

Gillian Doyle appointed by the European Commission as Member of European Expert Network on Culture and Audiovisual (EENCA) to provide advice on development of policy (2016 - 2018).
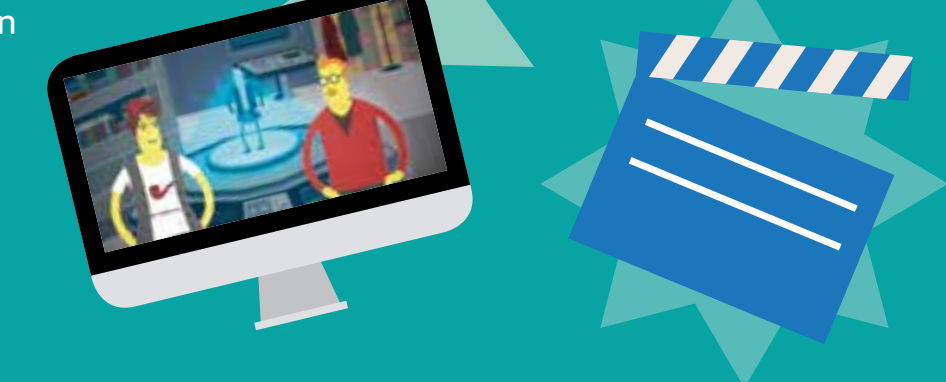

Derek McAuley appointed special advisor to House of Lords EU committee inquiry into Online Platforms.

Daithi Mac Sithigh appointed by the Irish Government as a member of its Open Data

Governance Board.

Martin Kretschmer elected President of the European Policy for Intellectual Property (EPIP) Association.

Victoria Stobo appointed as Copyright Policy Advisor to the Scottish Council on Archives (following Deazley's appointment in 2014) paving the way for CREATe to offer tailored copyright training to the Scottish archive sector and for representation at international bodies such as WIPO Standing Committee. 


\section{Engagements with Industry}

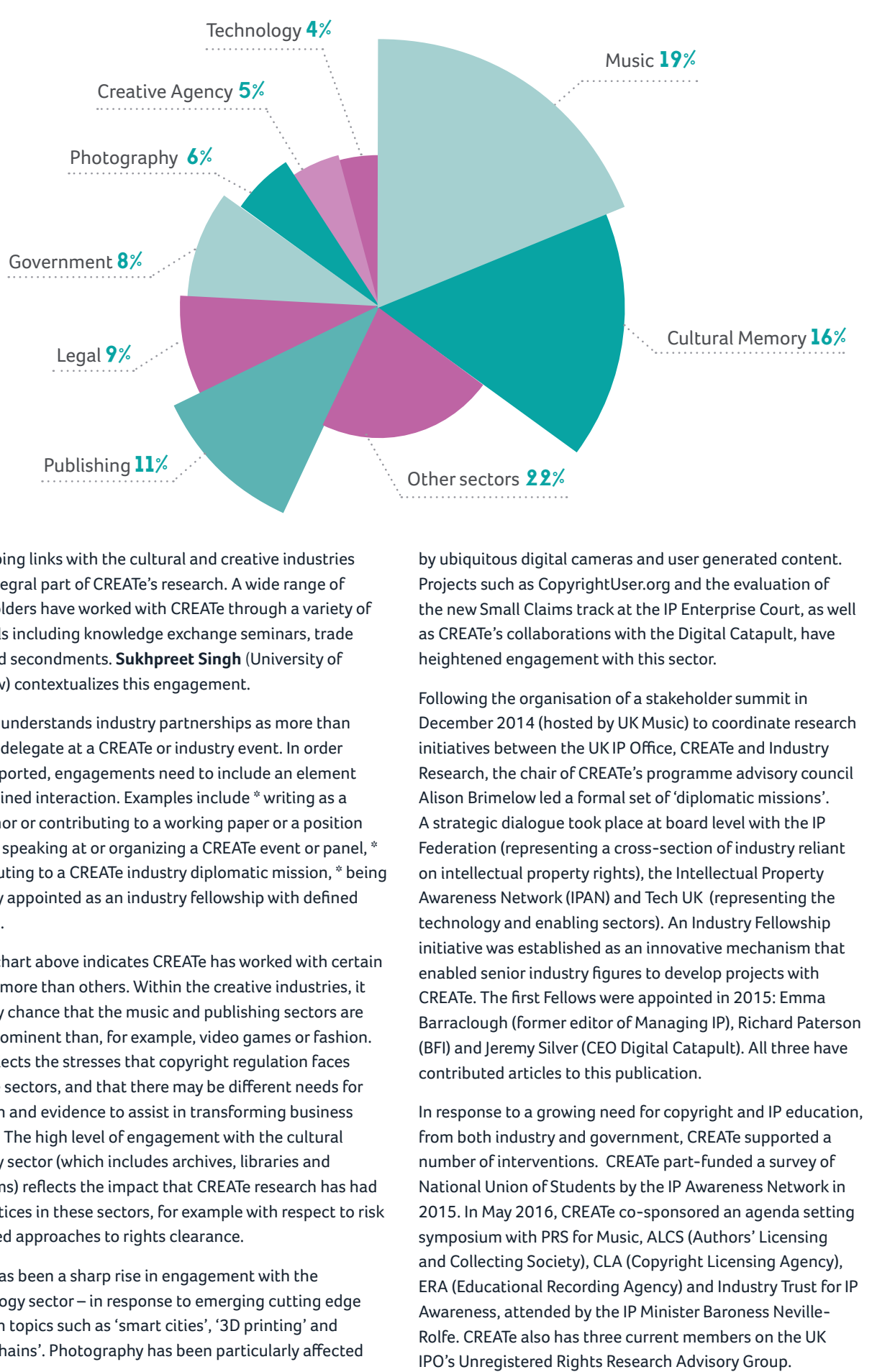

\section{Providing a Forum for Evidence} based IP Policy

Pamela Samuelson at EPIP 2015

It's not a surprise to many of us, perhaps all of us, that, generally speaking, intellectual property policy making and industry groups bring forward as proposals, and a lot of times that results from negotiation among the players.

I think that one thing that we can say pretty clearly is that the copyright industries used to be a pretty backwater, small segment of economies. They have gotten a lot bigger. IP intensive industries are now crilically important to the ongoing innovation. Rapid technological change and disrupted markets make copyright policy making awfully difficult.

Evidence based intellectual property policy making is not as unfamiliar to folks at this conference as it is to many other people, but it's certainly the case that empirical work tells little better is a good idea if you wast to regute f what noticed in atrending som sessions and f what inoticed in wa was how many differenty peple a wing: perle qualitative interviews with hu subjects, comparative types of empirical work that people are doing. I'm especially pcouraged to see young scholars and even graduate students doing some really outstanding and interesting work.

For at least some of the people who are here, copyright is not just about the economic rights. It has a kind of cultural and personal value. That means that evidence based approaches,
This is an edited excerpt from Berkeley professor keynote at the European Policy for Intellectual Property conference (EPIP) hosted by Glasgow in September 2015.

which often tend to be focused on economic issues, are not things that are going to surface those values.

Most of us who do intellectual property work are speaking to each other. That's actually a good thing. But if you think that your work has policy relevance-"I collected this evidence because I want to support this particular policy"-just writing articles to your colleagues is not going to do the work. So part of what you need to do is begin to think about how else to reach the policy making community. One thing you can do is publish things in venues where they will read your work Another is to learn how to do what in the United States we call "two-pagers", which is distill everything down to the crispest form and say why the data that you have support it. Evidence-based IP policy is a theme worth pursuing. It's not always going to win but it gives this community something useful to debate and to offer to policy makers. Reform is possible but it's not going to be easy, and generational change will probably make more of a difference than anything we write today.

This conference is a great forum for exchange of ideas. The fact that you've been able to attract a couple hundred people from different sectors-lawyers, economists, other social scientists and researchers, some industry people and some policy makers - that's really unusual and so it is a really special, special thing. I wish there was something like this in the United States. There really isn't. So keep up the good work. A video with full text transcript is available at: $\rightarrow$ bit.ly/1Kum Owx 


\section{The CREATe}

\section{IMPACT}

A research institute widely respected by stakeholders as independent of both politics and industry, exhibiting fine grained understanding of the differenges affecting the different sectors of industrie

The research councils took a risk when they launched the call for a Centre for Copyright and New Business Models in the Creative Economy (that became CREATe), and invited a group of intiplinary researchers to (ass tha fontested field. Yetwithin sen as a pior of copyrigh law from an innovation pers f CREATe's Programme Advisory Oof CREATe's Programme Advisory researchers and their funders, offers thoughts on the impact of CREATe's research.

Alison writes: The Programme Advisory Council (PAC), which I chair, must have a view on the effect CREATe is having if it is to be of any use to CREATe's governing body and funders.

One approach is to offer a catalogue of output and citations (of which there are lots and they are impressively diverse). But that seems to me to be rather tough going for a document like this, and better suited to an annual report (or annex thereto). The facts matter, but they are the underpinning of an assessment, not the assessment itself.

So I shall start anecdotally. In May I took part in a Symposium in Munich, marking the 50th anniversary of the Max Planck Institute for Competition and Innovation. The Institute is instiute for Competiton and Intovation. The lnstite is rightly celebrated for its long tradtion of rigorous work on Intellectual Property Rights, and found myself in a large and distinguished company. I was very pleased to find that CREATewas well know and my modest connection with prompted a lot of admiring comments on the scope of the venture and the quality or workit is producing. Given the reputation of the instlute, and the spread of academic talent from across Europe, and indeed further afield, taking part in the event, that is to my mind a reaction which it is worth recording with satisfaction. The admiration was both for the cross disciplinary nature of the work CREATe undertakes and for the vigour (and rigour) of its output. This is echoed some of the comments offered by PAC members last year after the European Policy for IP (EPIP 2015) conference in Glasgow.

But impressing other academics (however distinguished) while comforting, is not CREATe's key objective. It was while comforting is not shape policy. the Hargreaves copyright reform process (2011-14), in official impact assessn in Parliament, in the High Court, in the European Court of Justice, as well as in international policy documents.

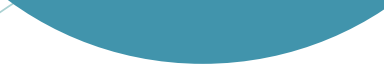

After a fairly tranquil second half of the twentieth century, where the working of the system and its utility was widely understood, Intellectual Property policy suddenly found itself wrestling with innovation, the pace and nature of whic sometimes left the legislative framework flat footed (or irrelevant) and citizens minded to break the law.

But looking at the case for change is not necessarily welcome As Roger Burt (a distinguished patent attorney and PAC member who served on the Advisory Panel for the 2011 Hargreaves Review) commented on CREATe's performance last year: 'The field of IP is of huge value to companies and commercial organisations; this value means that CREATe will inevitably be dealing with organisations that may have a lot to lose if there are changes in the law or suggestions that they may not be operating in the best interest of society as a whole.' The hazards of working in this territory were nicely illustrated by what happened to the UK copyright exception for personal copies for private use (which was quashed in July 2015 by the High Court following a judicial review against the government brought by three music industry trade bodies). But I would be much more worried about whether CREATe was doing its job effectively if nobody complained.

The development of policy is not a binary process. There are many interests and behaviours to assess, particularly where the pace of innovation is fast, and the multidisciplin approach CREATe can bring to bear is very useful, thoug ti brings some 'learning opportunities' as one discipline discovers that its 'normal approach' is completely foreign to colleagues from another background. But the new way of working does bear fruit, for example in the way CREAT has pioneered a method of combining legal analysis and innovative digital empirical techniques, and the way this work is seen as having 'changed copyright law', not least by helping parody to make money.

So far, so good. But as several PAC colleagues have commented, there is a lot more for CREATe to do in building on what it has done and learned so far. It seems to me that there is no reason at all to say 'that is quite no but rather to say: 'and next we need...'
In June 2014, a letter sent by leading Intellectual Property Law professors to the Parliamentary Scrutiny Committee on Secondary Legislation, addressed concerns about the implementation of new copyright exceptions for parody and quotation and personal copying for private use. The parody Youtube video makers Cassetteboy, to work legitimately; "We were infringing copyright for 20 years before the law changed, and never dreamt that our work would ever be legalised. The change in the law has had a huge impact on the work we've been able to do." Chair: Alison Brimelow (former chief executive and Comptroller General of the UK Patent Office, now known as the Intellectual Propert
President of the European Patent Office 2007-2010)

Robert Ashcroft (CEO PRS Sor Music)

Hasan Bakhshi (Nesta)

Frank Boyd (KTN UK)

Roger Burt (Council Member at Chartered Institute of Patent Attorneys Chair Registered Rights
Hargreaves Review 2011)

Tony Clayton (Visiting Research Fellow at Imperial College London and Pippa Hall (Chief Economist at UK IPO)

Laurence Kaye (Shoosmiths LLP)

Jim Killock (Executive Director of the Open Rights Group)

Jerome Ma (Engineering and Physical Sciences Research Council)

Hector MacQueen (Scottish Law Commission)

Robin Smith (National Library of Scotland)

Eloise Meller (Economic and Social Research Council)

Richard Paterson (Head of Research and Scholarship at the British Film

Institute)

Jeremy Silver (member of the UK Creative Industries Council, Chairman of MusicGlue and SupaPass and advisor to Innove
and Growth Intelligence, CEO Digital Catapul|

Heather Williams (Arts and Humanities Research Councili)

International

Reto Hilty (Director, Max-Planck-Institute for IP \& Competition Law, Munich) Jeanette Hofmann (Director, Humboldt Centre for Internet \& Society, Berlin) Bernt Hugenholtz (Professor of Intellectual Property Law and Director of
the Institute for Information Law of the University of Amsterdam (ViR) Joe Karaganis (The American Assembly Columbia University)

Andrew Kenyon (University of Melbourne)

Zorina Khan (Bowdoin College Maine, USA)

Helge Ronning (University of Oslo, Professor Emeritus in the Department of Pamela Samuelson (Richard M. Sherman Distinguished Professor of Law,
Professor of School Information; Co-Director Berkeley Centerf for Law Professor of School Information; Co-Director
Technology at the University of California)

Sacha Wunsch-Vincent (World Intellectual Property Organization)
Martin Kretschmer spoke at the European Parliament Public Hearing on Copyright Reform (11 November 2014) and at high level expert meetings with the European Commission (Copyright and Innovation, European Political Strategy Center EPSC, in-house think tank of the European Commission, 23 September 2015).

Findings from CREATe's study on the Valuation of the Public Domain (jointly funded by ESRC and UKIPO) were launched on 5 December 2014 at the Digital Catapult in London, presented at WIPO (World Intellectual Property Organization) in June 2015. This study has been cited by Julia Reda MEP in the European Parliament.

CREATe has led and contributed to 39 policy responses, incluaing a response to the EUs Public Consultation on the Review of EU Copyright Rules, which was subsequently published in a leading practitioner journal (2013). CREATe has contributed to a number of European-wide academic interventions through the European Copyright Society, seeking to influence the decisions of the European Court of Justice and the Commission's legislative programme. These include the Svensson Hyperlinking Case, and a proposed new Neighbouring Right for Publishers.

CopyrightUser.org helps people and organisations exploitation and re-use of creative works. The development team has been working closely with the Digital Catapult in London, an early-stage technology incubator, and the Catapult supported a new set of resources for SMEs and small businesses.

Cultural memory institutions are a significant source for learning and innovation, as well as of cultural value. In the UK alone, there are "up to 2,500 museums, 3,393 public libraries, 3,000 community archives, 979

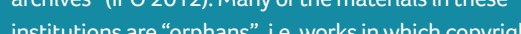
institutions are "orphans", i.e. works in which copyright the creator of the work or successor in title, cannot be the creat
located.

CREATe researchers have engaged with key stakeholders in the cultural heritage sector to gather evidence on the rights clearance process. Examples of best practice were dassen hated, further dightisation of culturaly significant material was encouraged, and detalied gride eveloped to support confident decision-makng in this complex and evolving area of and the researchers were invited to sit at working committees of global intellectual property bodies such as World intellectual Property Organization (WPO is a UN agency based in Geneva). 


\section{Building the Capacity for Interdisciplinary Research

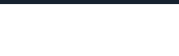

Doing interdisciplinary research is difficult. We sometimes use the word loosely to describe cross-disciplinary encounters or trans-disciplinary borrowing. In fact, interdisciplnanty involves committed, shared collaboration to develop nove appras held of study. This type of work is challenging not only because academics speak different languages and use different methods of inquiry but also because knowledge production in universites continues to be siloed. cultura divisions between disciplines have a strong organizing influence. Capacity building in this context means training a new generation of scholars in the skils, methods and perspectives needed to succeed in this academic landscap. CREATe researchers Elena Cooper \& Kris Erickson (both University of Glasgow) discuss three types of capacity building that have been applied effectively in the first phase of CREATe. These are i) translational, bringing academics up to speed in key methods and approaches, ii) integrative, creating linkages between researchers to generate new ii) practical, providing research

\section{Translational Capacity Building}

CREATe Studio is a postgraduate reading discussion workshop which occurs monthly throughout the year. The purpose is to provide PhD students and postdocs an opportunity to discuss working papers and research from outside of CREATe. The group attracts colleagues from law, economics, cultural studies, media management, languages and computer science. Postdocs are invited to lead the group on a rotating basis.

In June 2013 CREATe hosted a conference in Edinburgh, where researchers from seven UK universities discussed empirical research methods. Researchers presented projects to each other in rapid Pecha-Kucha style. Keynote presentations by established scholars discussed ways to conduct longitudinal studies, comparative studies and meta-analysis.
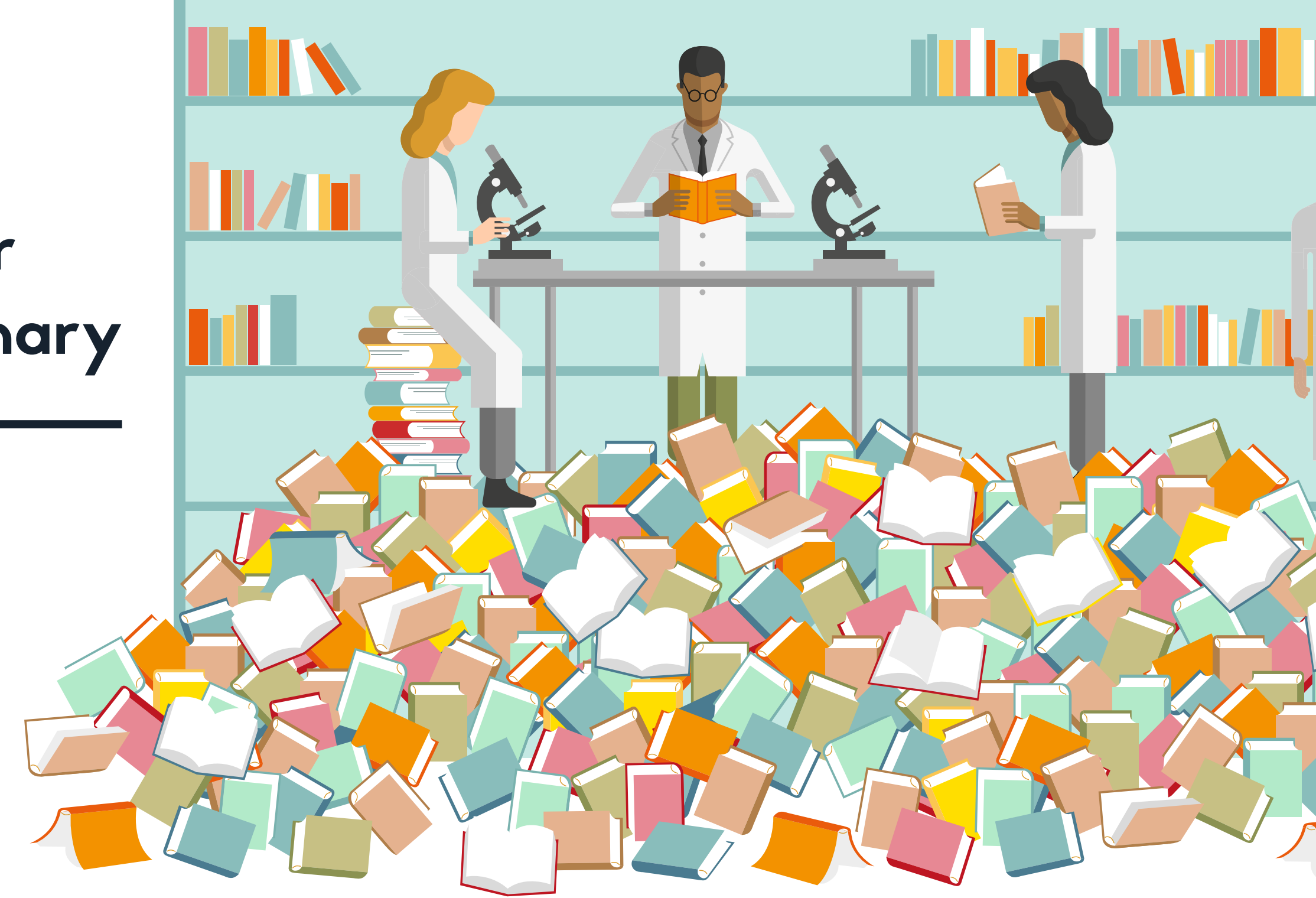

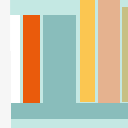

\section{Integrative Capacity Building}

Two events, the Technology Capacity Building event in Nottingham and the Economics of Creativity and Competition event at UEA occurred mid way throug CREATe's first phase. Converging around topical issues, these intiatives helped early career researchers identify challenges of the future for the digital economy. Attendees included Giancarlo Frosio (Stanford University), Jerome Reichma (Duke University), Alma Swan (SPARC

A series of workshops on Openness, IP and Innovation organised in March 2016 provided the opportunity for academics to converge around the concept of'openness'. Participants included Stefan Haefliger (Cass Business School, London), Natacha Estèves (Sciences Po Paris) and Rufus Pollock (Open Knowledge).
Practical Capacity Building

CREATe hosted a public stakeholder event on Valuing the Public Domain in December 2014, and a similar public even on Copyright and Ophan Wors in Sepenber 2015. These meetings we intended to promoper usability of empircal tesults obtined from CREATT reserch. Atrendees from policy, culturalinstiturion, cretive SMES

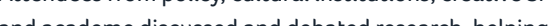
strenthen ration hips and alsoimproveresearch vap 作 communication.

In May 2016 CREATe hosted a hackathon. One of the challenges for researchers and $\mathrm{PhD}$ students was interacting with the software development paradigm. One of the outcomes (other than software tools) was a shared understanding of technical, legal, and academic perspectives on copyright.
Capacity building has been an ambition from the inception of CREATT. In 2012 the CREATe Governance Board noted that "A key stumbling block to effective research on innovation and the creative industries has been a lack of legal, business, technology and creative researchers trained to 'speak each others' languages". A legacy of the Centre will be a new generation of interdisciplinary researchers, including 16 (4 funded by CREATe, 12 as institutional contributions) and 36 Postdoctoral Researchers working across the CREATe consortium. CREATe has nurtured new PhD, LLM and MSC programme across the consortium. This will be the first major UK effort to systematically build such capacity 
An Open Access Journal for Internet Policy in Europe

We face urgent questions about how best to govern

communication networks in the information society. How should

European societies balance openness and digital innovation with

a need to preserve privacy, democratic sovereignty and cultural

value

Dubois (HIIG Berlin) and Kris Erickson (University of Glasgow)

introducenternet Polic Review ajounatestablsted 2013

to

editorial workflow and a commitment to transparency and ope

access. The journal tracks public regulatory changes as well as

private polig develon

lasting impacts on European societies.

The first thing that is different about Internet Policy Review is its fast-track peer review process. Unlike traditional social science journals, IntPolRev employs a transparent system by which authors and reviewers can see each others' comments on a shared draft document. Editors and reviewers comment directly on the text as well as provide substantive feedback. We believe that this approach leads to more accurate and more civil engagement with ideas and leads to more substantial improvement of submitted work. The typical time from first submission to publication is

currently three months.

A second difference is that Internet Policy Review is aimed at policymakers, civil society and practitioners alongside the

academic community. In order to communicate more effective

in these domains, IntPolRev encourages shorter submissions of

6000-8000 words, free from jargon and with clear policy-releva

recommendations. The journal is fully open access and free to

read. To encourage information sharing, all individual articles are

Internet Policy Review is published on a quarterly rolling basis by

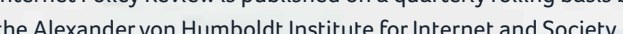

in cooperation with CREATe and the Institut des sciences

la communication at Paris-Sorbonne (CNRS-ISCC), the

online journal offers readers a clear and indepen

policy. For further details and submission

policy. For further
guidelines see:

policyreview.info

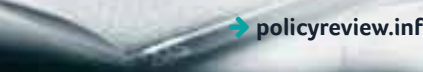

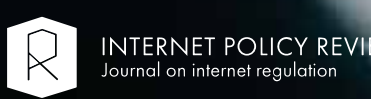

7 Big data: big pomer shifs?

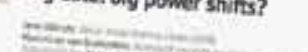

Equipping Digital Innovators and Creative Leaders

Intellectual property rights are devised to encourage innovation in culture, business, and technology. Laws give protection to different types of creations, turning culture in goods that can be bought and sold in the 'Creative Economy'. However, things change rapidly at the interface of rights, data, and information in the digital world, and these changes affect society in general and the work of creative businesses, digital innovators, cultural heritage organisations, and policy-makers, in particular. Sukhpreet Singh, CREATe Programme Leader and Director of the MSc in IP, Innovation and Creative Economy, shares the story of developing and launching an industry facing online Masters programme. Developed at the University of Glasgow, the MScaCREAT offers professional development and the validation of executive expertise, to develop creative industry leaders.

A common challenge for research centres is how to usefully disseminate research based knowledge to society, business and other interested parties in order to effect the skills base of the digital economy. To satisfy this goal, and to create a sustainable legacy of research, CREATe's bid to its funders included a commitment to a new degree programme. The attendee profile of research dissemination events included mid and senior level industry executives who expressed a need for formal learning about digital rights and obligations, and concepts of regulation and innovation, but were unable to take a year off their working lives to develop their careers. We therefore responded with an online Masters programme pitched towards a working executive profile.

The core of the programme crosses disciplines. The executive learners gain detailed knowledge of how copyright, trade mark, data legislation and judicial decisions regulate creative production, and what legal tools can be used to protect content and brands. They learn about economics,

acquiring a critical understanding of the fundamental determinants of economic performance and innovation, as well as analytical and applied shills, such as data analysis. Tools from social science are employed to teac about user behaviour and approaches to investigating onthe communities. Management plays a part, applying the insights from strategic management scholarship to lead creative firms. Vitally, connections are made across these specialist disciplines, by investigating the key econom

Cutting-edge online learning tools, populated with realworld research and case studies, guide learners throug the challenges of today's creative industries. Interactive forums and the option to attend live or recorded master classes give access to peers and industry and policy leaders. On successful completion of the programme, learners will have a detailed understanding of digital rights and obligations, enabling them to apply authoritative knowledge to their professional context.

$\rightarrow$ create.ac.uk/msc $\rightarrow$ create.ac.uk/msc

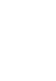
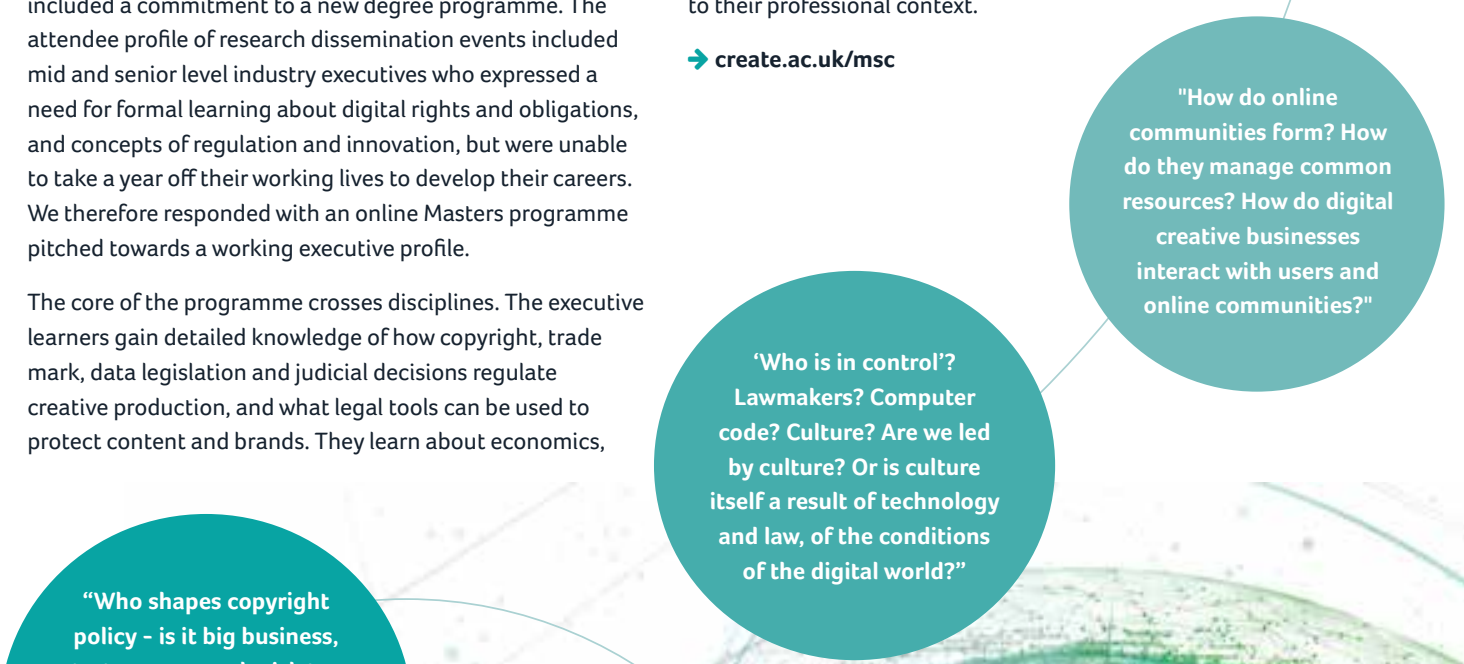

policy - is it big business,

or the courts? Or is it the

nation states, Europe, US

or the world? Is copyright

policy fit for the digital

MSc@CREATe 
The UK government is increasingly interested in developing initiatives that strengthen capacity for research and innovation within both the $U$ Kand developing countries and for high level cross-council interventions. CREATe Programme Leader, Sukhpreet Singh (University of Glasgow) highlights a number of strategic international partnerships spearheaded by the CREATe Centre.

\section{Internationalisation}

\section{Paving paths far away and close to home}

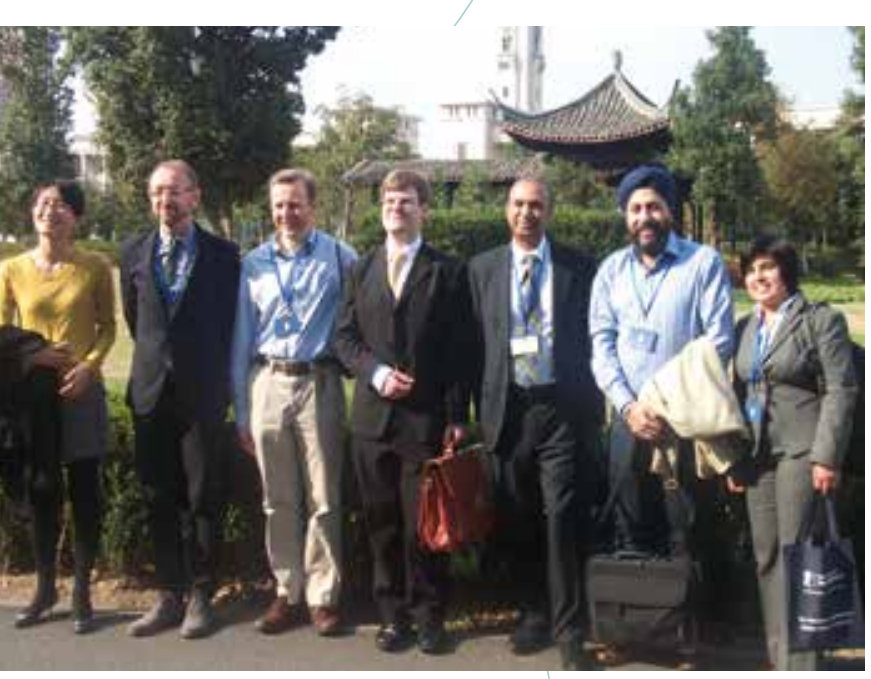

Sukhpreet Singh (CREATe Programme Leader, second from right) attending the scoping workshop for the launch of the (Nover

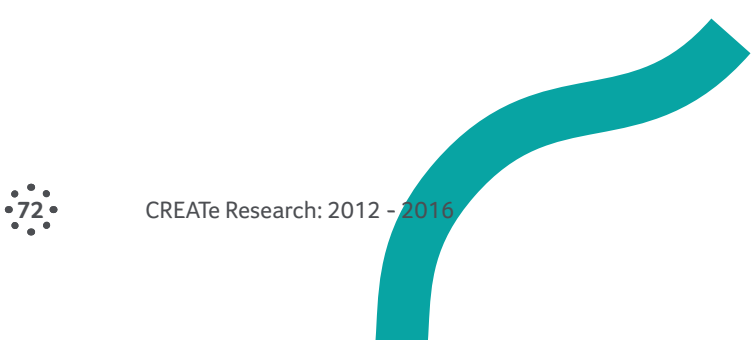
of Edinburgh) with contributions by Martina Gerst (based promote long-term sustainable growth. A prime example is the Research Councils' new Global Challenges Research Fund
CREAT's European partnerships include the Humboldo Institute for Internet and Society (HIIG) in Berlin and the University of Amsterdam's Institute for Information Law (IViR). CREATe and HIIG have collaborated on research staff exchanges and joint organization of academic and industry workshops. CREATe co-publishes the 'Internet Policy Review' an innovative open access journal that aims to combine academic rigour with policy relevance with HIIIG and the Sorbonne (CNRS-ISCC). Cos de la communication at Parisof Amsterdam has seen the award of EU funding (awarded in the UK by the AHRC under the Heritage Plus Joint EC Call) to explore the potential role of crowdsourcing in rights clearance, and a joint project Reconstructing Copyright's Economic Rights, funded by a Microsoft grant.

\section{Korea}

The Korean government has an ambitious goal to have mo than 10 million pieces of shared copyright works by 2017 This is expected to allow cost savings to the tune of 3.6 of production (mainly licensing costs) of cultural goods, an spurring innovation and creativity.

CREATe's engagement with Korea emerged from Martin Kretschmer's invited keynote on copyright law reform in sprope at the Seoul Copyight forum 2014, where other (US. Copright Offe) Masodis (U.S. Copyright Office), Masabumi Suzuki (Nagoya . In Japan) and Ping Zhang (Peking University, China). In October 2014 , a delegation led by the Diector of Industrial Research Yong a deng Leevisited CREATe Glasgow to explor approaches to economic research on copyright law and to evolve an approas copyright between Asia and Europe. Yong Jeong Lee said, "CREATe has a unique appoach, and is widely seen as a pioneer in empirical research in the area of digltal copyright" Diroci 2015 , another de Director of the Copyrght Dellberation \& Research Team, visited CREATe to share

\section{India}

The Indian media industry has grown at a rate of 10-15\% annually over the last 10 years, with expectations to grow to US $\$ 28$ billion by 2019 . India also has developed a distinct approach to IP questions, for example relating to compulsory licences, geographical indications, and net neutrality, emphasizing a development agenda. CREATe curated a pane in 2015 at the Global Congress on Intellectual Property and the Public Interest, hosted by the National Law University in New Delhi (chair: Smita Kheria, with Lilian Edwards, Sarah Kember, Daithí Mac Síthigh). The congress saw the participation of activist and campaign groups alongside academics and international bodies such as WIPO. CREATe is planning to extend its research interests with Indian partners. trillion won (approx 2.5bn GBP) by bringing down the cost

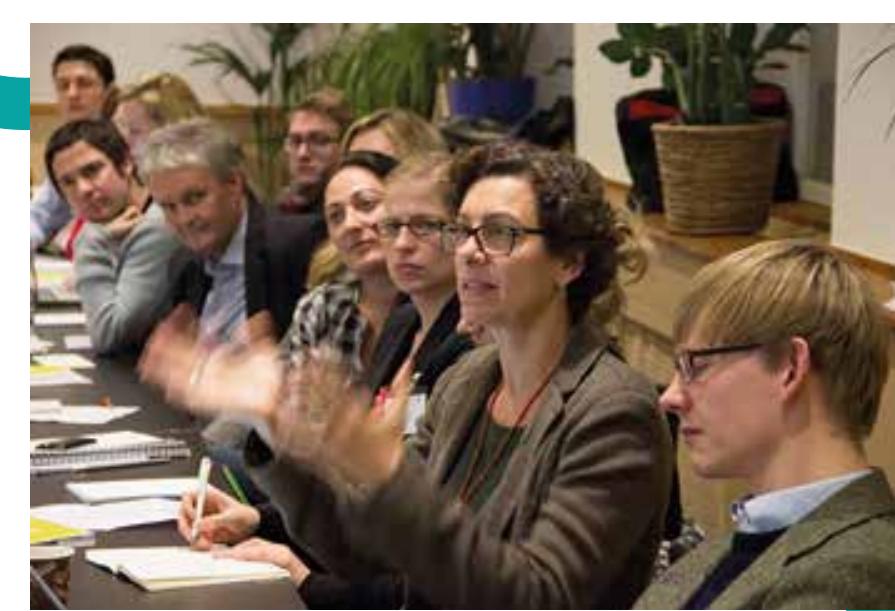

Jeanette Hofmann, a Director of Berlin based HIIG, speaking at a int CREATE-HIIG workshop in Dec 2013 titted 'Reforming Formats'

\section{Learning}

from China's

Creative Cultural

Industries

Upon the successful adoption in China of Western notions of intellectual property protection, therefered offering their product and services in the market. At the for fim and ther culural product surge in the market for film and other cultural products by home spun (C) and TenCent - also known as the BAT' group) are makn epering and service models. Various free and near-free services are being offered and tested in the Chinese arket, many of which differ significantly from what

Supported by CREATe and the Ningbo based AHRC Centre for Digital Copyright and IP Research in China, Xiaobai Shen (University of Edinburgh) is leading a project that explores the emergence of new business and service models for digital fim, music and e-fiction production and distribution in China. Project findings, subsequent to the currently ongoing intensive round of interviews with key players in China, will be shared on: (Tsinghua University). 
Notes

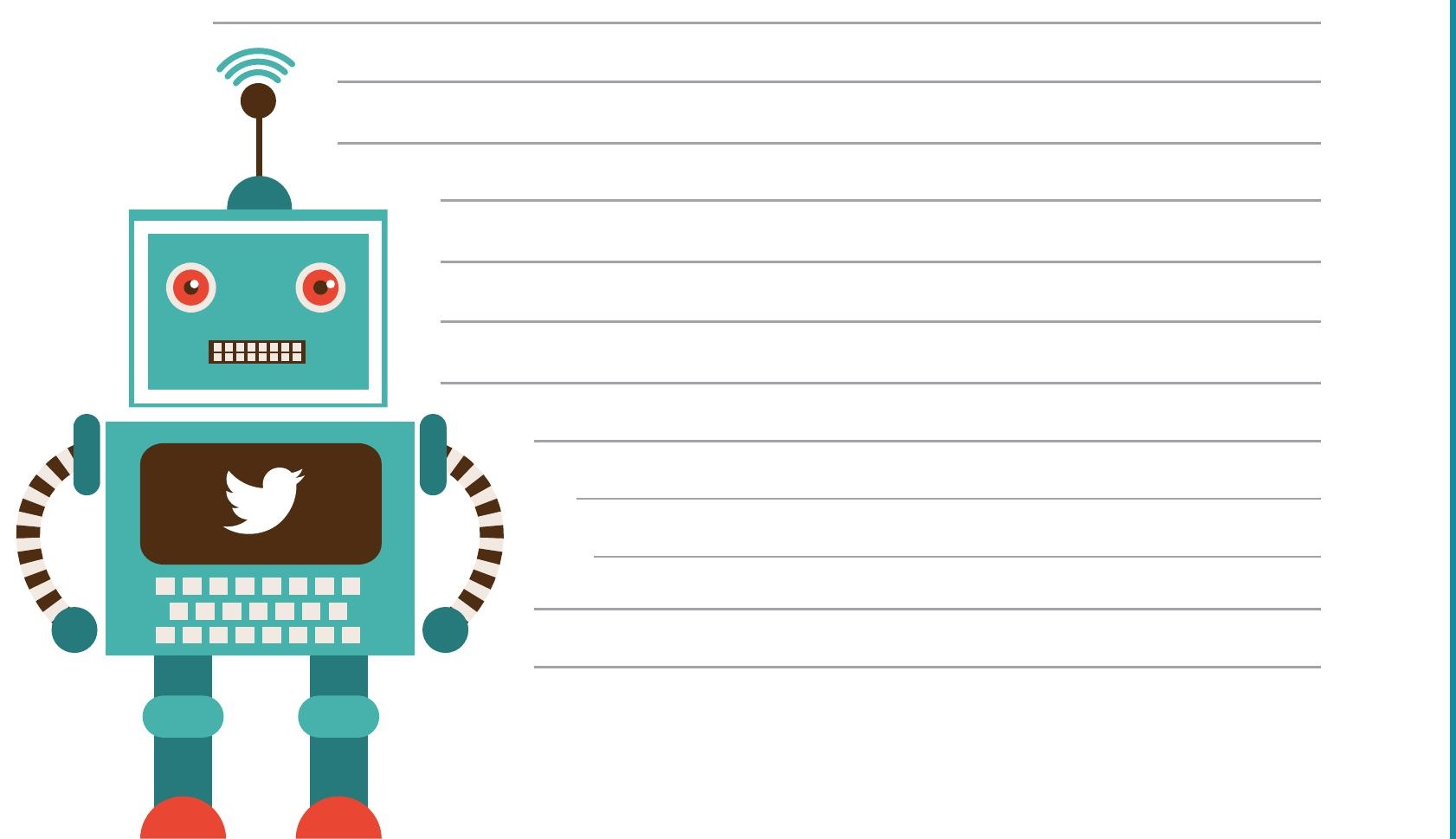

Image Credits:

Exhibitions: Copyright \& Cultural Memory / Image ‘Still Life with Flowers and a Watch' by Abraham Mignon from the Rijksmuseum. Exhibitions \& Article: CREATe Tartan / Images courtesy of Bute Fabrics. Workshops \& Article: Voices of CREATe/ Untitled photograph by Feans on Flickr is licensed under CC BY 2.0. Workshops: Fashion IP / Image copyright Teija Eilola. Workshops: Art Forgery / Image courtesy of Elena Cooper. Workshops \& Article: Endow / 'the swedish book corner' by ami photography on Flickr is licensed under CC BY-SA 2.0. Past Events: Archive o Copyright Sumposium / Image from the Rjkssmuseum. Past Events: Valuing the Public Domain / France in year 2000 (XXI century). Future school' by Jean Marc Cote/ Villemard. Image from Wikimedia Commons (in public domain). Past Events: Copyright \& Cultural Memory Symposium / Image of the Mona Lisas smile by Andrea Wallace. Article: Intellectual Property and Cultural Heritage / Helm Cocoa advertisment from the Library of Congress (in public domain); 'On the Waves of Love' by Edvard Munch from National Museum of Art, Architecture and Design - Nasjonalmuseet, Oslo (in public domain); Image of Scrapbook 12 by Edwin Morgan (c) The Edwin Morgan Trust. Article: Is Competition All we want? / Sherlock image courtesy of Hartswood Films Ltd. Article: Creative

Businesses / Images courtesy of Angharad McLaren and One Foot Taller. Article: Supporting Creative Practice Through

Technology / Cartoon strip by Liz Dowthwaite. Article: Emergent Infrastructures for IP Trading / Image courtesy of Hung The Nguyen. Article: Musicians \& Copyright / Image Credit: 'Blues a La Cité' by Alessandro Valli on Flickr is licensed under CC BY 2.0. 
